\title{
HIGH EFFICIENCY DESULFURIZATION OF SYNTHESIS GAS
}

\author{
Final Report
}

September 2002 - March 2004

\author{
Kwang-Bok Yi \\ Anirban Mukherjee \\ Elizabeth J. Podlaha \\ Douglas P. Harrison
}

March 2004

DE-FG26-00NT40813

Gordon A. and Mary Cain Department of Chemical Engineering Louisiana State University

Baton Rouge, LA 70803 


\section{DISCLAIMER}

This report was prepared as an account of work sponsored by an agency of the United States Government. Neither the United States Government nor any agency thereof, nor any of their employees, makes any warranty, express or implied, or assumes any legal liability or responsibility for the accuracy, completeness, or usefulness of any information, apparatus, product, or process disclosed, or represents that its use would not infringe privately owned rights. Reference herein to any specific commercial product, process, or service by trade name, trademark, manufacturer, or otherwise does not necessarily constitute or imply its endorsement, recommendation, or favoring by the United States Government or any agency thereof. The views and opinions of authors expressed herein do not necessarily state or reflect those of the United States Government or any agency thereof. 


\begin{abstract}
Mixed metal oxides containing ceria and zirconia have been studied as high temperature desulfurization sorbents with the objective of achieving the DOE Vision 21 target of 1 ppmv or less $\mathrm{H}_{2} \mathrm{~S}$ in the product gas. The research was justified by recent results in this laboratory that showed that reduced $\mathrm{CeO}_{2}$, designated $\mathrm{CeO}_{\mathrm{n}}(1.5<\mathrm{n}<2.0)$, is capable of achieving the 1 ppmv target in highly reducing gas atmospheres. The addition of $\mathrm{ZrO}_{2}$ has improved the performance of oxidation catalysts and three-way automotive catalysts containing $\mathrm{CeO}_{2}$, and was postulated to have similar beneficial effects on $\mathrm{CeO}_{2}$ desulfurization sorbents.
\end{abstract}

An electrochemical method for synthesizing $\mathrm{CeO}_{2}-\mathrm{ZrO}_{2}$ mixtures was developed and the products were characterized by XRD and TEM during year 01 . Nanocrystalline particles having a diameter of about $5 \mathrm{~nm}$ and containing from approximately $10 \mathrm{~mol} \%$ to $80 \mathrm{~mol} \% \mathrm{ZrO}_{2}$ were prepared. XRD analysis showed the product to be a solid solution at low $\mathrm{ZrO}_{2}$ contents with a separate $\mathrm{ZrO}_{2}$ phase emerging at higher $\mathrm{ZrO}_{2}$ levels. Unfortunately, the quantity of $\mathrm{CeO}_{2}-\mathrm{ZrO}_{2}$ that could be prepared electrochemically was too small to permit desulfurization testing.

Also during year 01 a laboratory-scale fixed-bed reactor was constructed for desulfurization testing. All components of the reactor and analytical systems that were exposed to low concentrations of $\mathrm{H}_{2} \mathrm{~S}$ were constructed of quartz, Teflon, or silcosteel. Reactor product gas composition as a function of time was determined using a Varian 3800 gas chromatograph equipped with a pulsed flame photometric detector (PFPD) for measuring low $\mathrm{H}_{2} \mathrm{~S}$ concentrations from approximately 0.1 to $10 \mathrm{ppmv}$, and a thermal conductivity detector (TCD) for higher concentrations of $\mathrm{H}_{2} \mathrm{~S}$.

Larger quantities of $\mathrm{CeO}_{2}-\mathrm{ZrO}_{2}$ mixtures from other sources, including mixtures prepared in this laboratory using a coprecipitation procedure, were obtained. Much of the work during year 02 consisted of characterization and desulfurization testing of materials obtained from commercial sources. Most of the commercial $\mathrm{CeO}_{2}$ and $\mathrm{CeO}_{2}-\mathrm{ZrO}_{2}$ materials were capable of reducing $\mathrm{H}_{2} \mathrm{~S}$ concentration from 5000 ppmv in highly reducing feed gas to less than $1 \mathrm{ppmv}$ in the product gas. However, to properly evaluate the effect of $\mathrm{ZrO}_{2}$ addition on desulfurization capability, the physical properties of the sorbent must be similar. That is, a $\mathrm{CeO}_{2}-\mathrm{ZrO}_{2}$ mixture from source $A$ would not necessarily be superior to pure $\mathrm{CeO}_{2}$ from source $B$ if the properties of the pure $\mathrm{CeO}_{2}$ were superior. Therefore, research during year 03 concentrated on $\mathrm{CeO}_{2}$ and $\mathrm{CeO}_{2}-\mathrm{ZrO}_{2}$ mixtures prepared in this laboratory using a coprecipitation procedure. The structural properties of these sorbents were similar and the effect of $\mathrm{ZrO}_{2}$ addition could better be separated from the structural effects.

X-ray diffraction tests of the sorbents prepared in house confirmed the formation of a solid solution of $\mathrm{ZrO}_{2}$ in $\mathrm{CeO}_{2}$. Crystallite sizes ranged from 12.7 to $18.8 \mathrm{~nm}$ and surface areas from 75 to $85 \mathrm{~m}^{2} / \mathrm{g}$. Reduction tests using an electrobalance reactor confirmed that $\mathrm{CeO}_{2}-\mathrm{ZrO}_{2}$ mixtures were more easily reduced than pure $\mathrm{CeO}_{2}$. 
Reduction of $\mathrm{CeO}_{2}-\mathrm{ZrO}_{2}$ began at a lower temperature and the final value of $\mathrm{n}$ in $\mathrm{CeO}_{\mathrm{n}}$ $(1.5<\mathrm{n}<2.0)$ was smaller in $\mathrm{CeO}_{2}-\mathrm{ZrO}_{2}$ than in pure $\mathrm{CeO}_{2}$.

Sorbent performance during desulfurization testing was judged both by the minimum $\mathrm{H}_{2} \mathrm{~S}$ concentration achieved during the so-called prebreakthrough period and by the duration of the prebreakthrough period. The end of the prebreakthrough period was defined as the time when the $\mathrm{H}_{2} \mathrm{~S}$ concentration in the product gas exceeded $1 \mathrm{ppmv}$. Both $\mathrm{CeO}_{2}$ and $\mathrm{CeO}_{2}-\mathrm{ZrO}_{2}$ sorbents produced in house were capable of reaching the target sub-ppmv $\mathrm{H}_{2} \mathrm{~S}$ level in highly reducing gases for extended time periods. $\mathrm{H}_{2} \mathrm{~S}$ concentrations were reduced to levels approaching the minimum detectable limit of the PFPD detector, approximately $100 \mathrm{ppbv}$ for time periods corresponding to as much as $60 \%$ sorbent sulfidation.

The critical test of the sorbents was their performance when the reducing power of the feed gas was decreased by the addition of $\mathrm{CO}_{2}$ as an oxidant. While sub-ppmv levels of $\mathrm{H}_{2} \mathrm{~S}$ were still achieved using both $\mathrm{CeO}_{2}$ and $\mathrm{CeO}_{2}-\mathrm{ZrO}_{2}$ sorbents when the feed gas contained as much as $1 \% \mathrm{CO}_{2}$, the duration of the prebreakthrough time decreased as the $\mathrm{CO}_{2}$ concentration increased. However, the addition of $\mathrm{ZrO}_{2}$ moderated the decrease in the prebreakthrough time by a significant amount. For example, in a series of tests using various feed gas $\mathrm{CO}_{2}$ concentrations (up to $1 \mathrm{~mol} \%$ ), the duration of the prebreakthrough period was from $25 \%$ to $100 \%$ greater with $\mathrm{Ce}_{0.8} \mathrm{Zr}_{0.2} \mathrm{O}_{2}$ than with $\mathrm{CeO}_{2}$. 


\section{TABLE OF CONTENTS}

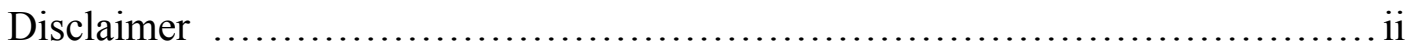

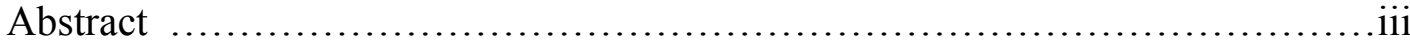

Table of Contents ..................................................................

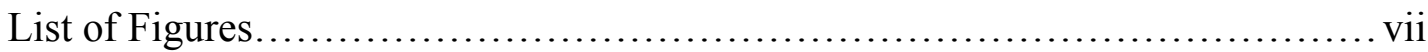

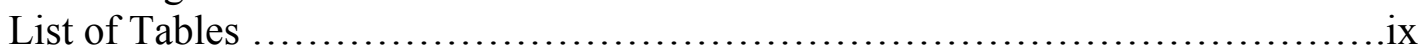

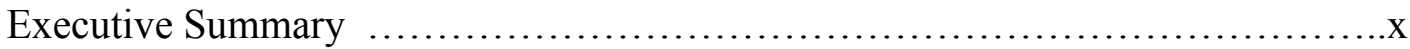

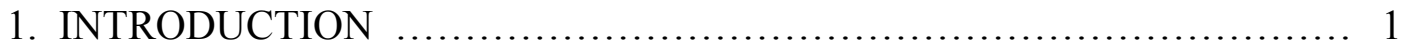

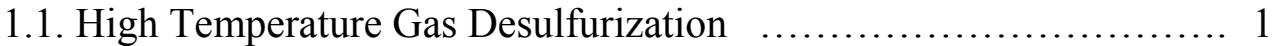

1.2 Ceria-Zirconia Catalyst Research ..................................... 3

1.3 Objectives of the Research...................................... 3

2. ELECTROCHEMICAL SYNTHESIS AND CHARACTERIZATION OF

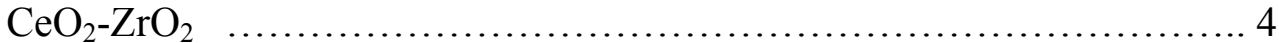

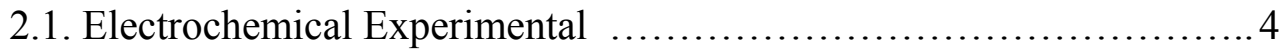

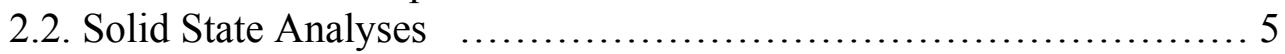

2.3. Electrosynthesis Results and Discussion.............................6

2.3.1. Composition............................................6

2.3.2. XRD and TEM Characterization ..........................6

2.3.3. Electrochemical Process Characterization...................12

3. REACTION AND SORBENT CHARACTERIZATION EQUIPMENT .......16

3.1. Fixed-Bed Reactor ............................................ 16

3.2. Gas Analysis .................................................... 18

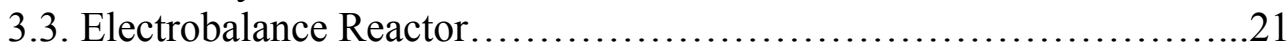

3.4. BET Surface Area....................................................24

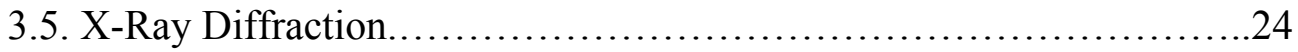

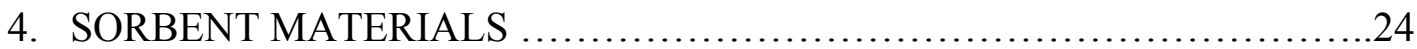

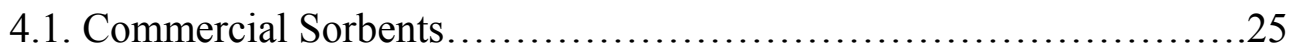

4.2 Sorbents Synthesized at LSU ...................................25

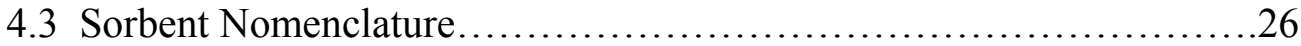

5. SORBENT CHARACTERIZATION RESULTS...............................26

5.1. X-Ray Diffraction Spectra.......................................26

5.2. BET Surface Area and Crystallite Size ...............................28

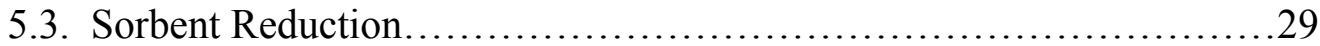

6. FIXED-BED DESULFURIZATION RESULTS...............................33

6.1. Reaction Conditions and Dimensionless Time.........................33

6.2. Typical Reactor Response Curves................................36

6.3. Commercial Ceria Sorbents........................................... 38

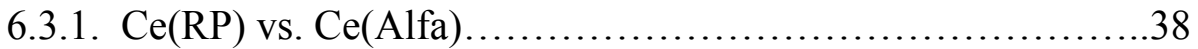

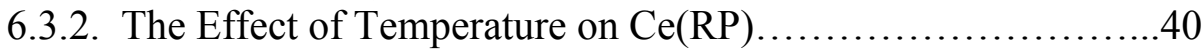

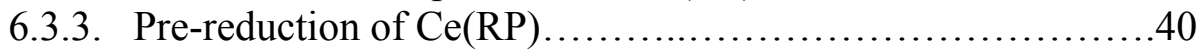


6.3.4. The Effect of $\mathrm{CO}_{2}$ on Sulfidation of $\mathrm{Ce}(\mathrm{RP}) \ldots \ldots \ldots \ldots \ldots \ldots 42$

6.4. Commercial Ceria-Zirconia Sorbents..................................43

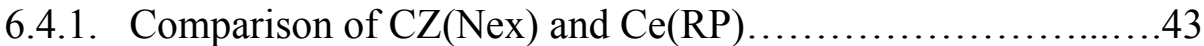

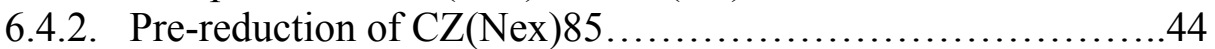

6.3.5. The Effect of $\mathrm{CO}_{2}$ on Sulfidation of $\mathrm{CZ}(\mathrm{Nex}) 70 \ldots \ldots \ldots \ldots \ldots . . . . . .45$

6.5. LSU Ceria and Ceria-Zirconia Sorbents.............................45

6.5.1. Defining Reference Time for Ceria-Zirconia Sorbents.........46

6.5.2. The Effect of Sulfidation Temperature.......................47

6.5.3. The Effect of Pre-reduction..................................49

6.5.4. The Effect of $\mathrm{CO}_{2}$ Addition................................51

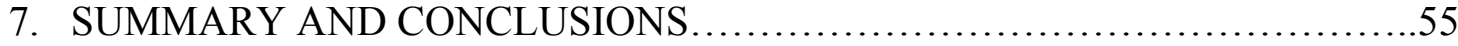

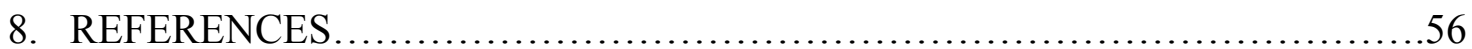




\section{LIST OF FIGURES}

Figure 1. Electrochemical Cell Schematic .................................5

Figure 2. Electrolyte Concentration vs. Final Powder Composition ..............7

Figure 3. TEM Images of (a) Ceria, (b) Ceria-7 mol\% Zirconia

(C) Ceria-18 mol\% Zirconia ................................... 8

Figure 4. Selected-Area Electron Diffraction (SAED) Pattern Taken Over a Large Area Shown in Figure 3.....................................9

Figure 5. XRD Analysis of (a) Electrochemically Generated Nanocrystalline $\mathrm{Ce}_{0.82} \mathrm{Zr}_{0.18} \mathrm{O}_{2}$, (b) Cubic $\mathrm{CeO}_{2}$ (JCPDS 34-394), and (c) Monoclinic (JCPDS 37-1484) and Tetragonal (JCPDS 42-1164) $\mathrm{ZrO}_{2} \ldots \ldots \ldots \ldots . . .10$

Figure 6. XRD Patterns for Three Different $\mathrm{Ce}_{1-\mathrm{x}} \mathrm{Zr}_{\mathrm{x}} \mathrm{O} 2$ Samples, where $\mathrm{x}$ Represents the Mol Fraction of Zirconia..............................11

Figure 7. A Comparison Between the LSU and Commercial NexTech XRD Powder Patterns.......................................................11

Figure 8. Heat Treated $700^{\circ} \mathrm{C}, 18.7 \mathrm{~mol} \% \mathrm{Zr}$ Ceria-Zirconia with Resulting Crystallite Size of (a) $9.5 \mathrm{~nm}$, (b) $10 \mathrm{~nm}$, (c) $11 \mathrm{~nm}$, (d) $12 \mathrm{~nm}$,

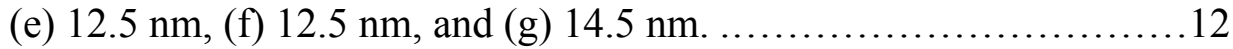

Figure 9. TEM Micrograph of $18.7 \% \mathrm{~mol} \mathrm{ZrO}_{2}$ After $106 \mathrm{hrs}$ of Heat Treatment at $700^{\circ} \mathrm{C}$.

Figure 10. Heat Treated $700^{\circ} \mathrm{C}, 65.2 \% \mathrm{~mol} \mathrm{Zr}$, Ceria-Zirconia with Resulting Crystallite Size of (a) $4 \mathrm{~nm}$, (b) 5nm, (c) 6nm, (d,e) $7 \mathrm{~nm}$, and (g) $8 \mathrm{~nm}$. Heat Treated Times Shown at Right.........................13

Figure 11. TEM Micrograph of $65.2 \%$ at. $\mathrm{Zr}$ After $106 \mathrm{hr}$ of Heat Treatment

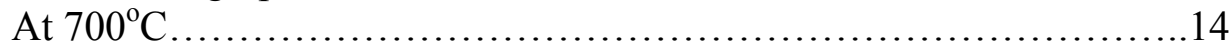

Figure 12. Current Characteristics for the Ce and Ce-Zr Electrolyte at an Applied Potential of $-2.0 \mathrm{~V}$ and Stagnant Solution.....................15

Figure 13. Current Characteristics of Ceria-Zirconia in Quiescent Solution and With a Stirring speed of $900 \mathrm{rpm}$ at an Applied Potential

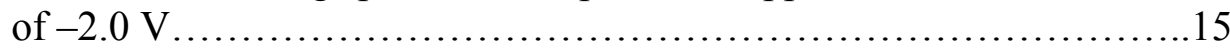

Figure 14. Polarization Curves Corrected for Ohmic Drop, Solution C

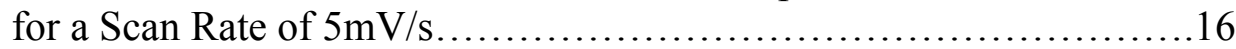

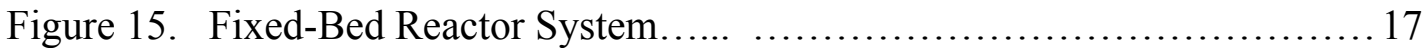

Figure 16. Details of the Quartz Reactor ..................................... 18

Figure 17. Chromatograph Sampling Arrangement ............................20

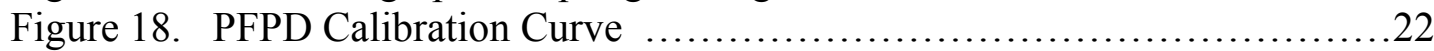

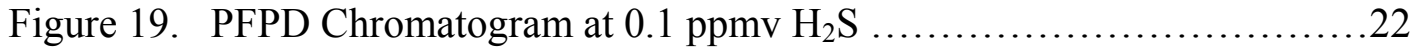

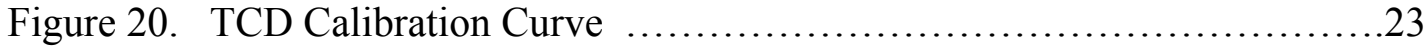

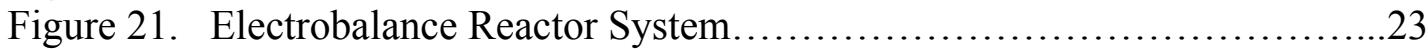

Figure 22. XRD Spectra of (a) $\mathrm{LSU} \mathrm{CeO}_{2}$, (b) cubic $\mathrm{CeO}_{2}$ (JCPDS 34-394) ........27

Figure 23. XRD Spectra of (a) CZ(Nex)85, (b) Tetragonal $\mathrm{ZrO}_{2}$ (JCPDS 88-1007) ............................27

Figure 24. XRD Spectra of (a) Ce(LSU), (b) CZ(LSU)90, and (c) CZ(LSU)80 ...28 Figure 25. Weight Loss Associated With Heating in an Inert Atmosphere............30

Figure 26. Reduction of $\mathrm{Ce}(\mathrm{RP})$ in Three Reducing Gas Compositions...............31

Figure 27. Comparison of Reduciility of $\mathrm{Ce}(\mathrm{RP})$ and $\mathrm{CZ}(\mathrm{Nex}) 80$ in Gas $2 \ldots \ldots \ldots . .32$

Figure 28. Reducibility of Ce(LSU), CZ(LSU)90 and CZ(LSU) 80 in Gas 3.........32 
Figure 29. Typical Sulfidation Breakthrough Curves and Sorbent Conversions

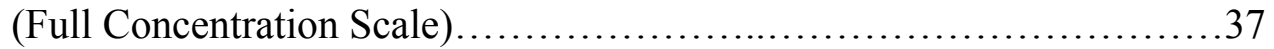

Figure 30. Typical Sulfidation Prebreakthrough Curves (Expanded Concentration Scale)....

Figure 31. Sulfidation Breakthrough Curves of Pure $\mathrm{CeO}_{2}$ Sorbents (Full Concentration Scale). 39

Figure 32. Sulfidation Breakthrough Curves of $\mathrm{Pure}^{\mathrm{CeO}_{2}}$ Sorbents (Expanded Concentration Scale)..........................................39

Figure 33. Temperature Effect on Sulfidation of Ce(RP) .........................41

Figure 34. The Effect of Pre-reduction on Sulfidation of Ce(RP) ...................41

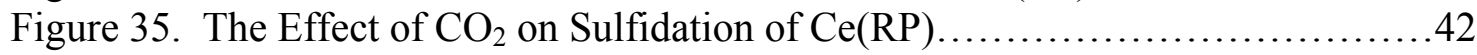

Figure 36. Comparison of the Sulfidation of $\mathrm{Ce}(\mathrm{RP})$ and $\mathrm{CZ}(\mathrm{Nex}) \ldots \ldots \ldots \ldots \ldots \ldots \ldots . . . \ldots 4$

Figure 37. The Effect of Pre-reduction on Sulfidation of CZ(Nex) $85 \ldots \ldots \ldots \ldots \ldots \ldots . . .45$

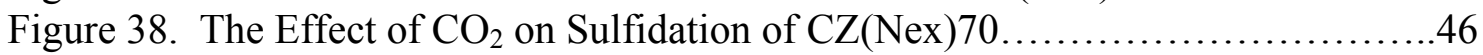

Figure 39. Complete Sulfidation Breakthrough Curves Using LSU Sorbents...........48

Figure 40. The Effect of Temperature on Sulfidation of Ce(LSU)..................48

Figure 41. The Effect of Temperature on Sulfidation of CZ(LSU) 80 .................49

Figure 42. Comparison of the Sulfidation Performance of Ce(LSU), CZ(LSU)90, and CZ(LSU) 80 .....................................50

Figure 43. The Effect of Prereduction on Sulfidation of CZ(LSU)90................50

Figure 44. The Effect of $\mathrm{CO}_{2}$ Addition Using Ce(LSU) (Full Concentration Scale)....52

Figure 45. The Effect of $\mathrm{CO}_{2}$ Addition Using $\mathrm{Ce}(\mathrm{LSU})$

(Expanded Concentration Scale)...

Figure 46. The Effect of $\mathrm{CO}_{2}$ Addition Using $\mathrm{CZ}(\mathrm{LSU}) 80$ (Full Concentration Scale)...........................................53

Figure 47. The Effect of $\mathrm{CO}_{2}$ Addition Using $\mathrm{CZ}(\mathrm{LSU}) 80$ (Expanded Concentration Scale). 


\section{LIST OF TABLES}

Table 1. Composition of the Various Electrolyte Solutions (M) .................5

Table 2. Resistivity of Solution C at Various Times of Deposition.................14

Table 3. Gas Chromatograph Operating Conditions ............................ 19

Table 4. Average Crystallite Sizes and BET Surface Areas of Test Sorbents ..... . 29

Table 5. Summary of Reduction Results for Eight Test Sorbents ..................34

Table 6. Calculation of the Reference Times for Sulfidation Reactions .............36

Table 7. Reference Times for Two Sulfidation Stoichiometries...................47

Table 8. Summary of Sulfidation Test Results at $700^{\circ} \mathrm{C}$ Using LSU

Sorbents and Varying $\mathrm{CO}_{2}$ Feed Gas Concentrations....................54 


\section{EXECUTIVE SUMMARY}

The DOE Vision 21 program requires extremely stringent control of $\mathrm{H}_{2} \mathrm{~S}$ concentration in coal-derived synthesis gas to be used in certain applications. Previous target levels of about $20 \mathrm{ppmv} \mathrm{H}_{2} \mathrm{~S}$ suitable for electric power generation using an integrated gasification combined cycle process (IGCC) have been replaced by $\mathrm{H}_{2} \mathrm{~S}$ targets of 1 ppmv or less required for fuel cell and other catalytic processes.

Zinc-based sorbents developed for IGCC applications are not capable of achieving the Vision 21 target. The thermodynamics of the exothermic $\mathrm{H}_{2} \mathrm{~S}-\mathrm{ZnO}$ reaction will not permit sub-ppmv $\mathrm{H}_{2} \mathrm{~S}$ concentrations to be achieved at high temperature.

Reduced cerium oxide, $\mathrm{CeO}_{\mathrm{n}}(1.5<\mathrm{n}<2.0)$, recently studied in this laboratory, was shown to be capable of reducing $\mathrm{H}_{2} \mathrm{~S}$ to less than $1 \mathrm{ppmv}$ at temperatures near $700^{\circ} \mathrm{C}$ in gas atmospheres having greater reducing power than typical coal-derived gases. In addition, the problem of ultimate sulfur control was eased since elemental sulfur is produced directly during the regeneration of ceria sorbent.

Related research in oxidation catalysis and three-way automotive catalysis has shown that catalyst performance is improved by the addition of $\mathrm{ZrO}_{2}$ to the $\mathrm{CeO}_{2}$. The reasons given for the improved performance, including increased oxygen exchange capacity, should also result in improved desulfurization performance.

This research project consisted of two major activities - the electrochemical synthesis and characterization of $\mathrm{CeO}_{2}-\mathrm{ZrO}_{2}$ materials, and high temperature desulfurization tests using $\mathrm{CeO}_{2}$ and $\mathrm{CeO}_{2}-\mathrm{ZrO}_{2}$ sorbents. Electrochemical synthesis received primary focus during year 01 and results were presented in the first annual report (Mukherjee et al. 2001). Nanocrystalline powders of approximately $5 \mathrm{~nm}$ diameter and containing from $10 \mathrm{~mol} \%$ to $80 \mathrm{~mol} \% \mathrm{ZrO}_{2}$ were deposited at an electrode surface using the cathodic generation of base method. Conditions required for the production of desired solid solutions of $\mathrm{ZrO}_{2}$ in $\mathrm{CeO}_{2}$ having a fluorite-type structure were identified. A separate $\mathrm{ZrO}_{2}$ phase was formed at high $\mathrm{ZrO}_{2}$ concentrations. Heat treatment at $700^{\circ} \mathrm{C}$ for as long as $106 \mathrm{hrs}$ at $700^{\circ} \mathrm{C}$ produced no phase separation, but the crystallite size increased from $5 \mathrm{~nm}$ to $14.5 \mathrm{~nm}$. Unfortunately, the quantities of $\mathrm{CeO}_{2}-\mathrm{ZrO}_{2}$ that could be produced using this method were too small to permit realistic desulfurization testing, and other sources of $\mathrm{CeO}_{2}-\mathrm{ZrO}_{2}$ sorbents were pursued.

A laboratory-scale fixed-bed reactor having a capacity of about $15 \mathrm{~g}$ of solid was constructed during year 01 for desulfurization testing. In order to avoid interaction between low concentrations of $\mathrm{H}_{2} \mathrm{~S}$ and stainless steel, all components of the reactor and analytical systems that were exposed to low $\mathrm{H}_{2} \mathrm{~S}$ concentrations were constructed of quartz, Teflon, or silcosteel. Reactor product gas composition as a function time was determined using a Varian 3800 gas chromatograph purchased for this project with LSU matching funds. The chromatograph was equipped with a pulsed flame photometric detector (PFPD) for measuring low $\mathrm{H}_{2} \mathrm{~S}$ concentrations between about $0.1 \mathrm{ppmv}$ and 10 ppmv, and a thermal conductivity detector (TCD) for higher concentrations of $\mathrm{H}_{2} \mathrm{~S}$. 
Limited quantities of $\mathrm{CeO}_{2}$ and $\mathrm{CeO}_{2}-\mathrm{ZrO}_{2}$ suitable for desulfurization testing were obtained from a number of commercial sources, including Rhone Poulenc, Alfa Aesar, and NexTech Materials. Characterization and desulfurization testing of these sorbents were emphasized during year 02 . X-ray diffraction tests confirmed the existence of a solid solution of $\mathrm{ZrO}_{2}$ in $\mathrm{CeO}_{2}$. Reduction tests using an electrobalance reactor confirmed that $\mathrm{CeO}_{2}-\mathrm{ZrO}_{2}$ mixtures are more easily reduced than pure $\mathrm{CeO}_{2}$. Reduction began at a lower temperature and the final value of $\mathrm{n}$ in $\mathrm{CeO}_{\mathrm{n}}(1.5<\mathrm{n}<2.0)$ was smaller in $\mathrm{CeO}_{2}-\mathrm{ZrO}_{2}$ than in pure $\mathrm{CeO}_{2}$. The experimental values of $\mathrm{n}$ decreased as the temperature and reducing power of the gas increased.

Most of these commercial ceria and ceria-zirconia sorbents were capable of reducing the $\mathrm{H}_{2} \mathrm{~S}$ concentration in highly reducing gases from 5000 ppmv to less than 1 ppmv at temperatures near $700^{\circ} \mathrm{C}$. However, the sorbents were from different sources, had been prepared by different methods, and possessed widely varying structural properties. In order to evaluate the effect of $\mathrm{ZrO}_{2}$ addition, the sorbents should have similar physical properties. A $\mathrm{CeO}_{2}-\mathrm{ZrO}_{2}$ sorbent from one source would not necessarily have superior desulfurization ability than pure $\mathrm{CeO}_{2}$ from another source if the properties of the pure $\mathrm{CeO}_{2}$ were superior. Experimental results using these commercial sorbents were described in annual report 02 (Yi et al. 2002).

Primary attention then turned to the synthesis, characterization, and desulfurization testing of $\mathrm{CeO}_{2}$ and $\mathrm{CeO}_{2}-\mathrm{ZrO}_{2}$ sorbents in this laboratory. A coprecipitation technique using $\mathrm{Ce}\left(\mathrm{NO}_{3}\right)_{3} \cdot 6 \mathrm{H}_{2} \mathrm{O}$ and $\mathrm{Zr}\left(\mathrm{NO}_{3}\right)_{2} \cdot \mathrm{xH}_{2} \mathrm{O}$ precursors and $\mathrm{NH}_{4} \mathrm{OH}$ precipitant was used. Pure $\mathrm{CeO}_{2}, \mathrm{Ce}_{0.9} \mathrm{Zr}_{0.1} \mathrm{O}_{2}$, and $\mathrm{Ce}_{0.8} \mathrm{Zr}_{0.2} \mathrm{O}_{2}$ were prepared for desulfurization testing using this method. The formation of solid solutions of $\mathrm{ZrO}_{2}$ in $\mathrm{CeO}_{2}$ was confirmed by x-ray diffraction analysis. BET surface area measurements and $\mathrm{x}$-ray line broadening analysis showed that the solid solutions had similar structural properties, thereby allowing the effect of $\mathrm{ZrO}_{2}$ addition to be better understood. Like the commercial materials, the $\mathrm{LSU} \mathrm{CeO} \mathrm{CrO}_{2}$ materials were more easily reduced than $\mathrm{ZrO}_{2}$-free sorbents. Reduction began at a lower temperature and the degree of reduction was greater when $\mathrm{ZrO}_{2}$ was present.

Desulfurization tests using the LSU sorbents, which were limited to 1 bar because of the quartz reactor, examined the effects of temperature, pre-reduction in a sulfur-free gas, and sulfidation gas composition. Sulfidation temperature was varied between $600^{\circ} \mathrm{C}$ and $750^{\circ} \mathrm{C}$. Sulfidation feed gas contained $0.25 \% \mathrm{H}_{2} \mathrm{~S}$, varying quantities of $\mathrm{H}_{2}$ and $\mathrm{CO}_{2}$, and balance $\mathrm{N}_{2}$. The proportions of $\mathrm{H}_{2}$ and $\mathrm{CO}_{2}$ were varied to control the reducing power (oxygen partial pressure) of the feed gas. In selected tests the sorbent was prereduced in a sulfur-free gas of the same composition and temperature used in the subsequent sulfidation test.

Sorbent performance was judged on the basis of the minimum $\mathrm{H}_{2} \mathrm{~S}$ concentration achieved during the so-called "prebreakthrough" period and on the duration of the prebreakthrough period. $\mathrm{H}_{2} \mathrm{~S}$ concentrations below the 1-ppmv target were obtained consistently using both $\mathrm{CeO}_{2}$ and $\mathrm{CeO}_{2}-\mathrm{ZrO}_{2}$ sorbents in highly reducing, $\mathrm{CO}_{2}$-free, feed 
gas throughout the entire temperature range. Pre-reduced sorbents were successful in reducing the $\mathrm{H}_{2} \mathrm{~S}$ concentration to near zero (below the PFPD detection limit) during the prebreakthrough period. When up to $1 \% \mathrm{CO}_{2}$ was added as an oxygen source to control the reducing power of the feed gas, it was still possible to reduce the $\mathrm{H}_{2} \mathrm{~S}$ concentration to sub-ppmv levels, but for a shorter time period. $\mathrm{CeO}_{2}$ sorbents were more strongly affected by $\mathrm{CO}_{2}$ addition than $\mathrm{CeO}_{2}-\mathrm{ZrO}_{2}$. In a series of tests at $700^{\circ} \mathrm{C}$ with the feed gas containing varying $\mathrm{CO}_{2}$ concentrations, the duration of the prebreakthrough period was from $25 \%$ to $100 \%$ longer using $\mathrm{Ce}_{0.8} \mathrm{Zr}_{0.2} \mathrm{O}_{2}$ than $\mathrm{CeO}_{2}$. 


\section{INTRODUCTION}

Research relating to the high temperature desulfurization of coal-derived gas has been a major component of the DOE fossil energy program for a number of years. In the past, the primary objective was to reduce $\mathrm{H}_{2} \mathrm{~S}$ concentration to levels required for electric power generation using integrated gasification combined cycles (IGCC), approximately $20 \mathrm{ppmv}$. Desulfurization processes for this application using zinc-based sorbents have progressed to the demonstration stage. The new DOE Vision 21 program, however, requires much more stringent sulfur control measures. Sulfur levels equal to or less than $1 \mathrm{ppmv}$ are required for fuel cells and certain synthesis gas catalytic processes. New sorbents are needed to meet these more stringent sulfur limits.

Recent research in this laboratory (Zeng et al. 1999, Zeng et al. 2000) showed that reduced cerium oxide, designated $\mathrm{CeO}_{\mathrm{n}}(1.5<\mathrm{n}<2.0)$, is capable of reducing $\mathrm{H}_{2} \mathrm{~S}$ from $1 \mathrm{~mol} \%$ to less than $1 \mathrm{ppmv}$ at temperatures near $700^{\circ} \mathrm{C}$ in highly reducing gas compositions. However, the product compositions from gasifiers currently available in the United States (Texaco, KRW, etc.) do not have the reducing power required to achieve significant $\mathrm{CeO}_{2}$ reduction. The equilibrium $\mathrm{H}_{2} \mathrm{~S}$ content in contact with unreduced $\mathrm{CeO}_{2}$ is well above the more stringent Vision 21 target levels.

This research continued the investigation of $\mathrm{CeO}_{2}$ sorbents and extended the investigation to the performance of mixed oxide sorbents of $\mathrm{CeO}_{2}-\mathrm{ZrO}_{2}$ with the objective of meeting Vision 21 target levels in less reducing gas compositions. The addition of $\mathrm{ZrO}_{2}$ to $\mathrm{CeO}_{2}$ has improved the performance of oxidation catalysts and threeway automotive catalysts. The improvement is attributed to increased reducibility and improved oxygen mobility resulting from the addition of $\mathrm{ZrO}_{2}$, factors that should also improve desulfurization performance.

\subsection{High Temperature Gas Desulfurization}

High temperature desulfurization of coal-derived gas is based on the noncatalytic gas-solid reaction between $\mathrm{H}_{2} \mathrm{~S}$ and an appropriate metal oxide. The reaction may be written generically as follows:

$$
\mathrm{H}_{2} \mathrm{~S}(\mathrm{~g})+\mathrm{MeO}(\mathrm{s}) \leftrightarrow \mathrm{H}_{2} \mathrm{O}(\mathrm{g})+\mathrm{MeS}(\mathrm{s})
$$

The generic reaction for the regeneration of the metal sulfide is:

$$
\mathrm{MeS}(\mathrm{s})+1.5 \mathrm{O}_{2}(g) \leftrightarrow \mathrm{MeO}(s)+\mathrm{SO}_{2}(g)
$$

For economic reasons, the sorbent must maintain activity through many sulfidationregeneration cycles. A number of metals including $\mathrm{Zn}, \mathrm{Fe}, \mathrm{Mn}, \mathrm{Cu}$, and $\mathrm{Ca}$ have been studied but most of the recent research has focused on $\mathrm{Zn}$-based materials, including $\mathrm{ZnO}$

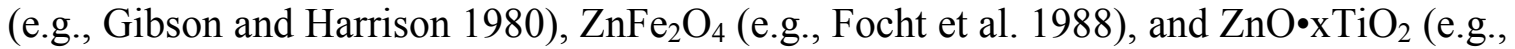
Woods et al. 1990). 
Harrison (1998) has discussed the advantages and disadvantages of zinc-based sorbents. Advantages include favorable desulfurization thermodynamics, rapid kinetics, large stoichiometric sulfur capacity ( $39 \mathrm{~g} \mathrm{~S} / 100 \mathrm{~g} \mathrm{ZnO})$, and relatively low cost. Disadvantages include the tendency for $\mathrm{ZnO}$ to be reduced to volatile metallic $\mathrm{Zn}$ at high temperature, the highly exothermic nature of the regeneration reaction, and the possible formation of $\mathrm{ZnSO}_{4}$ during regeneration. The tendency for $\mathrm{ZnO}$ reduction followed by $\mathrm{Zn}$ vaporization can be moderated, but not eliminated, by the addition of $\mathrm{TiO}_{2}$ to form the mixed metal oxide $\mathrm{ZnO} \bullet \mathrm{xTiO}_{2}$. However, $\mathrm{TiO}_{2}$ addition increases the sorbent processing cost and reduces the sulfur capacity. Dilute $\mathrm{O}_{2}$ may be used to control temperature during regeneration, but this causes dilute $\mathrm{SO}_{2}$ to be produced and complicates the ultimate sulfur control problem. $\mathrm{ZnSO}_{4}$, because of its large molar volume, has been identified as a cause of rapid sorbent deterioration in multicycle tests, and careful control of temperature and the partial pressures of $\mathrm{O}_{2}$ and $\mathrm{SO}_{2}$ are required to prevent its formation.

The performance of $\mathrm{CeO}_{2}$ as a high temperature desulfurization sorbent was recently studied in this laboratory (Zeng et al. 1999, Zeng et al. 2000). $\mathrm{H}_{2} \mathrm{~S}$ concentrations were reduced from $1 \mathrm{~mol} \%(10,000 \mathrm{ppmv})$ to $1 \mathrm{ppmv}$ or less at temperatures in the range of $650^{\circ} \mathrm{C}$ to $800^{\circ} \mathrm{C}$ in highly reducing atmospheres. Reduction of $\mathrm{CeO}_{2}$ to oxygen-deficient $\mathrm{CeO}_{n}(n<2)$ was the key in achieving low $\mathrm{H}_{2} \mathrm{~S}$ concentrations. The sulfided product, $\mathrm{Ce}_{2} \mathrm{O}_{2} \mathrm{~S}$, was easily regenerated using $\mathrm{SO}_{2}$ with sulfur liberated in elemental form. Preliminary multicycle tests (25 complete cycles) showed no evidence of sorbent deterioration.

The complete cycle using cerium sorbent consists of three steps - reduction, sulfidation, and regeneration - as shown by the following reactions.

$$
\begin{aligned}
& \text { Reduction: } \mathrm{CeO}_{2}(s)+(2-n) \mathrm{H}_{2}(g) \leftrightarrow \mathrm{CeO}_{n}(s)+(2-n) \mathrm{H}_{2} \mathrm{O}(g) \\
& \text { Sulfidation: } 2 \mathrm{CeO}_{n}(s)+\mathrm{H}_{2} \mathrm{~S}(g)+(2 n-3) \mathrm{H}_{2}(g) \leftrightarrow \mathrm{Ce}_{2} \mathrm{O}_{2} \mathrm{~S}(s)+2(n-1) \mathrm{H}_{2} \mathrm{O}(g) \\
& \text { Regeneration: } \mathrm{Ce}_{2} \mathrm{O}_{2} \mathrm{~S}(s)+\mathrm{SO}_{2}(g) \leftrightarrow 2 \mathrm{CeO}_{2}(s)+\mathrm{S}_{2}(g)
\end{aligned}
$$

Reactions (3) and (4) occur simultaneously in the reducing synthesis gas. The ultimate degree of reduction, i.e., the equilibrium value of $\mathrm{n}$, depends on temperature and the oxygen partial pressure of the reducing gas, as described by Bevan and Kordis (1964) and Sorensen (1976). Reduction experiments in this laboratory using $\mathrm{CeO}_{2}$ and an electrobalance reactor showed that the level of reduction, i.e., the experimental value of $\mathrm{n}$, is in reasonable agreement with the results of Bevan and Kordis. Unfortunately the oxygen partial pressure in the product gas from typical U.S coal gasifiers (Texaco and $\mathrm{KRW}$ ) is too large to achieve significant $\mathrm{CeO}_{2}$ reduction.

The current research examined the addition of $\mathrm{ZrO}_{2}$ to $\mathrm{CeO}_{2}$ in the hope that reduction to $\mathrm{CeO}_{\mathrm{n}}$ could be more easily accomplished. The expected benefits were based on results from recent research in the areas of oxidation and automotive catalysis summarized in the following section. 


\subsection{Ceria-Zirconia Catalyst Research}

$\mathrm{CeO}_{2}$ serves an important role in three-way automotive catalysts (TWC) by regulating the oxygen pressure in the exhaust gas. During fuel rich operation, $\mathrm{CeO}_{2}$ is reduced to $\mathrm{CeO}_{\mathrm{n}}$ and the oxygen released assists in the oxidation of $\mathrm{CO}$ and hydrocarbons to $\mathrm{CO}_{2}$. Under fuel lean conditions $\mathrm{CeO}_{\mathrm{n}}$ is re-oxidized to $\mathrm{CeO}_{2}$ and removal of oxygen from the gas phase assists in the reduction of $\mathrm{NO}_{\mathrm{x}}$ to $\mathrm{N}_{2}$. In oxidation catalysis, the $\mathrm{CeO}_{2}$ is reduced to $\mathrm{CeO}_{\mathrm{n}}$ by surface adsorbed species as they are oxidized to $\mathrm{CO}_{2}$, and the $\mathrm{CeO}_{\mathrm{n}}$ is then re-oxidized to $\mathrm{CeO}_{2}$ by oxygen from the gas phase.

Recent research has shown that the addition of $\mathrm{ZrO}_{2}$ to $\mathrm{CeO}_{2}$ enhances the redox reactions. Colon et al. (1998) state that the addition of $\mathrm{ZrO}_{2}$ enhances the oxygen mobility within the crystal and improves the catalyst thermal stability at $1000^{\circ} \mathrm{C}$. Zamar et al. (1995) discuss the enhanced oxygen storage and release capacity of $\mathrm{CeO}_{2}-\mathrm{ZrO}_{2}$ mixtures used for $\mathrm{CH}_{4}$ combustion. $\mathrm{ZrO}_{2}$ was said to promote the formation of oxygen vacancies and increase the mobility of bulk oxygen. The $50 \% \mathrm{CH}_{4}$ conversion level was reached at a temperature $130^{\circ} \mathrm{C}$ lower using $\mathrm{Ce}_{0.8} \mathrm{Zr}_{0.2} \mathrm{O}_{2}$ compared to $\mathrm{CeO}_{2}$ alone.

Hori et al. (1998) report an increase in reversibly stored oxygen by a factor of 1.72.5 for phase separated $\mathrm{CeO}_{2}-\mathrm{ZrO}_{2}$ compared to $\mathrm{CeO}_{2}$ alone, and by a factor of 3 to 5 for solid solutions of $\mathrm{CeO}_{2}-\mathrm{ZrO}_{2}$. The optimum $\mathrm{Zr}$ concentration was $25 \mathrm{~mol} \%$, but performance was relatively insensitive to $\mathrm{Zr}$ loading between $15 \mathrm{~mol} \%$ and $50 \mathrm{~mol} \%$. Bunluesin et al. (1997) found that addition of $\mathrm{ZrO}_{2}$ slowed the catalyst deactivation rate for $\mathrm{CO}$ oxidation over a Ce-Pd catalyst. Deactivation without $\mathrm{ZrO}_{2}$ was attributed to a large increase in crystallite size, and $\mathrm{ZrO}_{2}$ was said to slow crystallite growth.

Trovarelli et al. (1997) and Cuif et al. (1996) discuss the improved performance of three-way automotive catalysts due to the addition of $\mathrm{ZrO}_{2}$ to $\mathrm{CeO}_{2}$. Trovarelli et al. state that the addition of $\mathrm{ZrO}_{2}$ enhances the catalytic, textural, redox, and oxygen storage properties of ceria. Trovarelli (1996) and Ozawa (1997) have published recent reviews describing the beneficial effects of $\mathrm{ZrO}_{2}$ addition.

These positive effects on the performance of $\mathrm{CeO}_{2}$ catalysts associated with $\mathrm{ZrO}_{2}$ addition - improved redox potential, increased oxygen mobility, higher oxygen exchange capacity, improved activity at lower temperature, and increased thermal stability - are the same factors thought to be needed to improve the performance of ceria-based desulfurization sorbents. Therefore, the goal of this research was to determine if ceriazirconia sorbents are capable of achieving Vision 21 desulfurization goals in typical coal gas compositions.

\subsection{Objectives of the Research}

The project was divided into two major activities - the electrochemical synthesis and characterization of $\mathrm{CeO}_{2}-\mathrm{ZrO}_{2}$ mixtures and high temperature desulfurization using $\mathrm{CeO}_{2}-\mathrm{ZrO}_{2}$ sorbents. Electrochemical synthesis and characterization, and construction of a laboratory-scale fixed-bed reactor suitable for determining sub-ppmv $\mathrm{H}_{2} \mathrm{~S}$ 
concentrations were emphasized during year 01. These topics were described in the first annual report (Mukherjee et al. 2001). While the electrochemical synthesis work was successful, it proved to be impossible to produce sufficient quantities of material to properly evaluate the desulfurization potential. Characterization and testing of commercially available $\mathrm{CeO}_{2}$ and $\mathrm{CeO}_{2}-\mathrm{ZrO}_{2}$ materials were emphasized in the annual report from year 02 ( $\mathrm{Yi}$ et al. 2002). Primary attention during the latter stages of the research turned to the preparation of $\mathrm{CeO}_{2}$ and $\mathrm{CeO}_{2}-\mathrm{ZrO}_{2}$ sorbents in this laboratory, the characterization of these sorbents, and desulfurization tests using these in-house sorbents. Much of this work was presented in the annual report from year 03 (Yi et al. 2003). This final report summarizes the overall research effort.

\section{ELECTROCHEMICAL SYNTHESIS AND CHARACTERIZATION OF $\mathrm{CeO}_{2}-\mathrm{ZrO}_{2}$}

A number of methods have been used for producing ceria-zirconia mixtures, including bulk co-precipitation, rapid solidification, high-energy mechanical milling, laser evaporation-condensation and sol-gel. An alternative electrochemical route was recently demonstrated by Switzer (1987) and Yanchun et al. (1995) for ceria and zirconia, respectively, but not the mixture $\mathrm{Ce}_{1-\mathrm{x}} \mathrm{Zr}_{\mathrm{x}} \mathrm{O}_{2}$. Independently, the powders were deposited by the cathodic generation of base method at an electrode surface. In this work, we have altered the synthesis method in order to codeposit the powders and to investigate the chemical composition, phase structure, and crystallite size as a function of the processing parameters. The effect of heat treatment on the resulting crystalline structure was also noted. Conditions have been identified for producing ceria-zirconia mixtures that exhibit solid solutions of the fluorite-type structure, are nanocrystalline, and have about $20 \mathrm{~mol} \%$ zirconia, which are recommended as the first choice for future desulfurization testing.

\subsection{Electrochemical Experimental}

Figure 1 shows the two-compartment electrochemical cell employed in the powder synthesis. The anolyte and catholyte were separated by a glass frit. A platinum mesh was used as the anode. The reference electrode was a saturated calomel electrode (SCE). An inverted, stationary, stainless steel shaft-disk electrode was used as described by Podlaha et al. (1997) with the electrode surface facing upwards in the electrolyte to avoid blockage of the electrode surface by trapped $\mathrm{H}_{2}$ gas bubbles produced from water and proton reduction. The stainless steel disc electrodes (AISI 304L) were embedded inside an epoxy resin such that only one side was exposed to the electrolyte. A thin, stainless steel shaft, encased in Teflon, was screwed into the disc-epoxy assembly. The shaft was threaded allowing electrical contact to the disc.

The electrolyte consisted of $0.5 \mathrm{M}$ ammonium nitrate, and varying concentrations of zirconyl (IV) nitrate hydrate and cerium (III) nitrate hexahydrate. All experiments were carried at room temperature of $23 \pm 1{ }^{\circ} \mathrm{C}$. Table 1 lists the different compositions of the electrolyte used. The $\mathrm{pH}$ was maintained at $1.5 \pm 0.1$ at the start of each experiment. 
Potentiostatic experiments were carried out with a BAS-Zahner IM6(e) potentiostat/galvanostat system. Three different potentials of $-1.8 \mathrm{~V},-1.9 \mathrm{~V}$ and $-2.0 \mathrm{~V}$ vs SCE were applied to investigate the effect of potential on the deposition. DC current was used in all the experiments conducted. Polarization curves were measured by ramping the potential at sweep rates of $5,10,25,50,100,200,500,750$ and $1000 \mathrm{mV} / \mathrm{s}$. The deposited powders were scraped from the electrode, dried in a desiccator at room temperature, and analyzed. The ohmic drop was measured with a BAS-Zahner IM6(e) Impedance Analyzer.

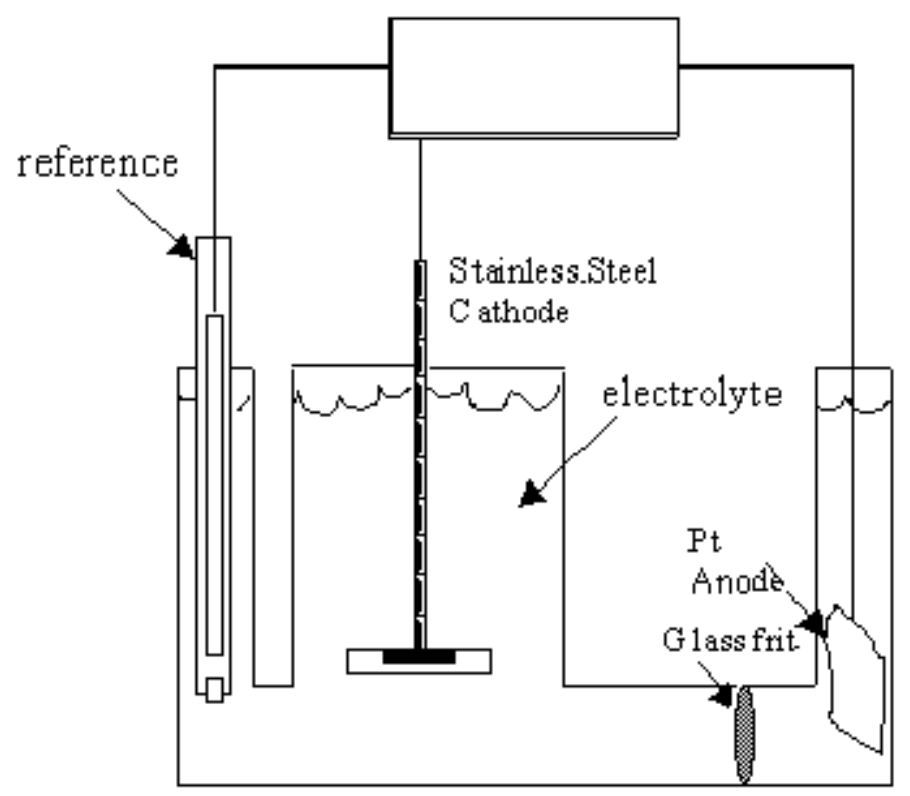

Figure 1. Electrochemical Cell Schematic

Table 1. Composition of the Various Electrolyte Solutions (M).

\begin{tabular}{|c|c|c|c|}
\hline Electrolyte & $\mathrm{Ce}\left(\mathrm{NO}_{3}\right)_{3} \cdot 6 \mathrm{H}_{2} \mathrm{O}$ & $\mathrm{Zr}\left(\mathrm{NO}_{3}\right)_{4} \cdot \mathrm{H}_{2} \mathrm{O}$ & $\mathrm{NH}_{4} \mathrm{NO}_{3}$ \\
\hline $\mathrm{A}$ & 0.5 & 0.0 & 0.5 \\
\hline $\mathrm{B}$ & 0.5 & 0.1 & 0.5 \\
\hline $\mathrm{C}$ & 0.5 & 0.2 & 0.5 \\
\hline $\mathrm{D}$ & 0.25 & 0.2 & 0.5 \\
\hline $\mathrm{E}$ & 0.125 & 0.2 & 0.5 \\
\hline $\mathrm{F}$ & 0.25 & 0.5 & 0.5 \\
\hline $\mathrm{G}$ & 0.125 & 0.5 & 0.5 \\
\hline
\end{tabular}

\subsection{Solid State Analyses}

The chemical composition of the deposits was measured by energy dispersive $\mathrm{x}$-ray fluorescence spectroscopy (EDXRF) (Kevex, Model Omicron) calibrated with bulk samples of ceria and zirconia. The composition was determined over a large region of pressed sorbent powder to verify uniformity of the ceria-zirconia mixture. The spot size 
of the x-ray analysis was a projection from a 100 micron collimeter and the chemical composition was mapped over an area of several centimeters. Four to five measurements were averaged for each sample of powder with a Rh tube potential of $45 \mathrm{kV}$, current of $0.8 \mathrm{~mA}$ (shaping index of 64) in an air atmosphere, using 400 seconds sampling time. Once the powder concentration was found in the desired range of $15-50 \mathrm{~mol} \%$ zirconia, further analysis by x-ray diffraction (XRD) and transmission electron microscopy (TEM) was carried out to verify the structure of the material. The crystallinity and particle size of the as-produced powder were analyzed by a bright-field high resolution TEM (JEOL Model JEM 2010). Specimens for the TEM were made by dispersing the powders in a solution of $10 \%$ methanol in water. A drop of the suspension was put on a holey carbon film and allowed to dry for analysis. The TEM analysis of the nanocrystalline $\mathrm{Ce}_{1-\mathrm{x}} \mathrm{Zr}_{\mathrm{x}} \mathrm{O}_{2}$ was done at $200 \mathrm{keV}$ with a point to point resolution of $23 \mathrm{~nm}$. The phase identification of the sample and the lattice parameters were determined with $\mathrm{x}$-ray diffraction analysis (XRD), carried out using a Bruker Advance D8 powder diffractometer equipped with a focusing $\mathrm{Ge}(111)$ incident beam monochromator $\left(\mathrm{Cu}-\mathrm{K}_{\alpha 1}\right.$ radiation). Finely ground samples were placed on a zero-background quartz sample holder. Intensity data were collected at ambient temperature in the $2 \theta$ range between $25^{\circ}$ and $60^{\circ}$ with a step width of $0.02^{\circ}$ and $8 \mathrm{~s}$ count time. The peaks of each compound were compared with phases in the International Center for Diffraction Data database (ICDD).

\subsection{Electrosynthesis Results and Discussion}

\subsubsection{Composition}

Figure 2 shows the parametric representation of final powder composition vis-a-vis the initial electrolyte concentration at various applied potentials. A linear relationship is observed between the concentration of $\mathrm{Zr}$ in the powder and the concentration in the electrolyte. The aim was to obtain a composition between 15 and $50 \mathrm{~mol} \% \mathrm{Zr}$ in the final powder, and was achieved by controlling the electrolyte concentration. Additionally, the powder composition was not found to be a function of the applied potential. At low $\mathrm{Zr}$ concentrations in the electrolyte ceria is preferentially deposited over zirconia, which diminishes as the concentration of $\mathrm{Zr}$ in the solution increases. As a reference point, a dashed line has been added to Figure 2 to show the 1:1 correspondence between the mol fraction of $\mathrm{Zr}$ in the powder with the concentration in solution.

\subsubsection{XRD and TEM Characterization}

The microstructure of the $\mathrm{Ce}_{1-\mathrm{x}} \mathrm{Zr}_{\mathrm{x}} \mathrm{O}_{2}$ with $\mathrm{x}=0,0.07,0.18$ at. fraction $\mathrm{Zr}$ samples were characterized by TEM. Figure 3 shows high-resolution TEM images of the sample. The average grain sizes of the nanocrystallites were approximately $5 \mathrm{~nm}$ in diameter, independent of composition. Crystallite size of this order competes with many of the standard wet and dry processing production methods.

The structure of the nanocrystallites was examined by electron diffraction. Figure 4 shows a selected-area electron diffraction (SAED) pattern taken from Figure 3 (c) for 


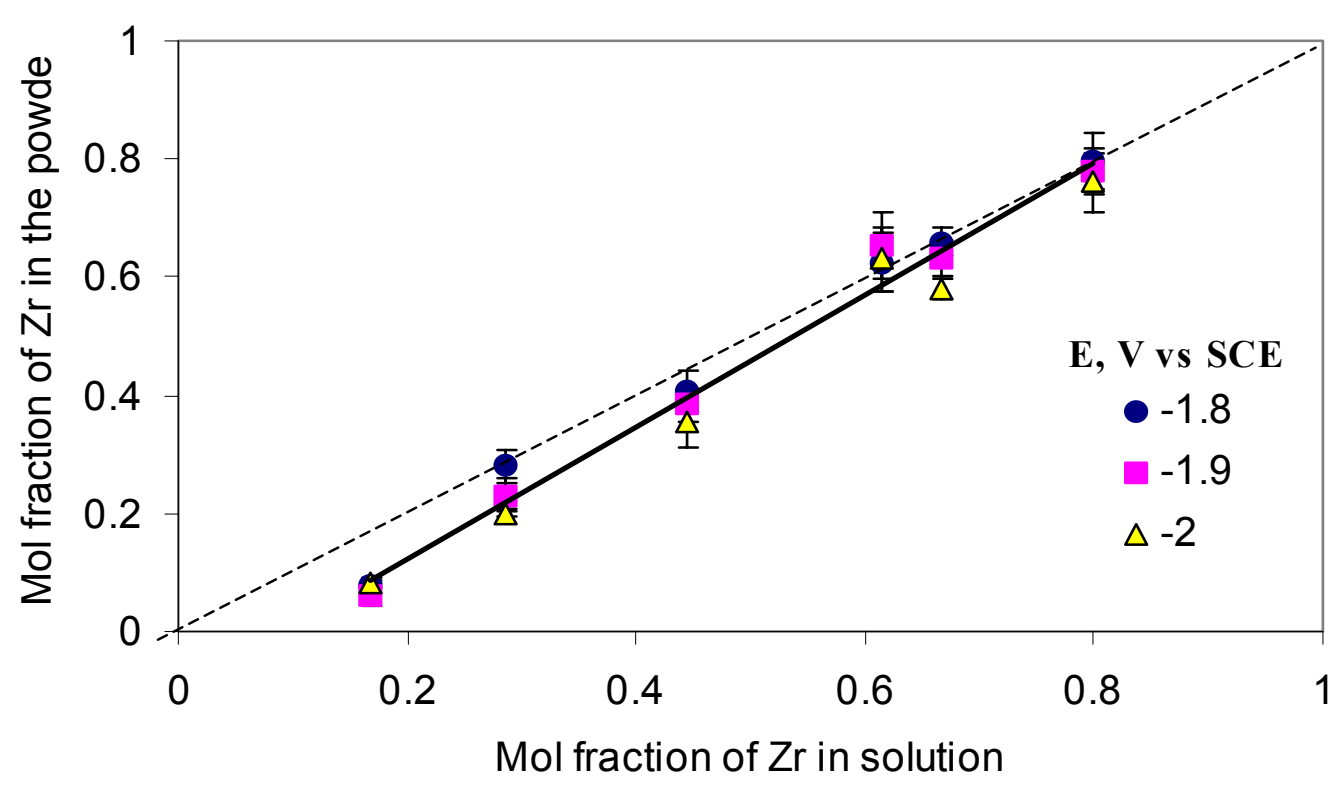

Figure 2. Electrolyte Concentration vs. Final Powder Composition.

the 18 at $\% \mathrm{Zr}$ case. The discrete rings indicate a crystalline material and are consistent with the lattice fringes observed in Figures 3 (a)-(c). The first 7 diffraction rings (start from the center) correspond to the (111), (200), (220), (311), (222), (400) and (331) reflections of the $\mathrm{CeO}_{2}$, and suggest a solid solution.

The crystallite size and phase were also verified with x-ray diffraction (XRD). The XRD of the powder sample having 18 at $\% \mathrm{Zr}$, produced from solution $\mathrm{C}$, is shown in Figure 5(a). It is compared to the standard library patterns of the end members (b) cubic $\mathrm{CeO}_{2}$ and (c) monoclinic and tetragonal $\mathrm{ZrO}_{2}$. Neither monoclinic nor tetragonal modification of $\mathrm{ZrO}_{2}$ was observed in the $\mathrm{x}$-ray powder diffraction of the sample. The spectrum exhibits a cubic single phase similar to other solid solution $\mathrm{ZrO}_{2}-\mathrm{CeO}_{2} \mathrm{XRD}$ patterns of samples generated by non-electrochemical techniques. The mean crystal size, calculated from the full width at half maximum of the (111) reflection, was $4.5 \mathrm{~nm}$, which is consistent with the TEM observation.

As the concentration of $\mathrm{ZrO}_{2}$ increased in the powder the emergence of a second phase is seen (Figure 6). The slight shift to the right of the main (111) peak indicates a decrease of the lattice parameter due to $\mathrm{Zr}$ incorporation. The shift provides evidence of the formation of a solid solution that has been associated with superior catalytic properties by Colon et al. (1998). Formation of a separate $\mathrm{ZrO}_{2}$ phase is thought to be undesirable for a desulfurization sorbent.

Comparing the LSU electrosynthesized $18 \%$ at. $\mathrm{Zr}$ powder with a commercial ceria-zirconia solid solution reveals a similar XRD pattern. Figure 7 shows that the (111) 
peak is slightly broader than the commercial product by NexTech due to the smaller grain size. A small shift of the peaks from the commercial product to the right indicates a higher $\mathrm{Zr}$ concentration than in the LSU synthesized solid solution.
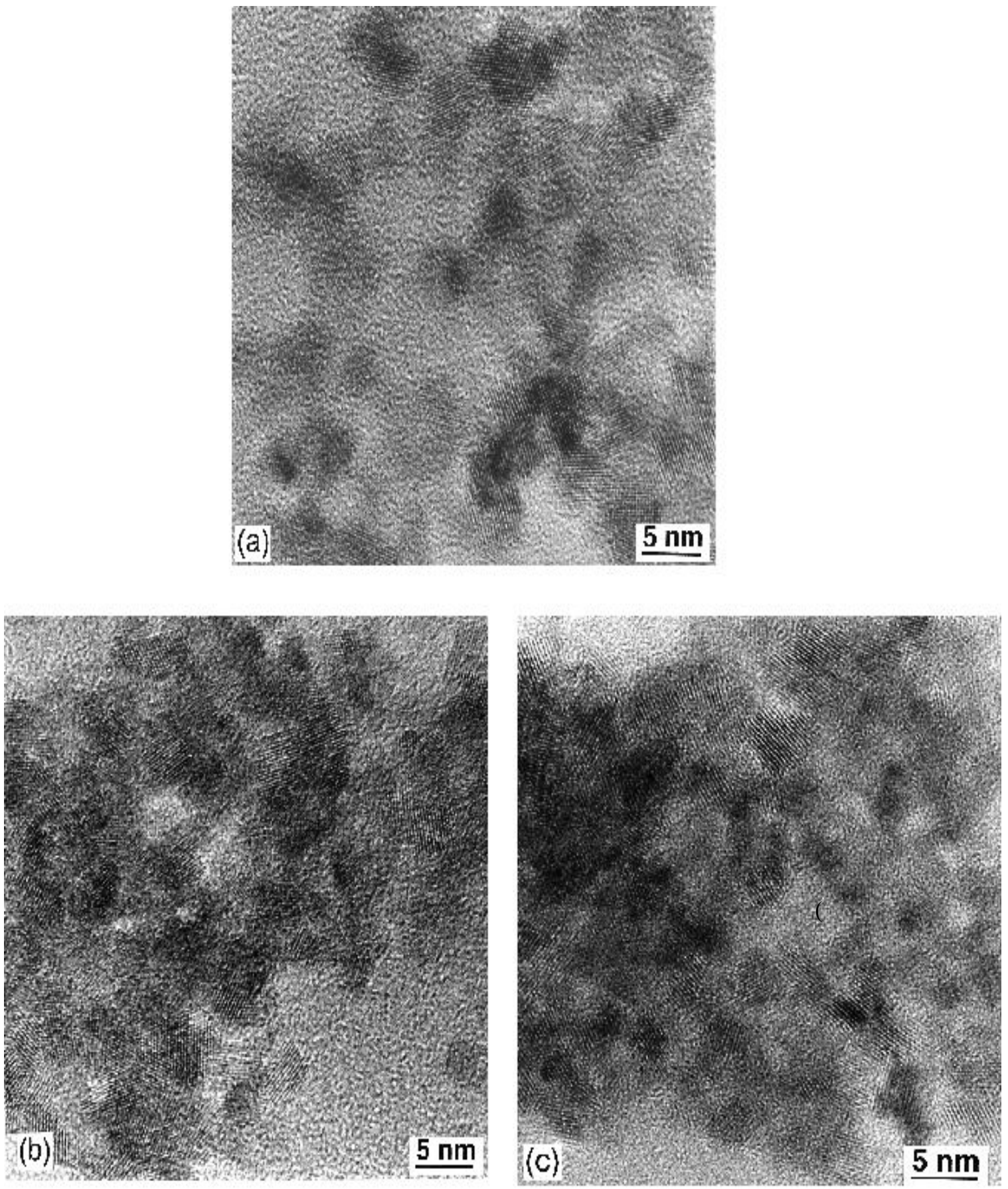

Figure 3. TEM images of (a) Ceria, (b) Ceria-7 mol\% Zirconia (c) Ceria-18 mol\% Zirconia 


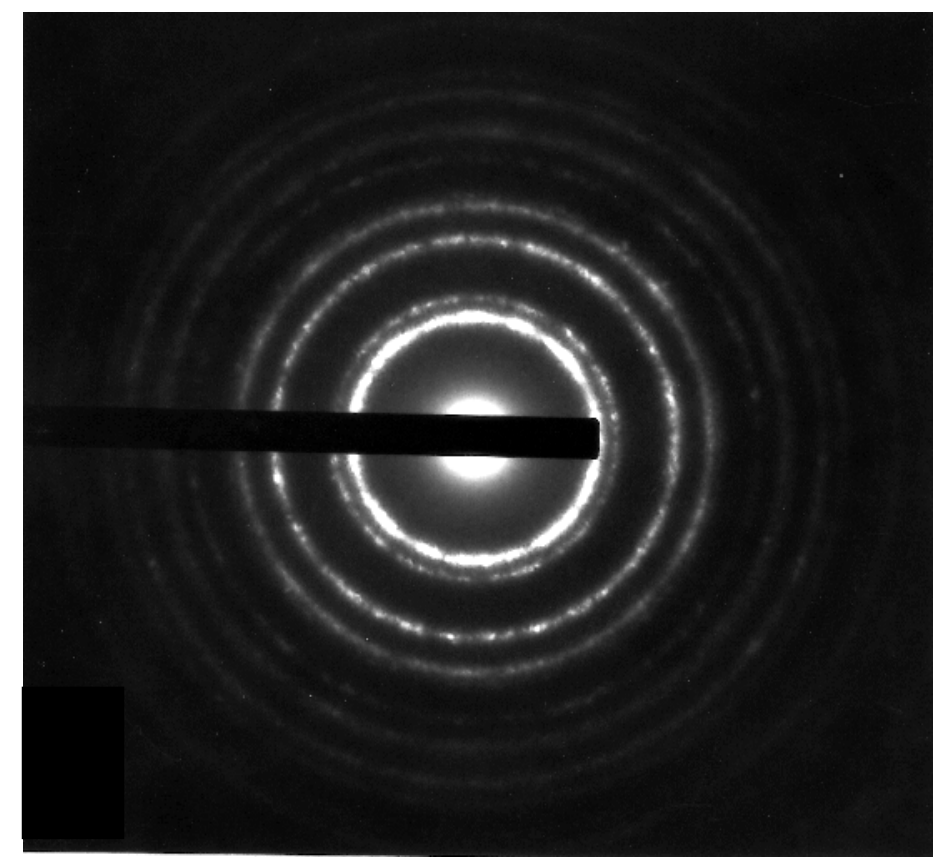

Figure 4. Selected-Area Electron Diffraction (SAED) Pattern Taken Over a Large Area Shown in Figure 3.

Nanostructured crystallite size and the presence of a solid solution are prerequisites for a quality sorbent material, in addition to its stability at high temperature. Since the reactor will be operated at temperatures $>600{ }^{\circ} \mathrm{C}$ the affect of a heat treatment was considered. XRD and TEM analysis are shown in Figures 8-11. The XRD pattern of a heat treated sample at $700^{\circ} \mathrm{C}$ from solution $\mathrm{C}$ is shown in Figure 8, having a $\mathrm{ZrO}_{2}$ composition of $18.7 \mathrm{~mol} \mathrm{\%}$. The choice of temperature was determined from desulfurization results using ceria sorbents (Zeng et al. 1999 and Zeng et al. 2000). The heat treatment was carried out for $2 \mathrm{hr}$ on a single sample, which was then cooled to room temperature to conduct the XRD analysis. The sample was then subjected to another heat treatment along with a cooling cycle for XRD testing. The procedure was repeated with the following heating times: 2, 2, 3, 5, 10, 24, $60 \mathrm{hr}$. Figure 8 shows the characteristic ceria peaks at heat heating steps corresponding to a solid solution as well as Al, which was present in the holder and not part of the powder. Additionally, phase separation was not observed upon heat treatment.

The particle size was found to increase slightly at different heat treatment steps, but after 106 hours of heating at $700^{\circ} \mathrm{C}$, the crystallite size was $14.5 \mathrm{~nm}$. Large increases in crystallite size are not considered desirable, but the increase observed here is small enough that it is not considered critical for the catalytic sorbent property. Figure 9 is a TEM micrograph that verifies the increase in crystallite size observed with XRD. The micrograph was taken after cooling of the last heat treatment at $106 \mathrm{hrs}$. Lattice fringes are present as previously observed. 

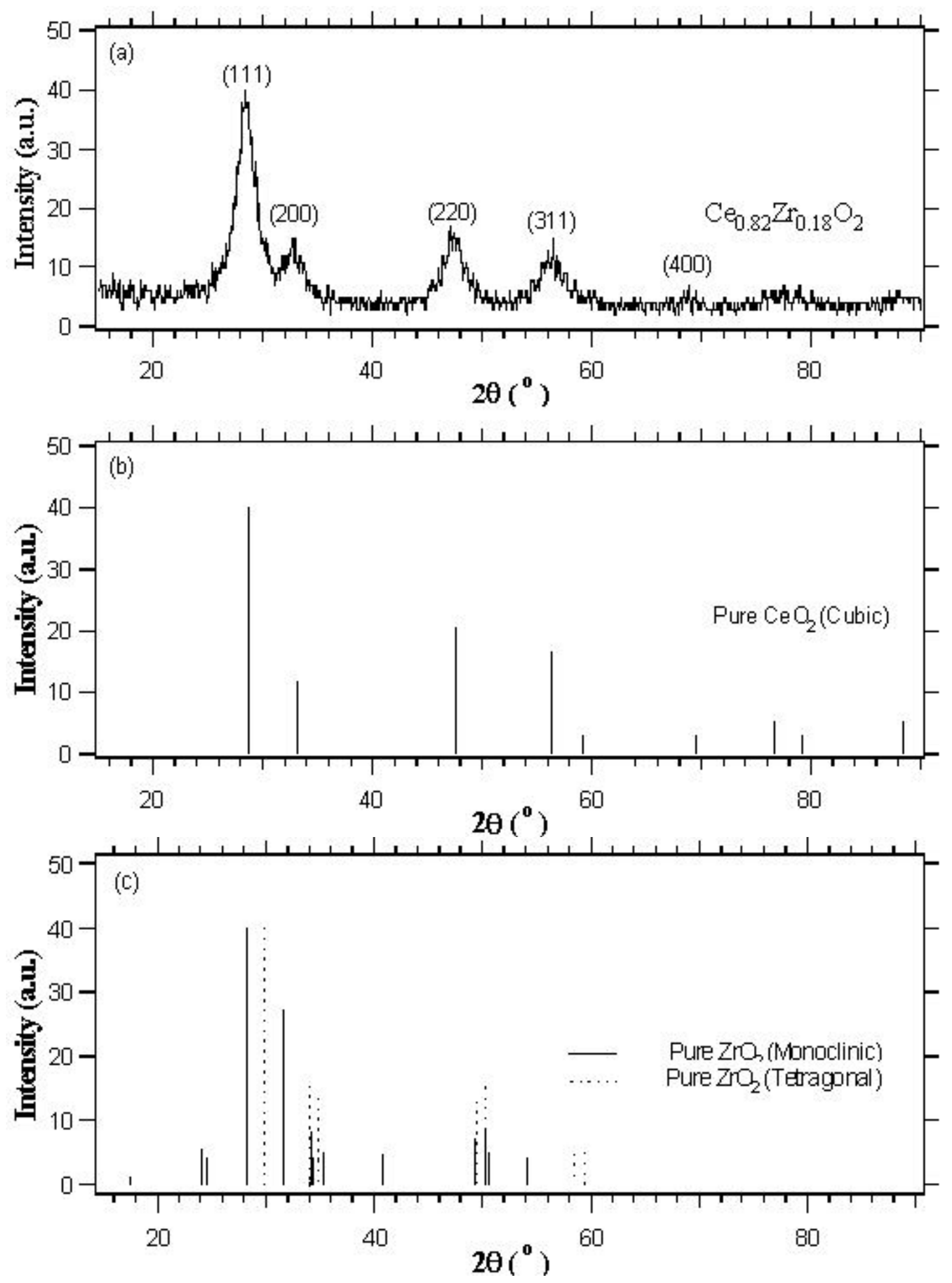

Figure 5. XRD Analysis of (a) Electrochemically Generated Nanocrystalline $\mathrm{Ce}_{0.82} \mathrm{Zr}_{0.18} \mathrm{O}_{2}$, (b) Cubic $\mathrm{CeO}_{2}$ (JCPDS 34-394), and (c) Monoclinic (JCPDS 37-1484) and Tetragonal (JCPDS 42-1164) $\mathrm{ZrO}_{2}$ 


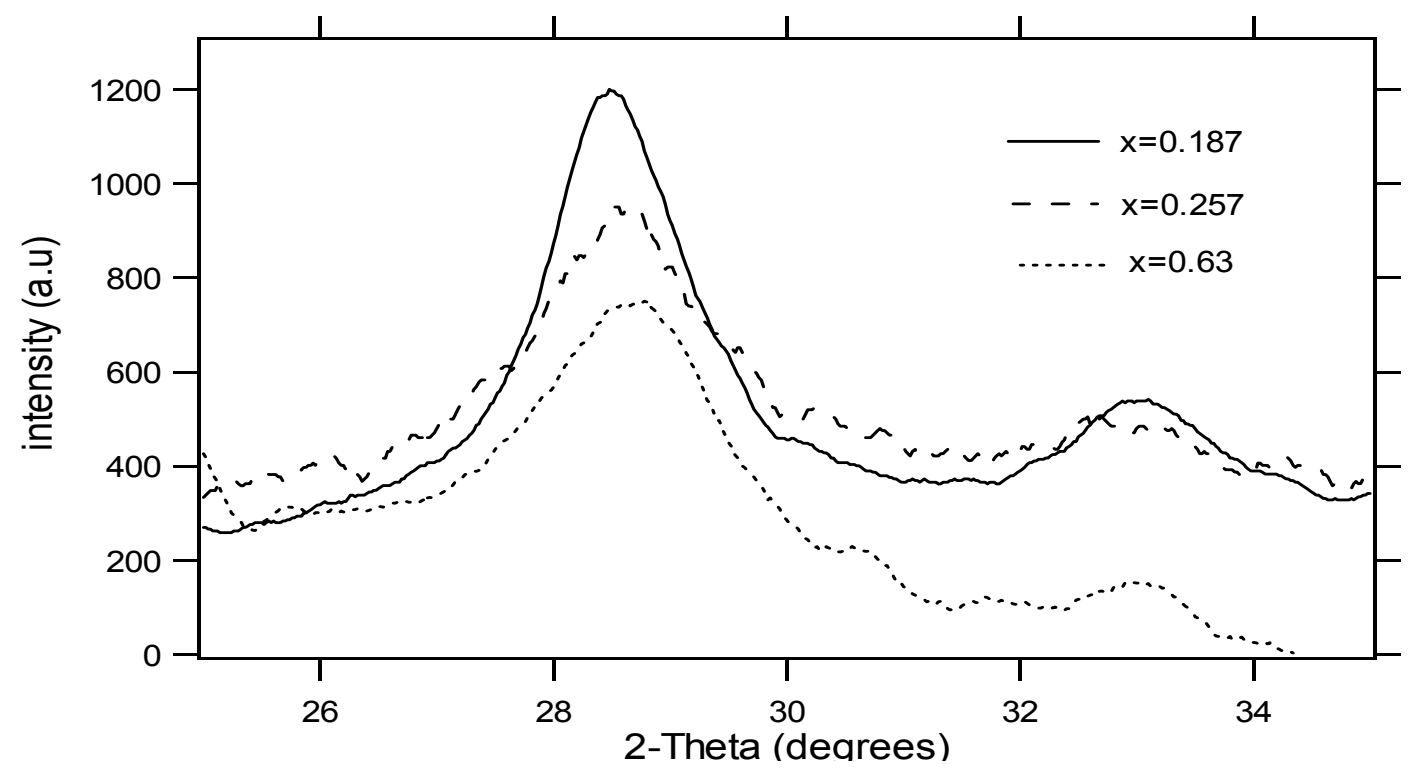

Figure 6. XRD Patterns for Three Different $\mathrm{Ce}_{1-\mathrm{x}} \mathrm{Zr}_{\mathrm{x}} \mathrm{O}_{2}$ Samples, where $\mathrm{x}$ Represents the Mol Fraction of Zirconia

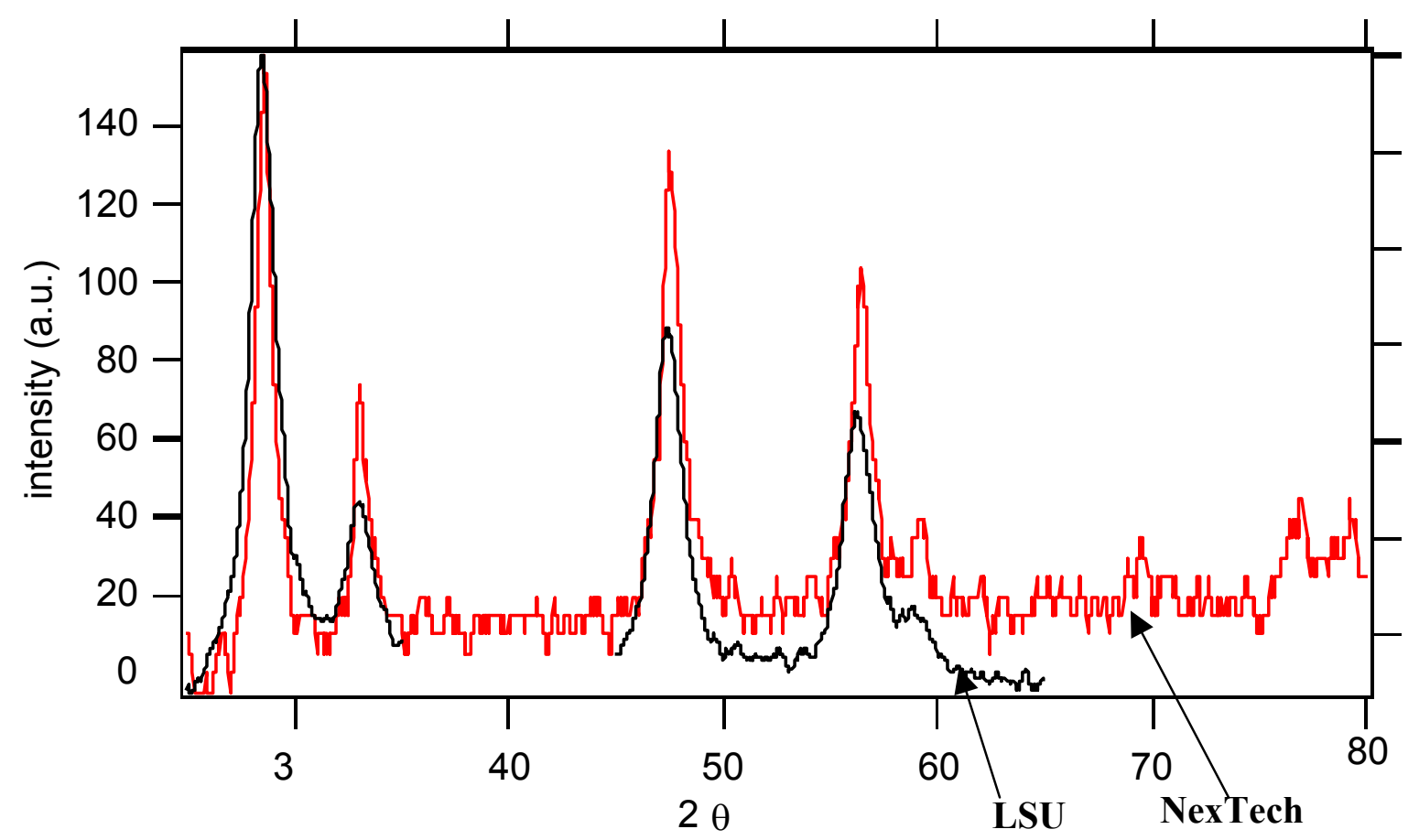

Figure 7. A Comparison Between the LSU and Commercial NexTech XRD Powder Patterns. 


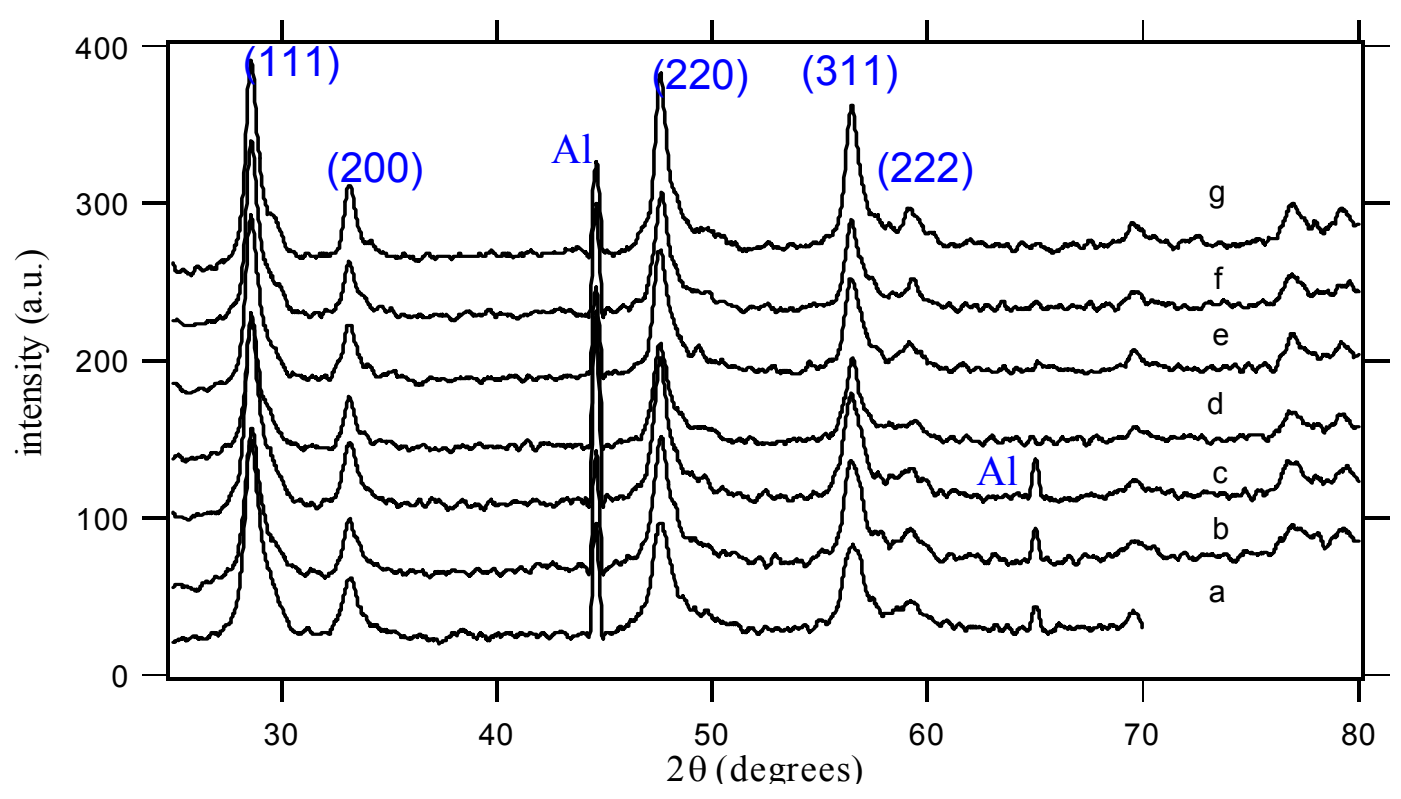

Figure 8. Heat Treated $700{ }^{\circ} \mathrm{C}, 18.7 \mathrm{~mol} \% \mathrm{ZrO}_{2}$ Ceria-Zirconia with Resulting Crystallite Size of (a) $9.5 \mathrm{~nm}$, (b) $10 \mathrm{~nm}$, (c) $11 \mathrm{~nm}$, (d) $12 \mathrm{~nm}$, (e) $12.5 \mathrm{~nm},(\mathrm{f}), 12.5 \mathrm{~nm}$, and (g) $14.5 \mathrm{~nm}$.

Figure 10 shows XRD results from heat treatment carried out on a sample which exhibits two distinct phases, one a mixture of ceria-zirconia and another pure zirconia, indicated by the vertical lines. Heat treatment was carried out at $700{ }^{\circ} \mathrm{C}$ and the procedure was the same as for the low $\mathrm{Zr}$ sample. There is no evidence of phase changes. Also, the crystallite size increases with heat treatment with a terminal size of $10 \mathrm{~nm}$ after $106 \mathrm{hr}$ of heating. Similarly to Figure 9, Figure 11 confirms the crystallite size with TEM.

\subsubsection{Electrochemical Process Characterization}

Figure 12 shows the current characteristics of pure $\mathrm{CeO}_{2}$ and a $\mathrm{CeO}-\mathrm{ZrO}_{2}$ mixture ( $18 \mathrm{~mol} \%$ of zirconia). The current decreases with time as more and more of the electrode surface is covered by powder. The initial curve is steeper for pure ceria suggesting that the rate of powder deposition is faster for pure ceria compared to the ceria-zirconia powder.

Figure 13 compares the current characteristics for quiescent and "stirred" solutions. Electrolyte stirring was induced by the rotation of the electrode. The current density for the stirred case was larger in magnitude and had more fluctuations than the unstirred experiment. The current fluctuations were likely due to the fact that the powder became dislodged from the surface while stirring, thereby creating new exposed areas on the electrode surface. The quantity of powder obtained with stirring was less than that for the unstirred case. The rate of deposition was $16 \mathrm{mg} / \mathrm{min}$ without stirring and $6 \mathrm{mg} / \mathrm{min}$ with stirring. The overall increase in the current density with stirring identifies a transport controlled electrochemical reactant. 


\section{$10 \mathrm{~nm}$}

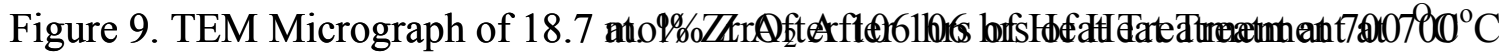

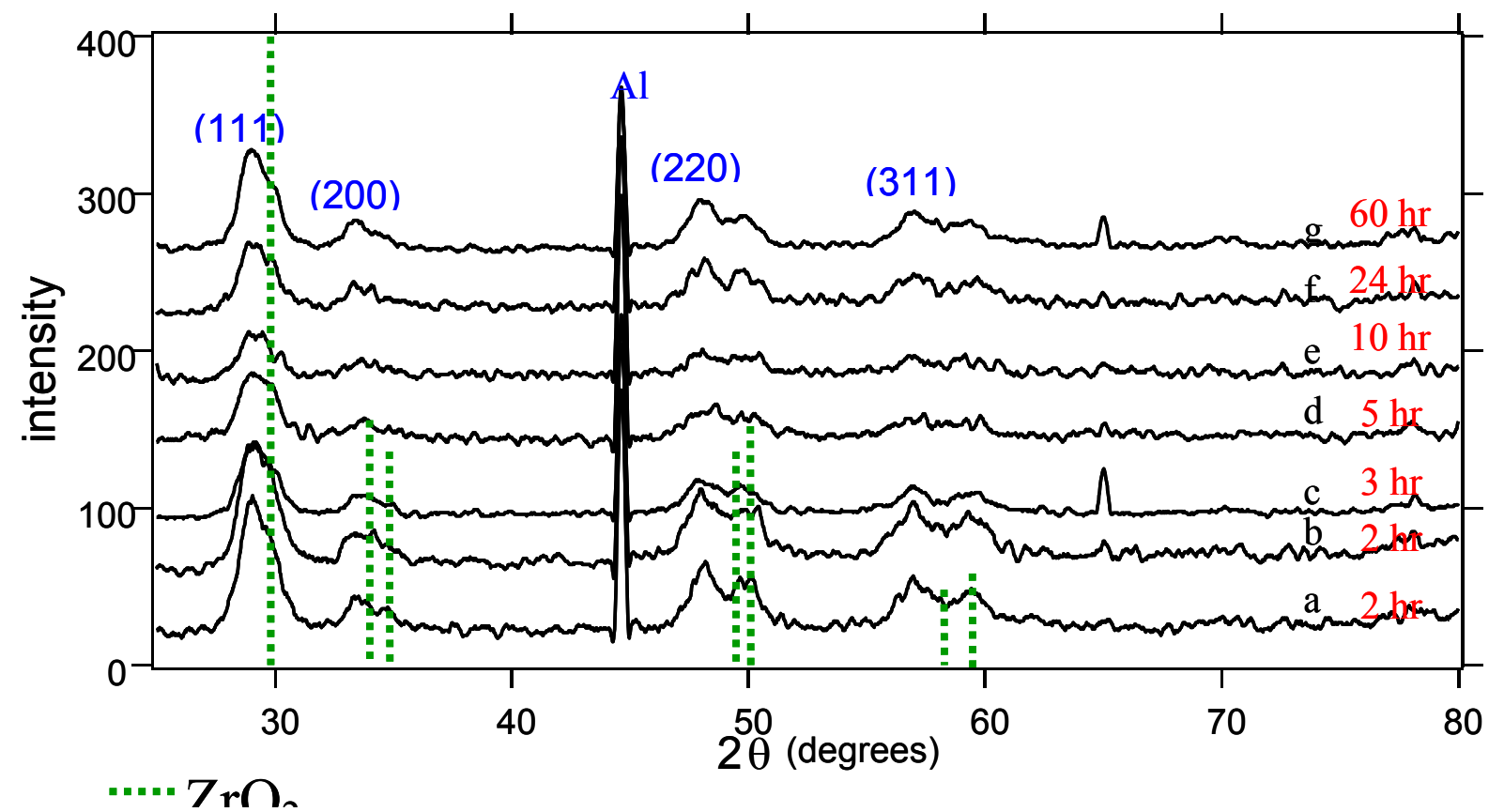

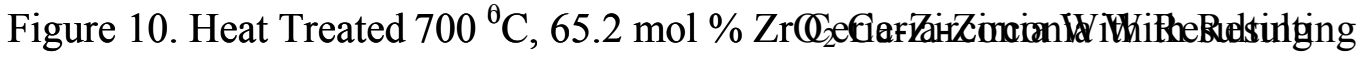
Crystallite Size of (a) $4 \mathrm{~nm}$, (b) $5 \mathrm{~nm}$, (c) $6 \mathrm{~nm}$, (d,e) $7 \mathrm{~nm}$ and (g) $8 \mathrm{~nm}$. Heat Treated Times Shown at Rioht 
As the deposition continued the electrode surface became covered with powder and an ohmic drop was incorporated into the applied potential. The ohmic contribution was confirmed by impedance spectroscopy and values of the increasing resistance between the reference and cathode are provided in Table 2. The actual potential at the working electrode is given by elimination of the ohmic potential drop, $\mathrm{E}=\mathrm{E}_{\mathrm{app}}-\mathrm{IR}$.

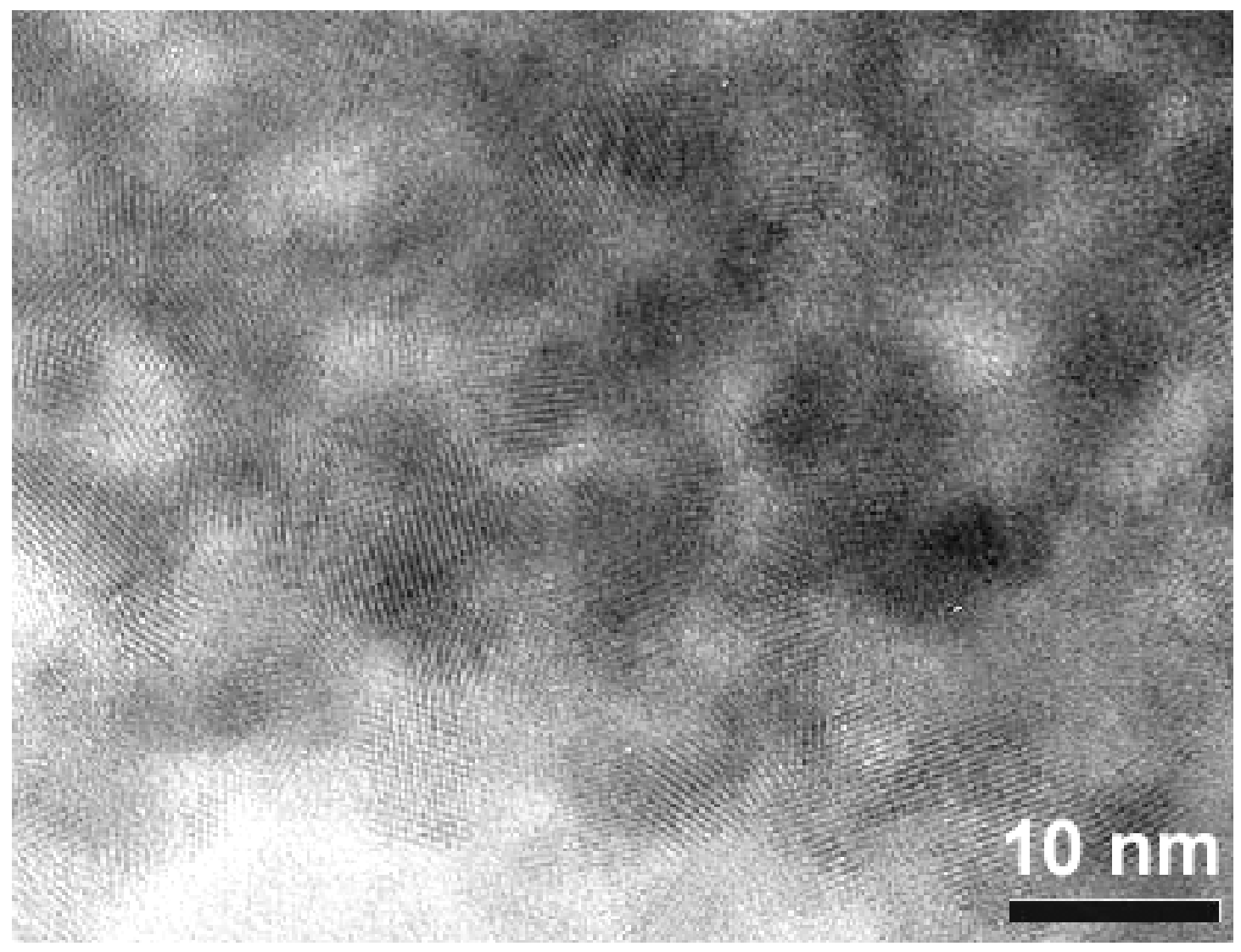

Figure 11. TEM Micrograph of $65.2 \mathrm{~mol} \% \mathrm{ZrO}_{2}$ after $106 \mathrm{hr}$ of Heat Treatment at $700{ }^{\circ} \mathrm{C}$

Figure 14 shows the current-potential relationship with the ohmic component removed. The current decreases at a given potential with deposition time and is indicative of the rate of generation of $\mathrm{OH}^{-}$necessary for co-precipitation of ceria-zirconia.

Table 2. Resistivity of Solution C at Various Times of Deposition.

\begin{tabular}{|c|c|}
\hline Resistivity, $\mathrm{R}, \mathrm{ohms}$ & Time of Deposition, mins \\
\hline 5.41 & 0 \\
\hline 7.82 & 30 \\
\hline 24.13 & 60 \\
\hline 34.76 & 90 \\
\hline
\end{tabular}




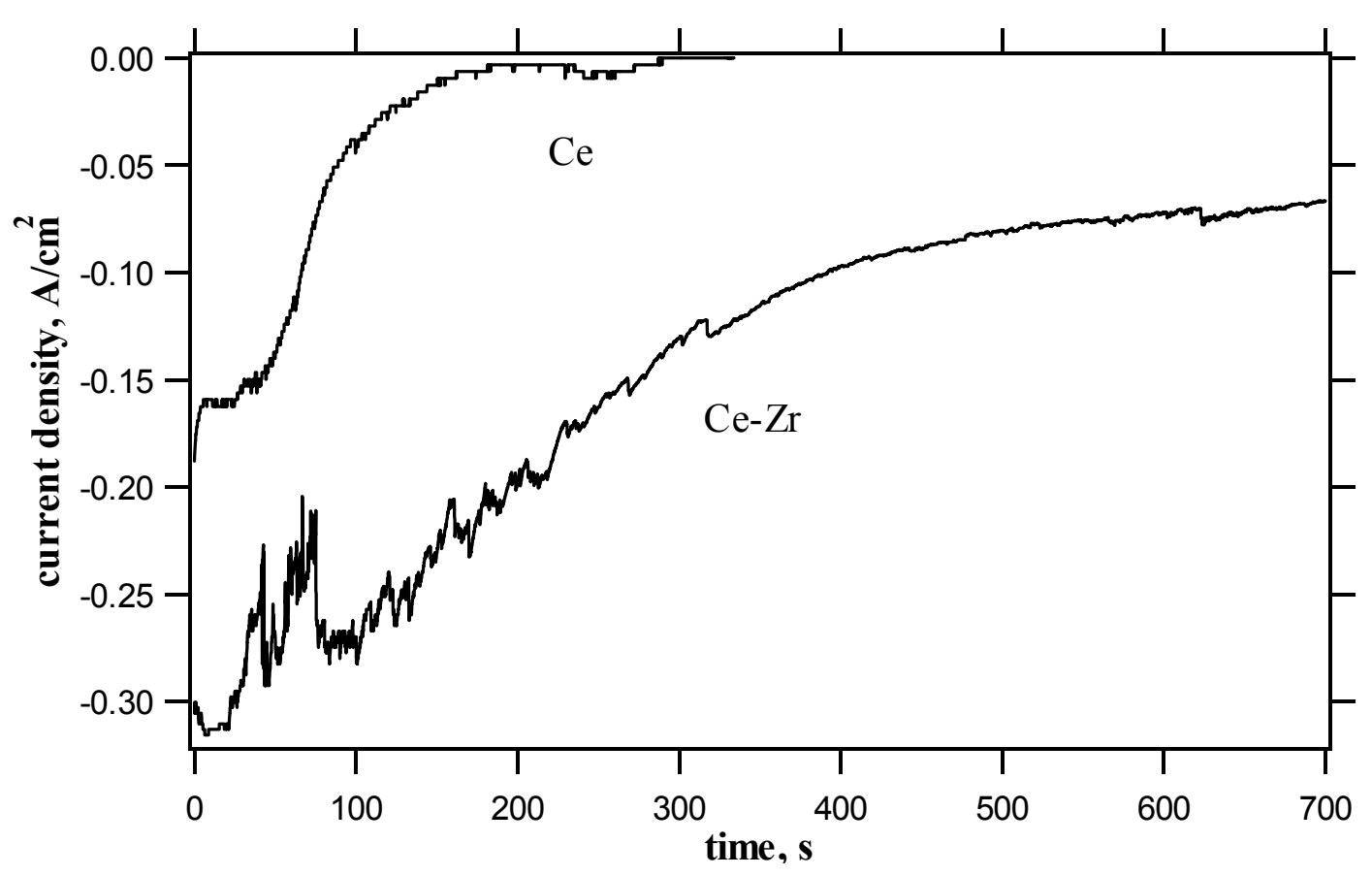

Figure 12. Current Characteristics for the Ce and Ce-Zr Electrolyte at an Applied Potential of $-2.0 \mathrm{~V}$ and Stagnant Solution.

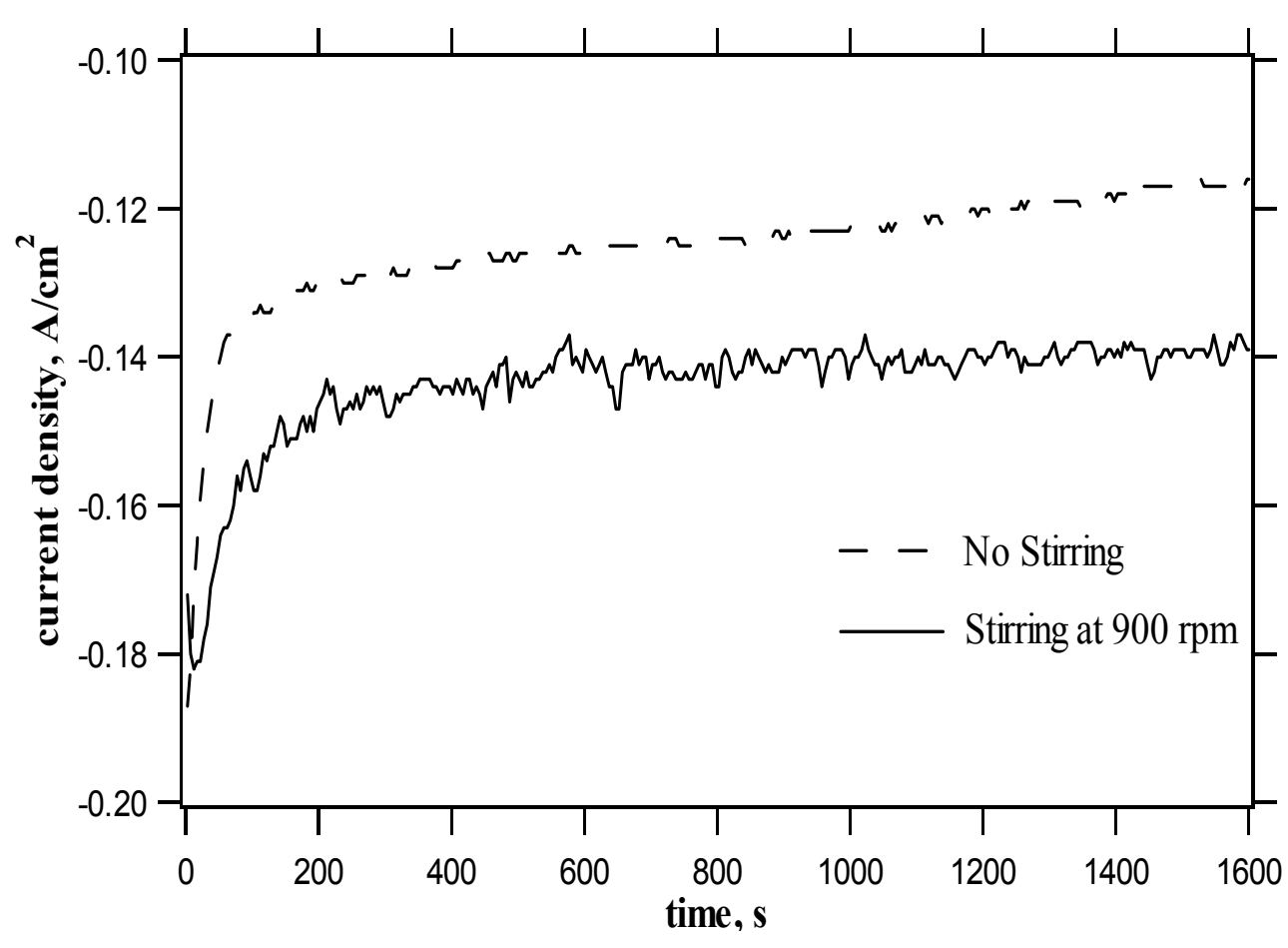

Figure 13. Current Characteristics of Ceria-Zirconia in Quiescent Solution and With a Stirring Speed of $900 \mathrm{rpm}$, Both With an Applied Potential of -2.0 V. 


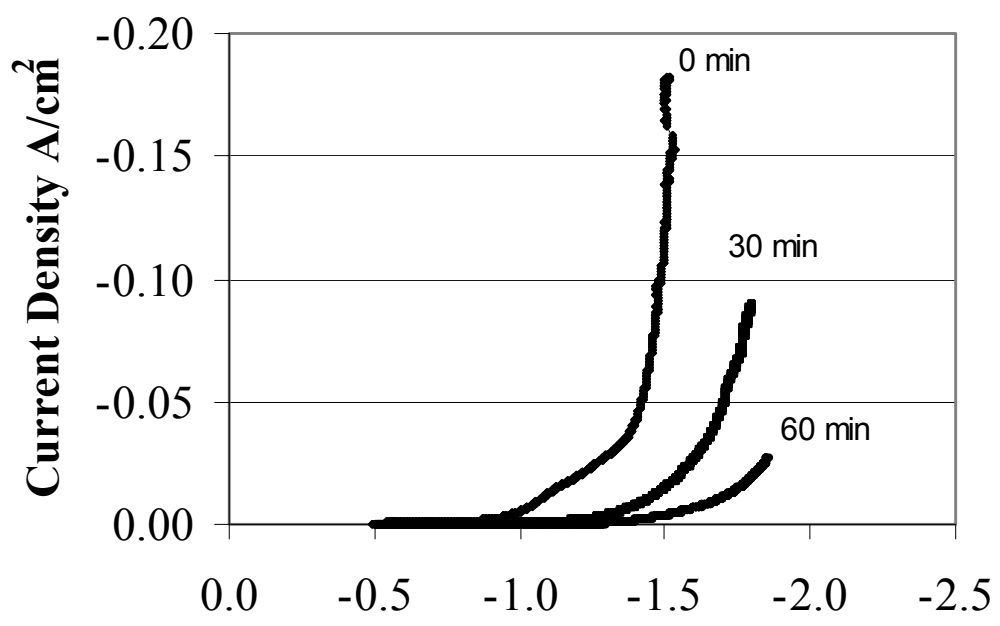

Potential(corrected) V vs SCE

Figure 14. Polarization Curves Corrected for Ohmic Drop, Solution C for a Scan Rate of $5 \mathrm{mv} / \mathrm{s}$.

\section{REACTION AND SORBENT CHARACTERIZATION EQUIPMENT}

A laboratory-scale fixed-bed reactor was used to study $\mathrm{H}_{2} \mathrm{~S}$ removal from highly reducing feed gas compositions. $\mathrm{H}_{2} \mathrm{~S}$ concentration in the product gas was analyzed using a gas chromatograph equipped with both thermal conductivity (TCD) and pulsed flame photometric (PFPD) detectors. In addition, an electrobalance reactor (TGA) was used to study the reducibility of various sorbents. Desulfurization was studied as a function of temperature and feed gas composition, while sorbent reducibility was studied under similar conditions, except using sulfur-free reducing gas. In addition, sorbents were characterized by their BET surface area and by x-ray diffraction.

While the ceria-zirconia materials produced electrochemically possessed the desired properties, it was impractical to produce sufficient quantities for desulfurization testing. Therefore, desulfurization testing began using ceria and ceria-zirconia materials obtained commercially. These materials were available only in limited quantities and possessed quite widely varying structural properties so that the effects of $\mathrm{ZrO}_{2}$ addition could not be properly evaluated. We then began to prepare sorbent materials in house having similar structural properties and to evaluate their desulfurization properties.

This section provides a detailed description of the reactors, the gas analysis system, and characterization techniques.

\subsection{Fixed-Bed Reactor}

Sorbent performance during $\mathrm{H}_{2} \mathrm{~S}$ removal was evaluated using the fixed-bed reactor system shown in Figure 15. Feed gases $-\mathrm{H}_{2} \mathrm{~S}, \mathrm{H}_{2}, \mathrm{~N}_{2}$, and $\mathrm{CO}_{2}-$ were obtained from high purity cylinders and flow rates were controlled using calibrated mass flow 


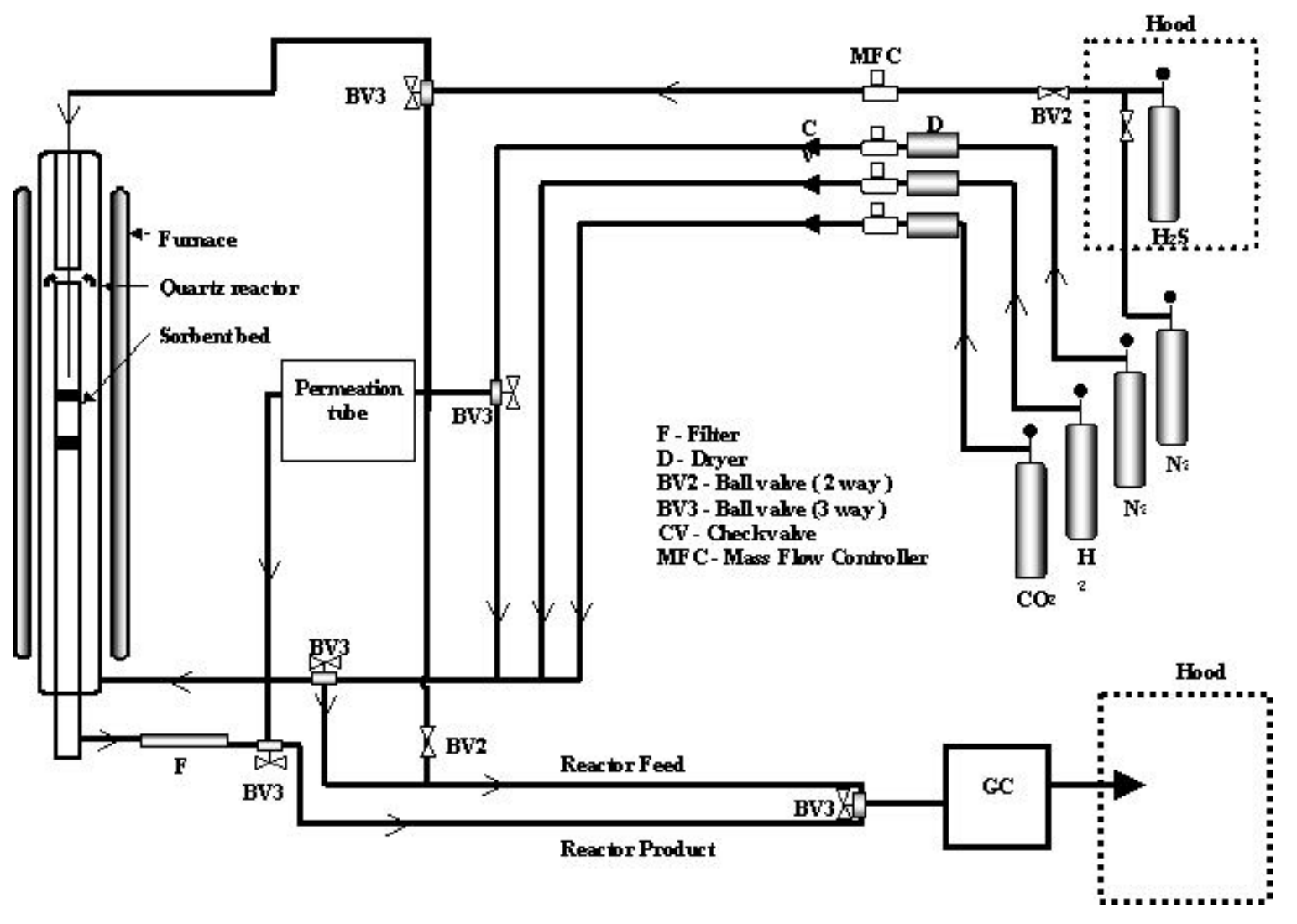

Figure 15. Fixed-Bed Reactor System

controllers. The proportions of $\mathrm{H}_{2}$ and $\mathrm{CO}_{2}$ were adjusted to control the reducing power (oxygen partial pressure) of the feed gas. Valves were arranged so that either feed or product gas could be sent to the gas chromatograph for analysis. In addition, $\mathrm{N}_{2}$ feed gas could be directed past a calibrated $\mathrm{H}_{2} \mathrm{~S}$ permeation tube where a standard quantity of $\mathrm{H}_{2} \mathrm{~S}$ was added for calibration of the gas chromatograph at low $\mathrm{H}_{2} \mathrm{~S}$ concentrations $(<10$ ppmv). Calibration at higher $\mathrm{H}_{2} \mathrm{~S}$ concentrations was accomplished by mixing pure cylinder gases using the mass flow controllers.

In normal operation $\mathrm{H}_{2}, \mathrm{CO}_{2}$, and $\mathrm{N}_{2}$ were mixed in the desired proportions and fed to the bottom of the quartz reaction vessel. These gases were preheated as they flowed upward in the annular region outside of the reactor insert. $\mathrm{H}_{2} \mathrm{~S}$ was added to the preheated gases just before they contacted the sorbent bed, which was supported inside the reactor on a porous quartz disc and quartz wool. Sorbent pre-reduction, if used, was carried out in the same manner except that $\mathrm{H}_{2} \mathrm{~S}$ was not added. Product gas exited from the bottom of the reactor, and flowed through a quartz wool filter to remove any particulate matter and/or traces of elemental sulfur that might be present, and to the gas chromatograph for analysis.

All components of the reactor vessel and insert and all valves were of quartz or Teflon to prevent interaction between low concentrations of $\mathrm{H}_{2} \mathrm{~S}$ and steel surfaces. Steel 
surfaces within the gas chromatograph were silcosteel to eliminate interaction. The only untreated steel surfaces that contacted $\mathrm{H}_{2} \mathrm{~S}$ were the feed gas lines.

A more detailed diagram of the quartz reactor, including dimensions, is shown in Figure 7 . The total capacity of the reactor was approximately $15 \mathrm{~g}$ of solid.

\subsection{Gas Analysis}

$\mathrm{H}_{2} \mathrm{~S}$ concentration of the feed and product gas was determined using a Varian model 3800 gas chromatograph purchased for this project using LSU matching funds. The chromatograph was equipped with dual columns, two Valco multiport sampling valves, and both a pulsed flame photometric detector (PFPD) and a thermal conductivity detector (TCD). The PFPD was used for $\mathrm{H}_{2} \mathrm{~S}$ concentrations from sub-ppmv to about 10

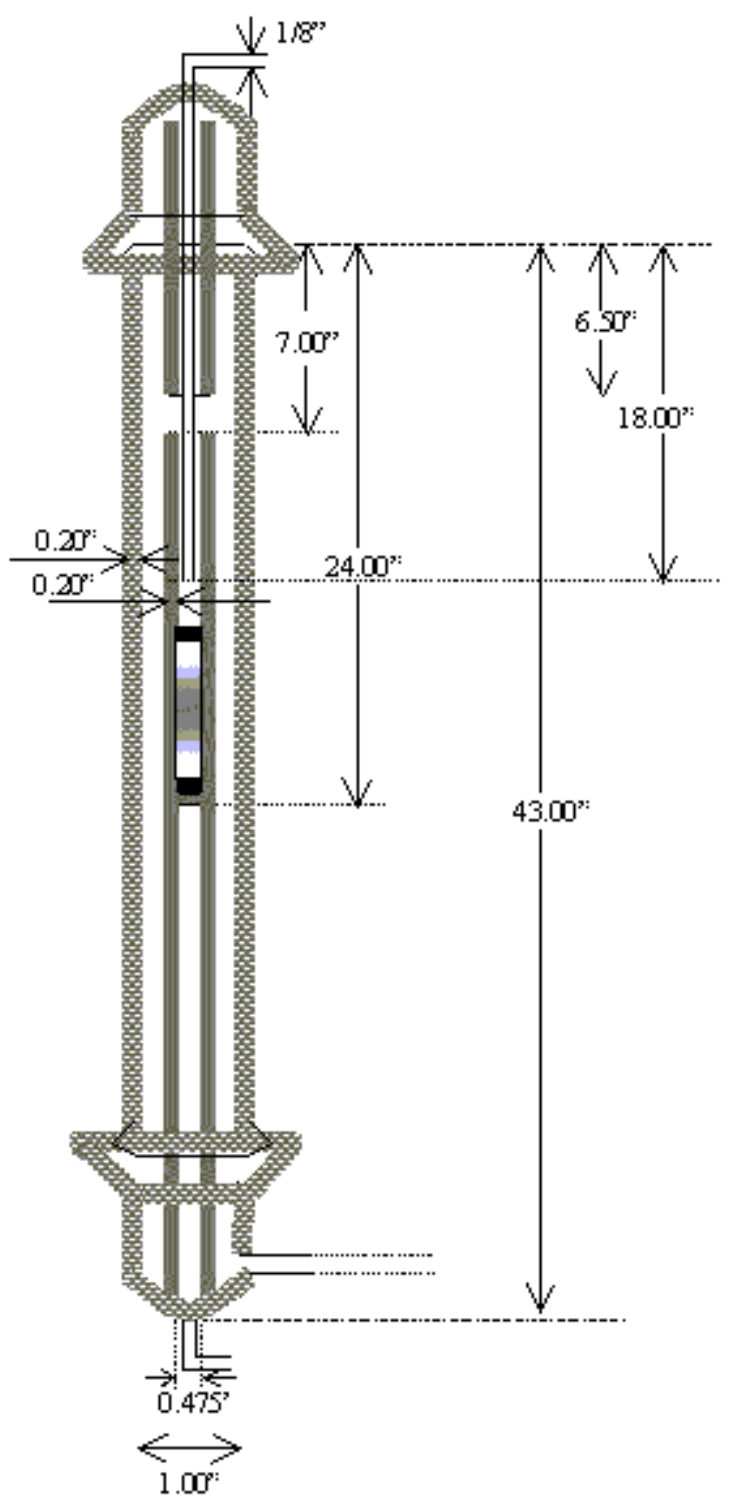

Figure 16. Details of the Quartz Reactor 
ppmv while the TCD was used for concentrations in excess of 100 ppmv. There was a gap in the analytical capability between about 10 and 100 ppmv, but primary interest was in the low concentration range. The PFPD provided analytical capability to about 0.1 ppmv $\mathrm{H}_{2} \mathrm{~S}$ (100 ppbv) and is about 10 times more sensitive than a standard flame photometric detector. A summary of chromatograph operating conditions is presented in Table 3

Table 3. Gas Chromatograph Operating Conditions

\begin{tabular}{|c|c|l|}
\hline \multirow{4}{*}{ PFPD } & \multirow{2}{*}{ Column: } & CP SIL5, $5 \mu$ \\
\cline { 2 - 3 } & Carrier Gas: & $\mathrm{L}=3 \mathrm{~m}, \mathrm{D}=530 \mu, \mathrm{T}=200^{\circ} \mathrm{C}$ \\
\cline { 2 - 3 } & Sample Loop: & SilcoSteel, $50 \mu \mathrm{min}$ \\
\hline \multirow{4}{*}{ TCD } & Column: & HAYESEP A SilcoSteel \\
\cline { 2 - 3 } & \multirow{2}{*}{ Carrier Gas: } & $\mathrm{L}=3.3 \mathrm{~m}, \mathrm{D}=3.13 \mu, \mathrm{T}=200^{\circ} \mathrm{C}$ \\
\cline { 2 - 3 } & & $\mathrm{He}, 31.2 \mathrm{ml} / \mathrm{min}$ \\
\cline { 2 - 3 } & Sample Loop: & SilcoSteel $2 \mathrm{ml}$ (backflush) \\
\hline
\end{tabular}

The flow arrangement through the two automatic valves (one 10-port and one 6port) is shown in Figure 17. The upper left diagram shows gas flows in normal operation. The gas to be analyzed entered the 10-port valve at position 4, exited to the PFPD sample loop at position 5, re-entered the 10-port valve at position 8 , exited to the TCD sample loop at position 9, again entered the 10-port valve at position 2, and was vented to a laboratory hood through position 3 . In this operating mode the contents of both sample loops were continually purged and replenished with the most recent product gas. Three carrier gases were used. Carrier 1 entered the 10-port valve at position 7 and exited at position 6 to the PFPD column and then to the PFPD. Carrier 2 entered the 10-port valve at position 10, exited at position 1, and flowed to the 6-port valve. It entered the 6-port valve at position 2 and exited through position 1 to the TCD column, then back into the 6-port valve at position 3 and out through position 4 to the TCD and laboratory vent. Carrier 3 entered the 6-port valve at position 5 and exited through position 6 to vent.

Samples for both the PFPD and TCD were acquired simultaneously by switching the 10-port valve to the position shown in the upper right diagram of Figure 17 . The reactor product gas entered the 10-port valve at position 4 and exited through position 3 directly to the laboratory vent. Carrier gas 1 entered the 10-port valve at position 7, exited through position 8 and picked up the sample from the PFPD sample loop. It reentered the 10-port valve at position 5 and exited through position 6 to the PFPD column. Column effluent then flowed directly to the PFPD. Carrier gas 2 entered at position 10 and exited through position 9 where it picked up the TCD sample. It re-entered the 10-port valve at position 2 and exited through position 1 to the 6-port valve. The TCD sample entered the 6-port valve at position 2 and exited to the TCD column through position 1. The TCD column effluent re-entered the 6-port valve at position 3 and exited through position 4 to 


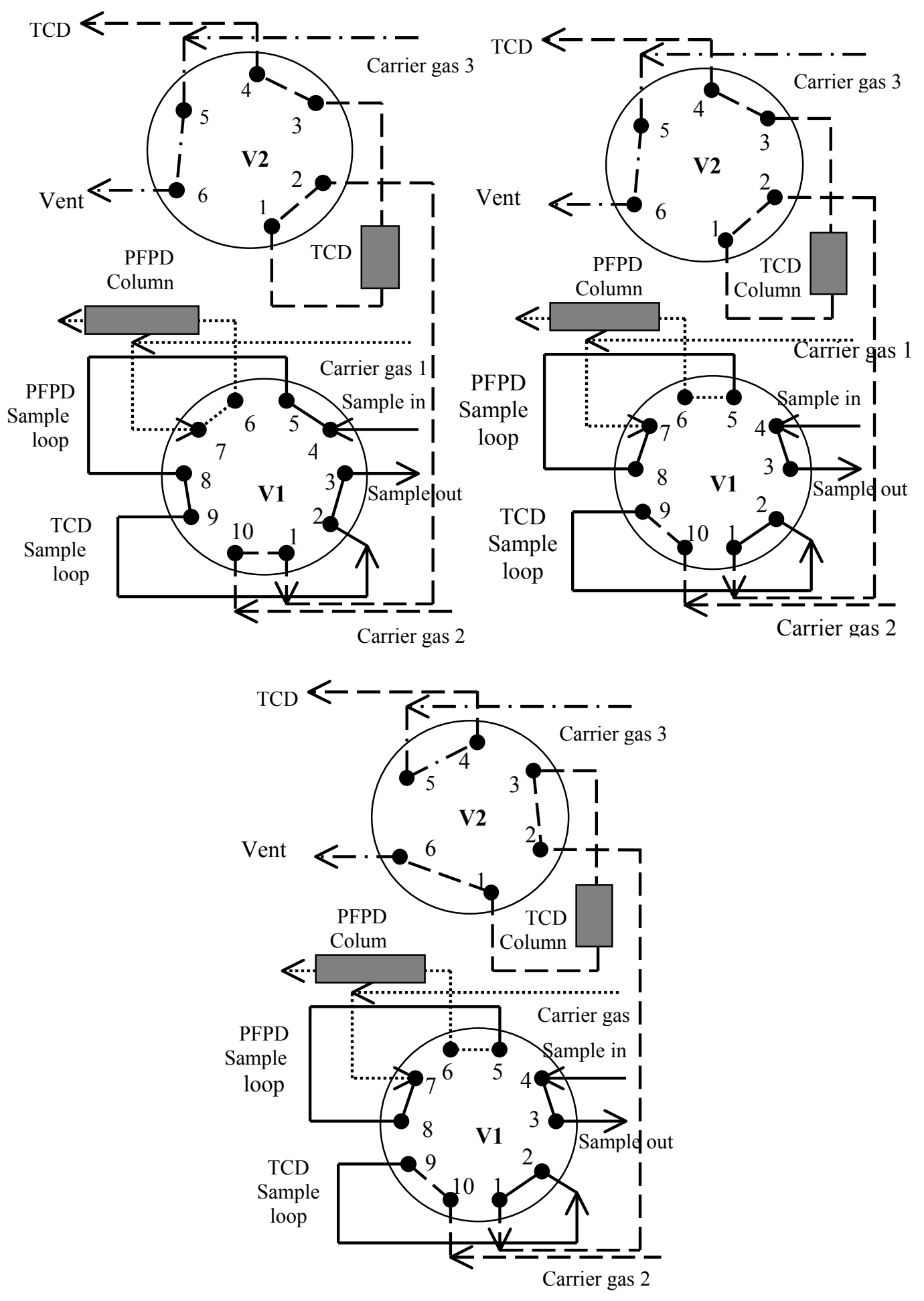

Figure 17. Chromatograph Sampling Arrangement 
the TCD. Flow of carrier 3 was unchanged. It entered the 6-port valve at position 5 and exited through position 6 to vent.

The position of the 6-port valve was switched in the lower center diagram of Figure 17 to permit $\mathrm{H}_{2} \mathrm{O}$ formed during the desulfurization reaction to be backflushed to vent. Switching occurred after $\mathrm{H}_{2} \mathrm{~S}$ had eluted from the TCD column but before water was eluted. Sample gas and carrier gas 1 flows were not changed from the previous case. However, with the 6-port valve in the new position, carrier gas 2 flowed through the 10port valve as before. It entered the 6-port valve at position 2, exited through position 3 , and flowed in the reverse direction through the TCD column to backflush the $\mathrm{H}_{2} \mathrm{O}$. Carrier gas 2 plus the $\mathrm{H}_{2} \mathrm{O}$ then re-entered the 6-port valve at position 1 and exited through position 6 directly to vent. Carrier gas 3 entered the 6-port valve at position 5 and exited through position 4 to the TCD so that carrier gas flow was maintained through the TCD at all times.

PFPD calibration was accomplished by flowing $\mathrm{N}_{2}$ at a known rate past a calibrated $\mathrm{H}_{2} \mathrm{~S}$ permeation tube maintained at $30^{\circ} \mathrm{C}$ (see Figure 15). A PFPD calibration curve between 0.1 and 6 ppmv $\mathrm{H}_{2} \mathrm{~S}$ is shown in Figure 18. The chromatogram obtained from the 0.1 ppmv $\mathrm{H}_{2} \mathrm{~S}$ sample shown in Figure 19 indicates that the signal-to-noise ratio is strong even at this low $\mathrm{H}_{2} \mathrm{~S}$ concentration. The best calibration was obtained by correlating $\mathrm{H}_{2} \mathrm{~S}$ peak height versus $\mathrm{H}_{2} \mathrm{~S}$ concentration using a third order polynomial with a zero intercept. The calibration equation shown on the figure has a $\mathrm{R}^{2}$ value of 0.9982 .

TCD calibration was accomplished by mixing $\mathrm{N}_{2}$ and $\mathrm{H}_{2} \mathrm{~S}$ from the high purity cylinders with flow rates controlled using the mass flow controllers. Results of the TCD calibration between $100 \mathrm{ppmv}$ and 1.5\% (15,000 ppmv) are shown in Figure 20. The calibration was also based on $\mathrm{H}_{2} \mathrm{~S}$ peak height using a second order polynomial with a zero intercept and the $\mathrm{R}^{2}$ value was 0.9996 .

Calibration curves were checked periodically and the detectors were recalibrated when necessary.

\subsection{Electrobalance Reactor}

A Cahn Instruments Inc. Model 2000 TGA was used to study sorbent reduction. The system, shown in Figure 21, included a Cahn 2000 electrobalance, a MicRIcon temperature programmer/controller, a Nichrome resistance furnace, and a gas flow system. Experimental temperature, time, and solid weight were collected using a Labtech Notebook V 12 real-time data acquisition system and stored on a lab PC. The system has a maximum temperature of $1000^{\circ} \mathrm{C}$, a capacity of $1.0 \mathrm{~g}$, a sensitivity of $0.2 \mu \mathrm{g}$, and an accuracy of $\pm 0.1 \%$. The temperature programmer/controller controls the temperature at a specified isothermal value or according to a linear rate of temperature increase or decrease. 


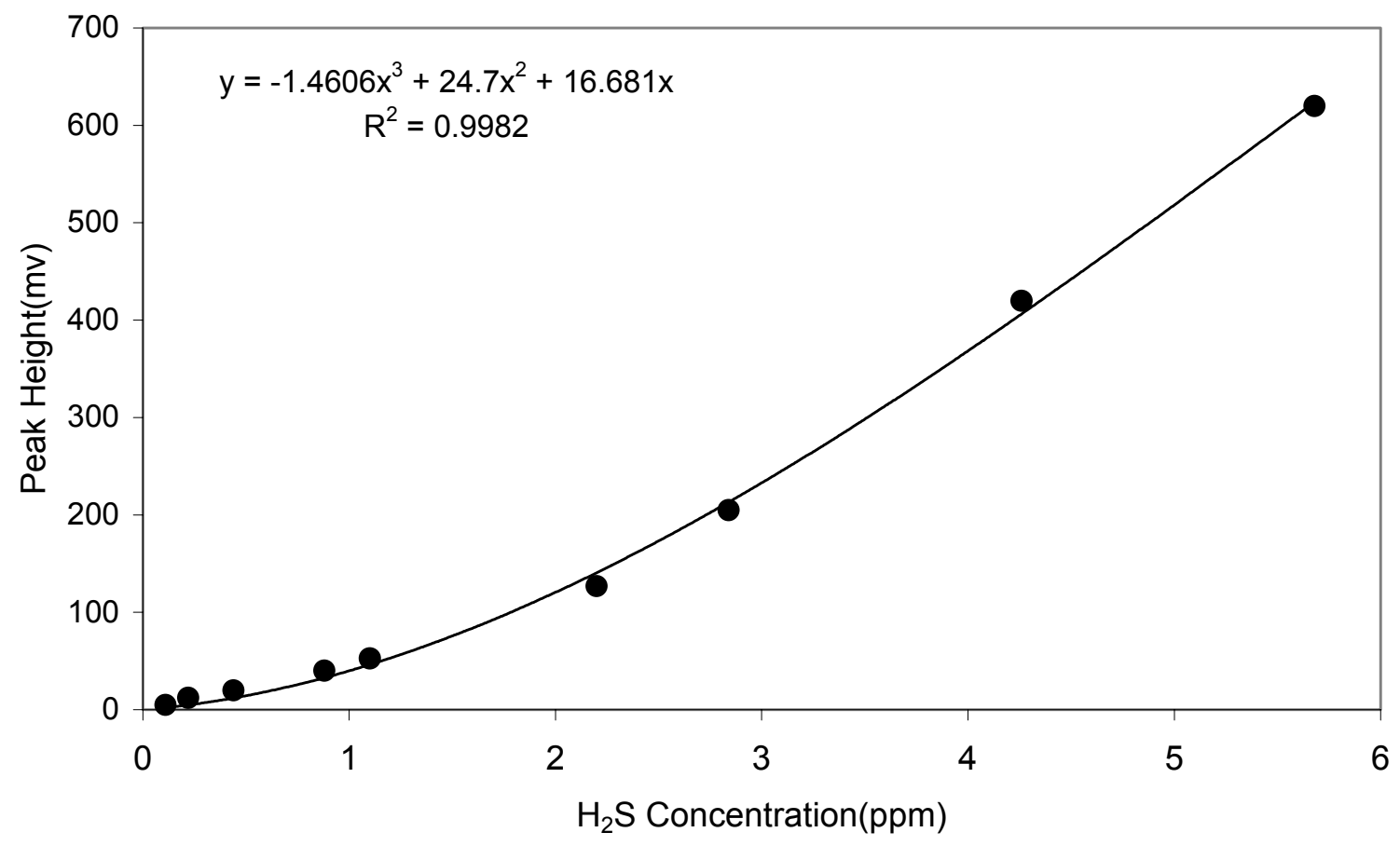

Figure 18. PFPD Calibration Curve

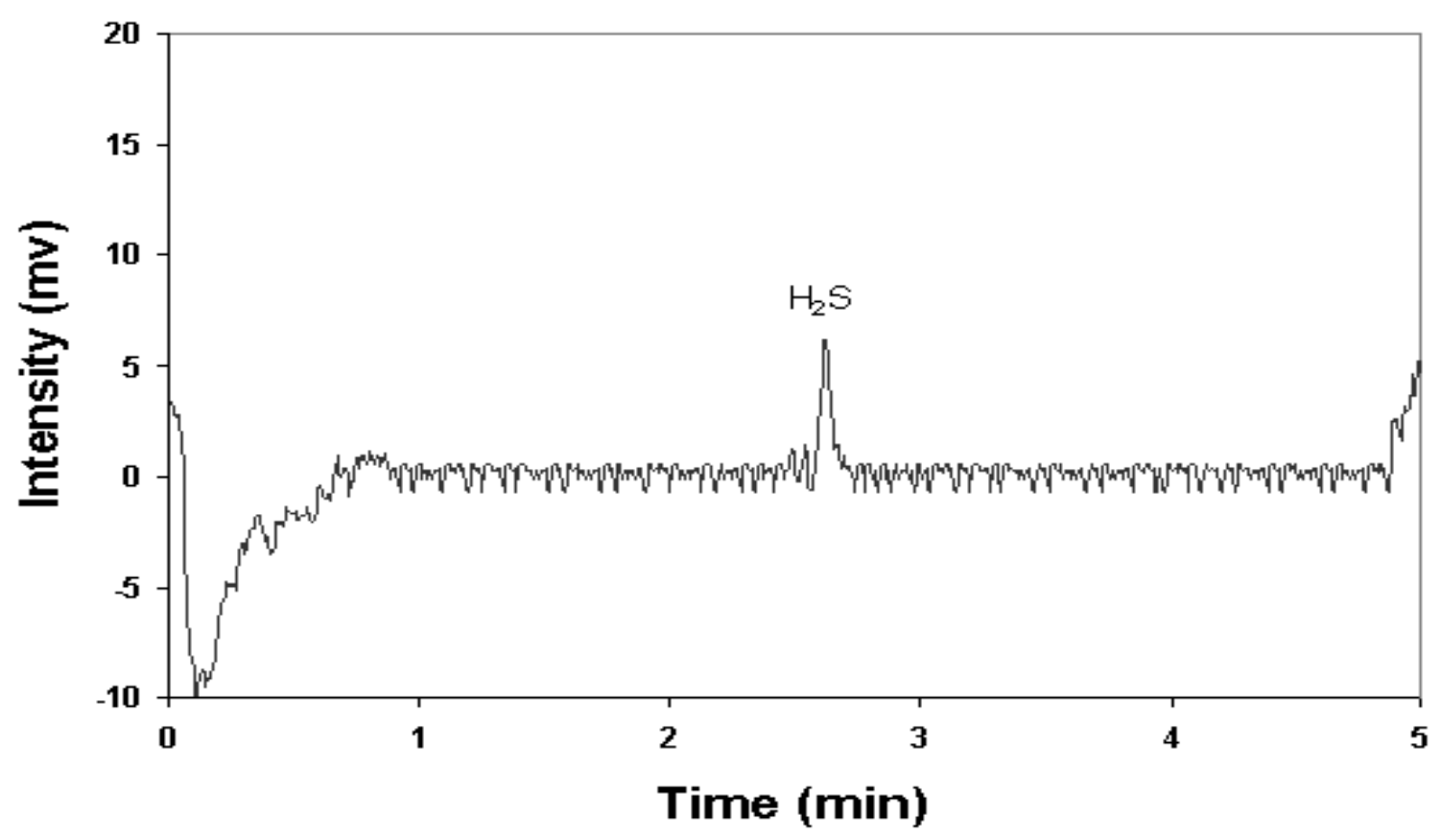

Figure 19. PFPD Chromatogram at $0.1 \mathrm{ppmv}_{2} \mathrm{~S}$ 


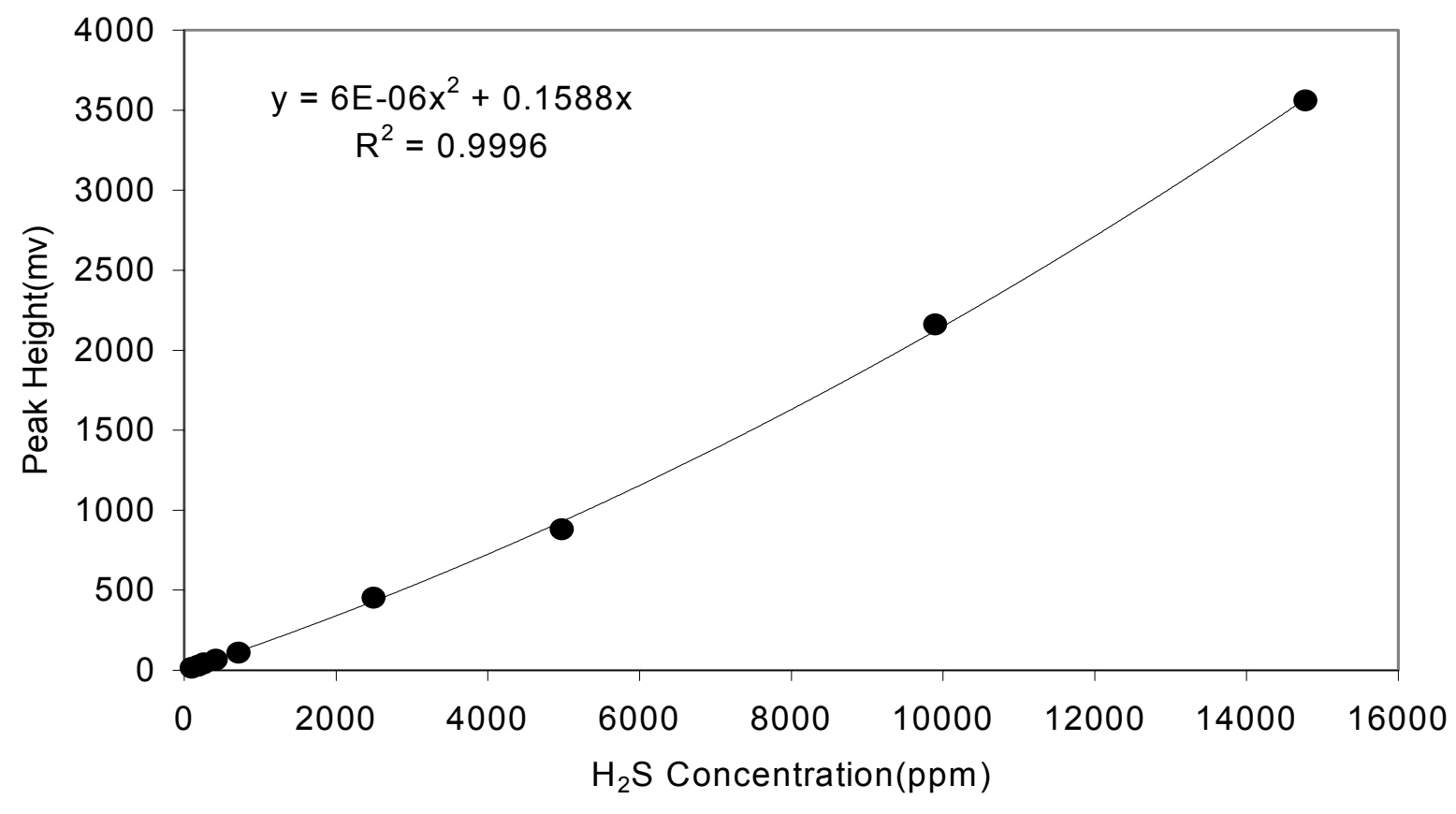

Figure 20. TCD Calibration

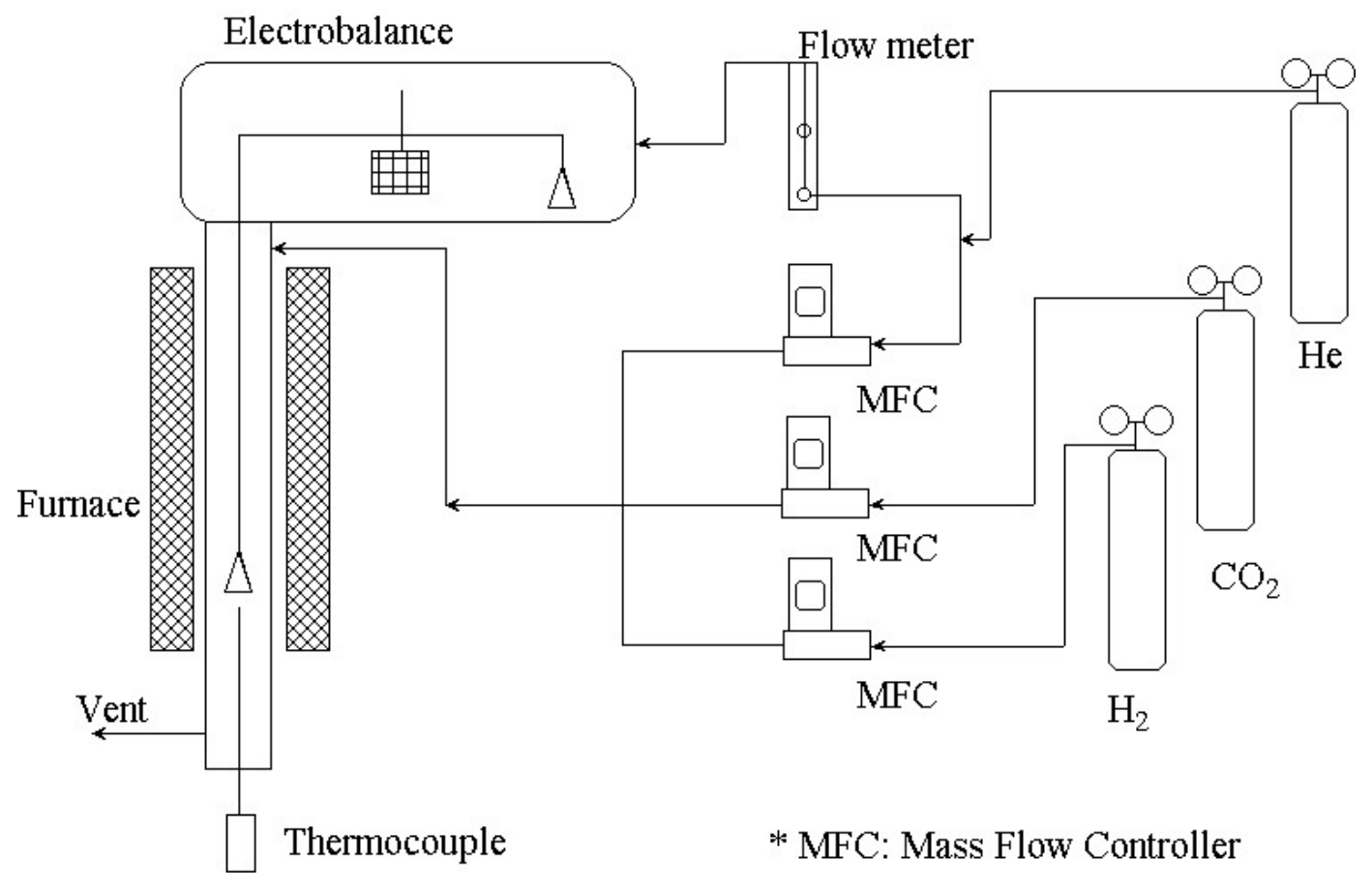

Figure 21. Electrobalance Reactor System 
$\mathrm{CO}_{2}$ was used as an oxidizing agent and $\mathrm{H}_{2}$ as a reducing agent and the quantities of these two gases were varied to obtain the desired reducing power of the mixed gas. He was used as the carrier gas to reduce aerodynamic noise and to provide increased balance sensitivity. A portion of the He flowed through the electrobalance chamber to prevent possible electrobalance damage from reactive gas components. The remaining $\mathrm{He}$ was mixed with $\mathrm{CO}_{2}$ and $\mathrm{H}_{2}$ and fed to the side arm of the hangdown tube. The flow rate of $\mathrm{He}$ into the electrobalance chamber was controlled using a calibrated rotameter and needle valve. Other gas flows were controlled using mass flow controllers.

About $80 \mathrm{mg}$ of test sorbent was first heated from room temperature to $800^{\circ} \mathrm{C}$ at $10^{\circ} \mathrm{C} / \mathrm{min}$ in pure He to remove volatile material, then cooled to $200^{\circ} \mathrm{C}$ in $\mathrm{He}$ before beginning a reduction test. Sorbent reduction was then monitored by recording the sample weight as it was heated from $200^{\circ} \mathrm{C}$ to $1000^{\circ} \mathrm{C}$ at $10^{\circ} \mathrm{C} / \mathrm{min}$ in the desired reducing atmosphere.

\subsection{BET Surface Area}

An Omnisorp model 360 (Omicron Technology, Inc.) was used to measure BET surface areas of sorbents. About $0.5 \mathrm{~g}$ of the sample was placed in the sample cell and oven-dried under vacuum at $250^{\circ} \mathrm{C}$ overnight. The sample was then transferred to the BET section for surface area measurement using $\mathrm{N}_{2}$ adsorption. The system was automatically controlled and pressure data were collected and stored in the PC. Data were analyzed using custom software supplied by Omicron Technology.

\subsection{X-Ray Diffraction}

Powder X-ray diffraction data were collected with a Rigaku MiniFlex X-ray Diffractometer using $\mathrm{Cu} K \alpha$ radiation $(\lambda=1.548 \AA$ ). Data were collected over a $2 \mathrm{hr}$ period from $2 \theta=20 \sim 90^{\circ}$ with a $0.02^{\circ}$ step size. Signals were fitted with Voigt functions and data were collected from the 9 main reflections of an fcc structured material corresponding to (111), (200), (220), (311), (222), (400), (331), (420), and (422) diffraction planes.

The mean crystallite size was calculated according to the Scherrer equation (Bauer et al., 1978) based on the full width at half maximum intensity (FWHM) of the (111) reflection. Instrument corrections based on the diffraction spectrum of a single crystalline silicon wafer were included. These calculations were made using XRD instrument software.

\section{SORBENT MATERIALS}

Because it was impossible to produce sufficient quantities of $\mathrm{CeO}_{2}$ and $\mathrm{CeO}_{2}$ $\mathrm{ZrO}_{2}$ needed for desulfurization testing using electrochemical synthesis, a number of ceria and ceria-zirconia sorbent materials from other sources were acquired and screened for desulfurization performance. Ceria samples were obtained from Rhone Poulenc and Alfa Aesar while NexTech Materials donated small quantities of three ceria-zirconia 
materials having different zirconia contents. These materials were prepared using different techniques and had widely differing structural properties. Initial desulfurization screening tests indicated that sorbents having similar properties would be required if the effects of $\mathrm{ZrO}_{2}$ addition were to be evaluated. Emphasis then turned to ceria and ceriazirconia materials synthesized at LSU, which had similar structural properties. All materials were characterized in terms of their x-ray diffraction patterns, specific surface areas, and reducibility in addition to their ability as a $\mathrm{H}_{2} \mathrm{~S}$ sorbent.

\subsection{Commercial Sorbents}

Two samples of pure ceria, the first from Rhone Poulenc and the second from Alfa Aesar, were used in this study. The Rhone Poulenc material was the same as used by Zeng (1999) and the available quantity was limited. The Alfa Aesar material was purchased and available in whatever quantity was needed. NexTech Materials donated small quantities of three ceria-zirconia materials containing 15, 20, and $30 \mathrm{~mol} \% \mathrm{ZrO}_{2}$. This provided sufficient material for characterization and desulfurization screening, but not enough for a complete test program. In addition to testing the desulfurization ability of these five materials, they were characterized in terms of their reducibility, BET surface area, and crystallite size.

Two additional materials, hydrated cerium carbonate, $\mathrm{Ce}_{2}\left(\mathrm{CO}_{3}\right) \cdot \mathrm{xH}_{2} \mathrm{O}$, and an equal molar mixture of ceria-zirconia were also purchased from Alfa Aesar. We had hoped that calcination of $\mathrm{Ce}_{2}\left(\mathrm{CO}_{3}\right)_{3} \times \mathrm{xH}_{2} \mathrm{O}$ would produce $\mathrm{CeO}_{2}$ having high surface area and high desulfurization activity. However, the product $\mathrm{CeO}_{2}$ had only moderate surface area and exhibited relatively poor desulfurization performance in initial tests. Similarly, the ceria-zirconia from Alfa Aesar did not show good desulfurization performance in initial tests, and neither of these materials were tested to a significant extent.

\subsection{Sorbents Synthesized at LSU}

Because of the limited availability and widely varying structural properties of the commercial sorbents, it soon became apparent that larger quantities of material having similar physical properties were needed for complete desulfurization testing. $\mathrm{CeO}_{2}$ and two $\mathrm{CeO}_{2}-\mathrm{ZrO}_{2}$ materials were synthesized using a co-precipitation technique described by Rossignol et al. (1999).

$\mathrm{Ce}\left(\mathrm{NO}_{3}\right)_{3} \cdot 6 \mathrm{H}_{2} \mathrm{O}$ and $\mathrm{Zr}\left(\mathrm{NO}_{3}\right)_{2} \cdot \mathrm{xH}_{2} \mathrm{O}$, both from Aldrich Chemical Co., were used as precursors. Desired quantities of these materials were dissolved in distilled water at room temperature. The dissolved solutions were then mixed together and stirred for 0.5 hr. The solution was gently stirred while an aqueous solution of $80 \% \mathrm{NH}_{4} \mathrm{OH}$ (Fisher Scientific) was added dropwise until no further precipitation occurred. The precipitate was filtered and washed with distilled water. The filter cake was then dried overnight at $250^{\circ} \mathrm{C}$ followed by calcination at $450^{\circ} \mathrm{C}$ for $2 \mathrm{hr}$ in air. The calcined particles having diameters in the range of 0.5 to $5 \mathrm{~mm}$ were crushed and sieved with the $150-300 \mu \mathrm{m}$ size range selected for further testing. 


\subsection{Sorbent Nomenclature}

The following nomenclature was adopted to identify the sorbent composition and source.

$$
\mathrm{AA}(\mathrm{BB}) \mathrm{cc}
$$

AA represents sorbent composition with

$$
\begin{aligned}
& \mathrm{AA}=\mathrm{Ce} \quad \text { ceria sorbent } \\
& \mathrm{AA}=\mathrm{CZ} \quad \text { ceria-zirconia sorbent }
\end{aligned}
$$

$\mathrm{BB}$ identifies the sorbent source with

$$
\begin{array}{ll}
\mathrm{BB}=\mathrm{LSU} & \text { sorbent prepared at LSU } \\
\mathrm{BB}=\mathrm{RP} & \text { Rhone Poulenc } \\
\mathrm{BB}=\mathrm{Nex} & \text { NexTech Materials } \\
\mathrm{BB}=\text { Alfa } & \text { Alfa Aesar }
\end{array}
$$

The cc designation was used only with ceria-zirconia (CZ) sorbents and represents the molar percent ceria in the sorbent. Thus, $\mathrm{cc}=80$ indicates that the sorbent contained 80 $\mathrm{mol} \% \mathrm{CeO}_{2}$.

\section{SORBENT CHARACTERIZATION RESULTS}

\subsection{X-Ray Diffraction Spectra}

X-Ray diffraction tests were performed to confirm the formation of a solid solution of zirconia in ceria and to evaluate crystallite size. Selected diffraction spectra are presented and discussed in this section while results of the crystallite size determinations are presented in the following section.

The x-ray spectrum of $\mathrm{CeO}_{2}$ produced at LSU is presented in Figure 22(a) and compared to the standard library pattern of cubic $\mathrm{CeO}_{2}$ shown in Figure 22(b). There is close confirmation between the experimental and library spectra with no evidence of either extra or missing peaks in the experimental pattern.

Figure 23( $\mathrm{a}$ and $\mathrm{b})$ compares the spectra of the ceria-zirconia $\left(85 \% \mathrm{ZrO}_{2}\right)$ from NexTech with the standard spectrum for pure $\mathrm{ZrO}_{2}$ (tetragonal). In Figure 23(a) the dotted vertical lines indicate standard peak locations and intensities of pure $\mathrm{CeO}_{2}$ as shown in Figure 22(b). There is no correspondence between experimental peaks and standard $\mathrm{ZrO}_{2}$ peaks. The experimental ceria-zirconia peaks are located slightly to the right of the standard $\mathrm{CeO}_{2}$ peaks, which is attributed to solid solution formation with some of the $\mathrm{Ce}$ atoms replaced in the lattice with smaller $\mathrm{Zr}$ atoms.

Figure 24 compares the XRD spectra of the three sorbents prepared at LSU $\mathrm{Ce}(\mathrm{LSU}), \mathrm{CZ}(\mathrm{LSU}) 90$, and $\mathrm{CZ}(\mathrm{LSU}) 80$. No peaks other than those associated with $\mathrm{CeO}_{2}$ are present, and peaks from the two $\mathrm{CZ}$ materials are slightly shifted to the right of those of $\mathrm{Ce}(\mathrm{LSU})$, which is again indicative of solid solution formation. The peak shift is slightly larger for CZ(LSU)80 than for CZ(LSU)90. 


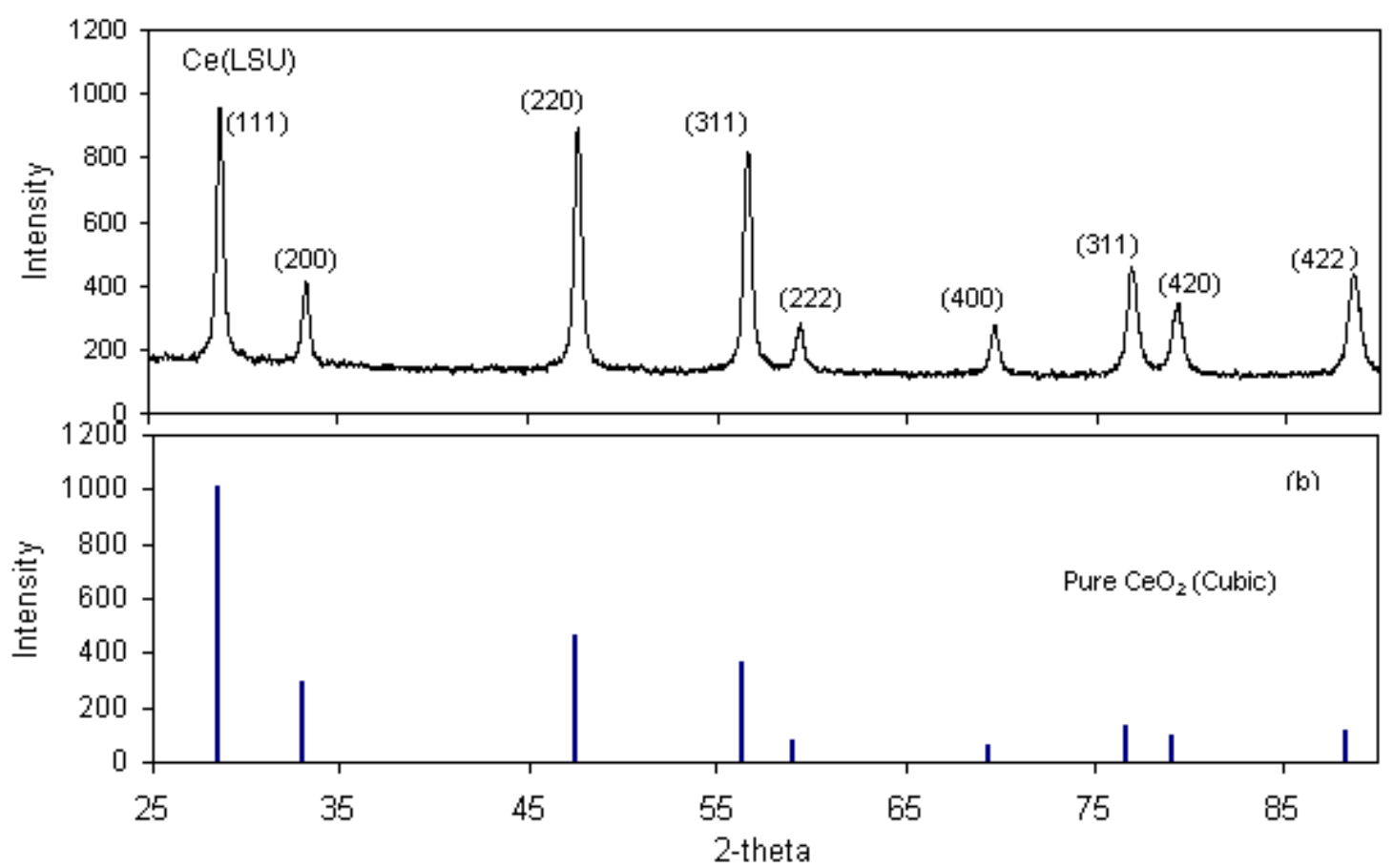

Figure 22. XRD Spectra of (a) $\mathrm{LSU} \mathrm{CeO}_{2}$, (b) cubic $\mathrm{CeO}_{2}$ (JCPDS 34-394)

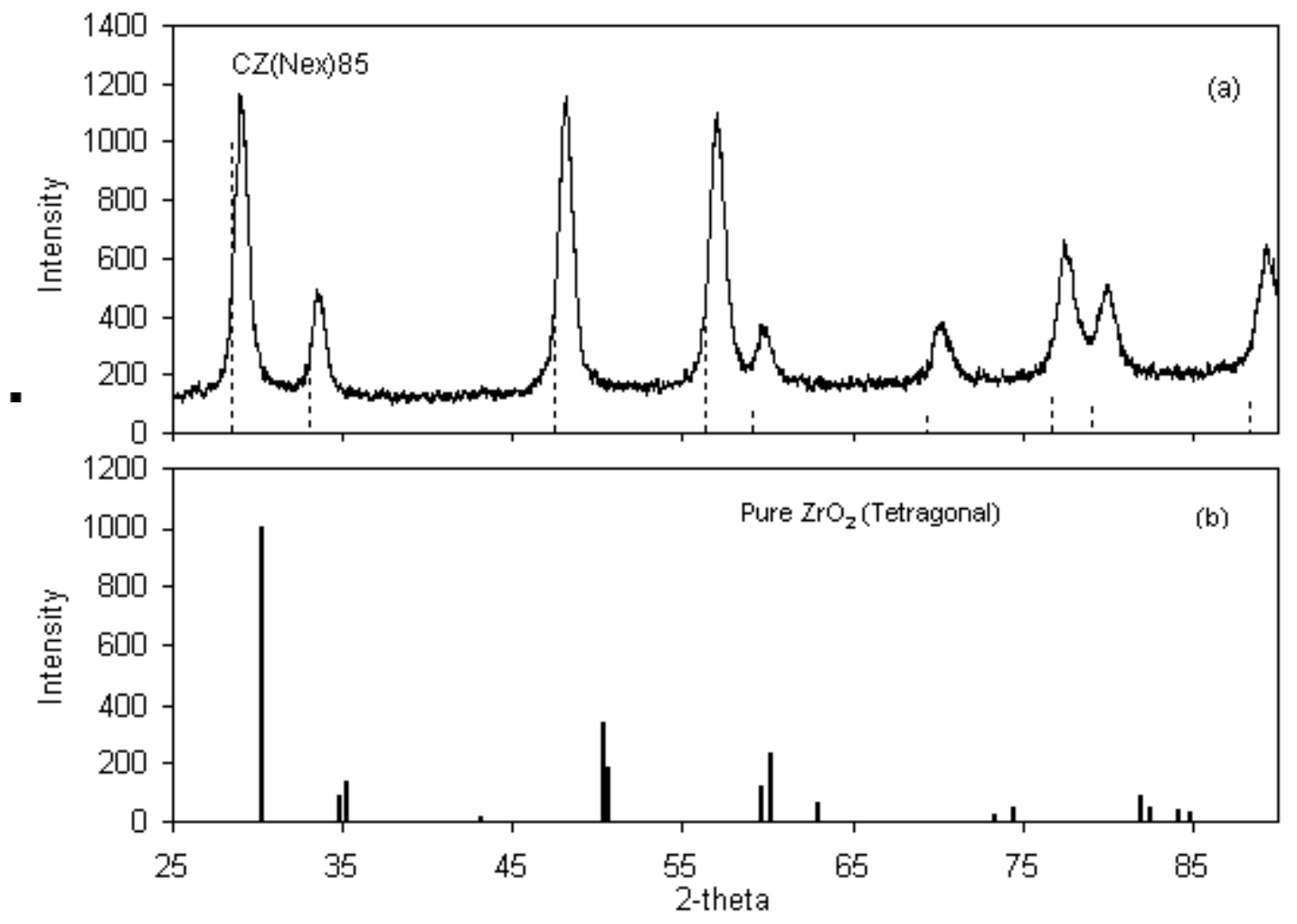

Figure 23. XRD Spectra of (a) $\mathrm{CZ}(\mathrm{Nex}) 85$, (b) Tetragonal $\mathrm{ZrO}_{2}$ (JCPDS 88-1007) 


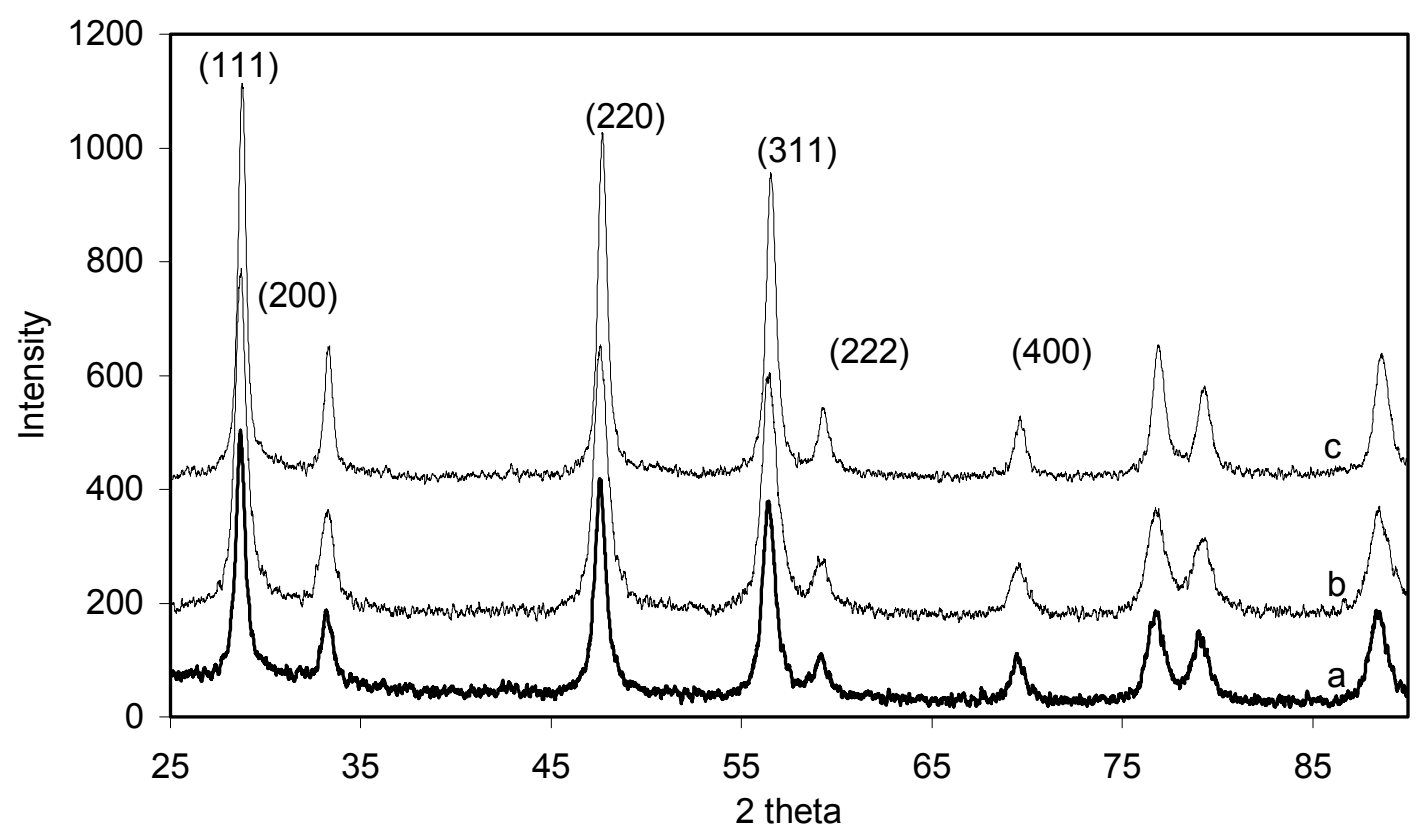

Figure 24. XRD Spectra of (a) Ce(LSU), (b) CZ(LSU)90, and (c) CZ(LSU)80

The experimental XRD spectra shown in Figures 22, 23, and 24 were typical of all results. Spectra for pure ceria materials closely matched the library spectra, while spectra of ceria-zirconia showed no evidence of a separate $\mathrm{ZrO}_{2}$ phase.

\subsection{BET Surface Area and Crystallite Size}

As previously described, average crystallite sizes of the test sorbents were determined based on the full width at half maximum (FWHM) of the (111) peak in the XRD spectra. BET surface areas were measured for the as-received (or as-prepared in the case of LSU sorbents) and following granulation and calcination in air at $700^{\circ} \mathrm{C}$ for 4 hrs. Because of their small particle sizes, the sorbents caused excessive pressure drop through the packed bed desulfurization reactor when used in the as-received form. This problem was overcome by dry pressing the powders into tablets using a hydraulic press at 10,000 psi. The tablets were crushed and sieved with the $150-300 \mu \mathrm{m}$ size used in the reaction tests. Results of both the average crystallite size and BET surface measurements are presented in Table 4.

There was a wide variation in both crystallite size and BET surface area. Crystallite sizes varied by almost a factor of 10 , from a minimum of $2.7 \mathrm{~nm}$ for $\mathrm{Ce}(\mathrm{RP})$ to $25.3 \mathrm{~nm}$ for Ce(Alfa). The crystallite size ranges of both the Nex and LSU materials were fairly small, but the average crystallite size of the $\mathrm{CZ}(\mathrm{Nex})$ sorbents were over three times larger than $\mathrm{Ce}(\mathrm{RP})$ and the average crystallite sizes of the LSU sorbents were almost six times larger than $\mathrm{Ce}(\mathrm{RP})$. 
Table 4. Average Crystallite Sizes and BET Surface Areas of Test Sorbents.

\begin{tabular}{|c|c|c|c|}
\hline \multirow{2}{*}{ Sample } & $\begin{array}{c}\text { Average Crystallite Size, } \\
\mathrm{nm}\end{array}$ & \multicolumn{2}{|c|}{ BET Surface Area, $\mathrm{m}^{2} / \mathrm{g}$} \\
\cline { 3 - 4 } & & As-Received & $\begin{array}{c}\text { Granulated and } \\
\text { Calcined* }\end{array}$ \\
\hline $\mathrm{Ce}(\mathrm{RP})$ & 2.7 & 210 & 110 \\
\hline $\mathrm{Ce}(\mathrm{Alfa})$ & 25.3 & 45 & 45 \\
\hline $\mathrm{CZ}(\mathrm{Nex}) 85$ & 8.7 & 110 & 80 \\
\hline $\mathrm{CZ}(\mathrm{Nex}) 80$ & 9.4 & 145 & --- \\
\hline $\mathrm{CZ}(\mathrm{Nex}) 70$ & --- & 125 & 70 \\
\hline $\mathrm{Ce}(\mathrm{LSU})$ & 16.1 & 75 & 35 \\
\hline $\mathrm{CZ}(\mathrm{LSU}) 90$ & 12.7 & 75 & 50 \\
\hline $\mathrm{CZ}(\mathrm{LSU}) 80$ & 18.8 & 85 & 55 \\
\hline
\end{tabular}

* Sorbents were hydraulically pressed into tablets, which were ground and sieved.

The $150-300 \mu \mathrm{m}$ size was then calcined in air at $700^{\circ} \mathrm{C}$ for $4 \mathrm{hr}$.

There was a similar wide variation in as-received surface areas, from $45 \mathrm{~m}^{2} / \mathrm{g}$ for $\mathrm{Ce}(\mathrm{Alfa})$ to $210 \mathrm{~m}^{2} / \mathrm{g}$ for $\mathrm{Ce}(\mathrm{RP})$. All of the Nex and LSU sorbents possessed intermediate as-received surface areas, and the ranges in these values of these two groups were reasonably small. Granulation and calcination had no effect on the surface area of $\mathrm{Ce}(\mathrm{Alfa})$ but reduced the surface area of $\mathrm{Ce}(\mathrm{RP})$ by almost a factor of two. Even with this loss, $\mathrm{Ce}(\mathrm{RP})$ retained the maximum surface area of the granulated and calcined materials. The Nex and LSU sorbents experienced moderate surface area decreases.

High desulfurization activity would be expected to be associated with small crystallite size and large surface area. On the basis of these structural properties, and ignoring the effect of the zirconia content on activity, the expected activity order would be:

Ceria: RP $>$ LSU $>$ Alfa

Ceria-Zirconia: Nex $>$ LSU

As a general rule this activity order was followed as will be shown in subsequent sections of this report.

\subsection{Sorbent Reduction}

Prior to all reduction tests the sorbent was heated to $800^{\circ} \mathrm{C}$ in an inert atmosphere to remove any volatile material. Figure 25 shows the electrobalance result for $\mathrm{Ce}$ (LSU) during this period. The sample started to lose weight as soon as the temperature began to increase. The rate of weight loss increased around $350^{\circ} \mathrm{C}$ (arrow 1) and no more weight was lost past about $500^{\circ} \mathrm{C}$ (arrow 2). There was no weight change when the sample was cooled from $800^{\circ} \mathrm{C}$ to $200^{\circ} \mathrm{C}$ (arrow 3). Total weight loss for $\mathrm{Ce}(\mathrm{LSU}$ ) was $5.2 \%$. Weight losses associated with volatiles were used in the analysis of sulfidation data.

Sorbent reduction between $200^{\circ} \mathrm{C}$ and $1000^{\circ} \mathrm{C}$ was studied in three reducing gas compositions: 


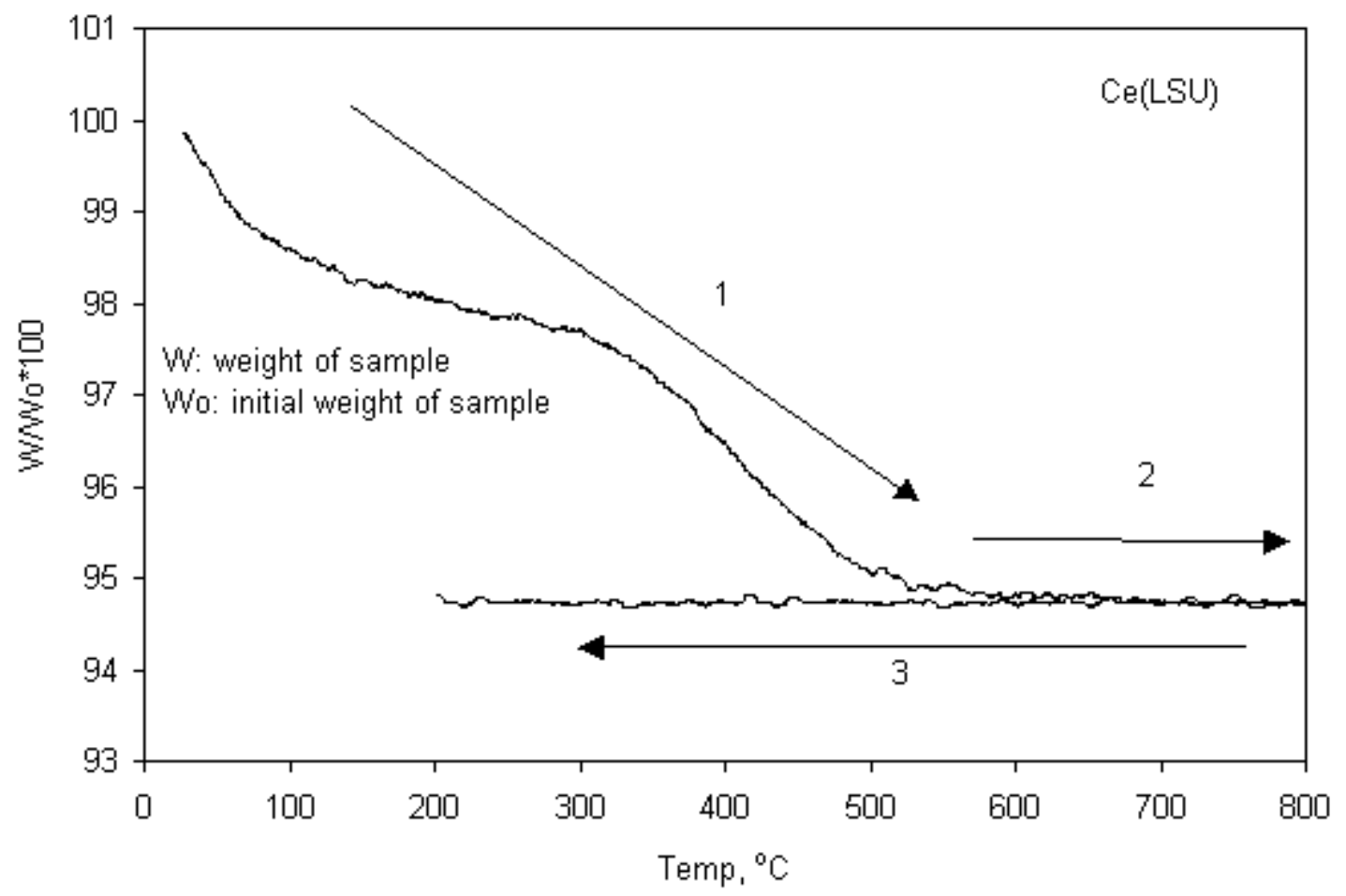

Figure 25. Weight Loss Associated With Heating in an Inert Atmosphere

Gas $1 . \quad 10 \% \mathrm{H}_{2}, 0.0 \% \mathrm{CO}_{2}$, balance $\mathrm{He}$

Gas 2. $\quad 10 \% \mathrm{H}_{2}, 3.5 \% \mathrm{CO}_{2}$, balance $\mathrm{He}$

Gas 3. $\quad 50 \% \mathrm{H}_{2}, 3.5 \% \mathrm{CO}_{2}$, balance $\mathrm{He}$

The equilibrium partial pressure of oxygen provides a measure of the reducing power of the gas. Gas 1 is oxygen free except for trace impurities present in the $\mathrm{H}_{2}$ and $\mathrm{He}$, and has, in principle, the greatest reducing power. The presence of $\mathrm{CO}_{2}$ in the other gases provides small quantities of free oxygen at elevated temperatures and the ratio of $\mathrm{H}_{2}$ to $\mathrm{CO}_{2}$ controls the reducing power. Thus, gas 3 has intermediate reducing power and gas 2 has the lowest reducing power. Equilibrium oxygen partial pressures, calculated using HSC Chemistry (Roine 1999), range between about $10^{-32}$ bars at $400^{\circ} \mathrm{C}$ for gas 3 to $10^{-11}$ bars at $1000^{\circ} \mathrm{C}$ for gas 2 , with the equilibrium oxygen pressure being one to two orders of magnitude smaller in gas three at all temperatures. At $700^{\circ} \mathrm{C}$, the most common experimental desulfurization temperature, the equilibrium oxygen pressures are about $10^{-}$ 20 and $10^{-19}$ bars for gases 2 and 3 , respectively.

Reduction results in this section are presented as $\mathrm{n}$ in $\mathrm{Ce}_{1-\mathrm{x}} \mathrm{Zr}_{\mathrm{x}} \mathrm{O}_{\mathrm{n}}$ versus temperature. The value of $\mathrm{n}$ is calculated from

$$
n=2-\frac{\left(M_{s}\right)\left(1-\left(w / w_{o}\right)\right)}{16}
$$

where: $M_{s}$ is the molecular weight of the initial sorbent $\left(\mathrm{Ce}_{1-\mathrm{x}} \mathrm{Zr}_{\mathrm{x}} \mathrm{O}_{2}\right), w / w_{o}$ is the dimensionless sorbent weight as a function of temperature and gas composition, $16=$ the 
atomic weight of oxygen, and 2 is the number of oxygen atoms in one mol of the original sorbent. For example, consider the reduction of $\mathrm{CZ}(\mathrm{Nex}) 80, \mathrm{Ce}_{0.8} \mathrm{Zr}_{0.2} \mathrm{O}_{2}$, with $M_{s}=$ $162.33 \mathrm{~g} / \mathrm{mol}$, where the dimensionless weight, $w / w_{o}$, at $1000^{\circ} \mathrm{C}$ in gas 1 was 0.975 .

$$
n=2-\frac{162.33(1-0.975)}{16}=1.75
$$

Reduction results in the three reducing gases using $\mathrm{Ce}(\mathrm{RP})$ are compared in Figure 26. In these tests the temperature was increased at $10^{\circ} \mathrm{C} / \mathrm{min}$ from $200^{\circ} \mathrm{C}$ to $1000^{\circ} \mathrm{C}$ immediately following the previously described test in which the volatile weight loss was determined by heating the sorbent to $800^{\circ} \mathrm{C}$ in an inert atmosphere. Results appear to be somewhat uneven because of the extremely small weight losses associated with reduction. In gas 1 , which is the most strongly reducing, reduction began at about $650^{\circ} \mathrm{C}$ and the value of $\mathrm{n}$ at the final temperature of $1000^{\circ} \mathrm{C}$ was 1.81 . In gas 3 having intermediate reducing power, reduction began near $700^{\circ} \mathrm{C}$ and the final value of $\mathrm{n}$ was 1.85. In the least powerful reducing gas 2 , reduction also began at about $700^{\circ} \mathrm{C}$ and the final value of $n$ was 1.88. The difference in the level of reduction in gases 2 and 3 first became appreciable at about $750^{\circ} \mathrm{C}$.

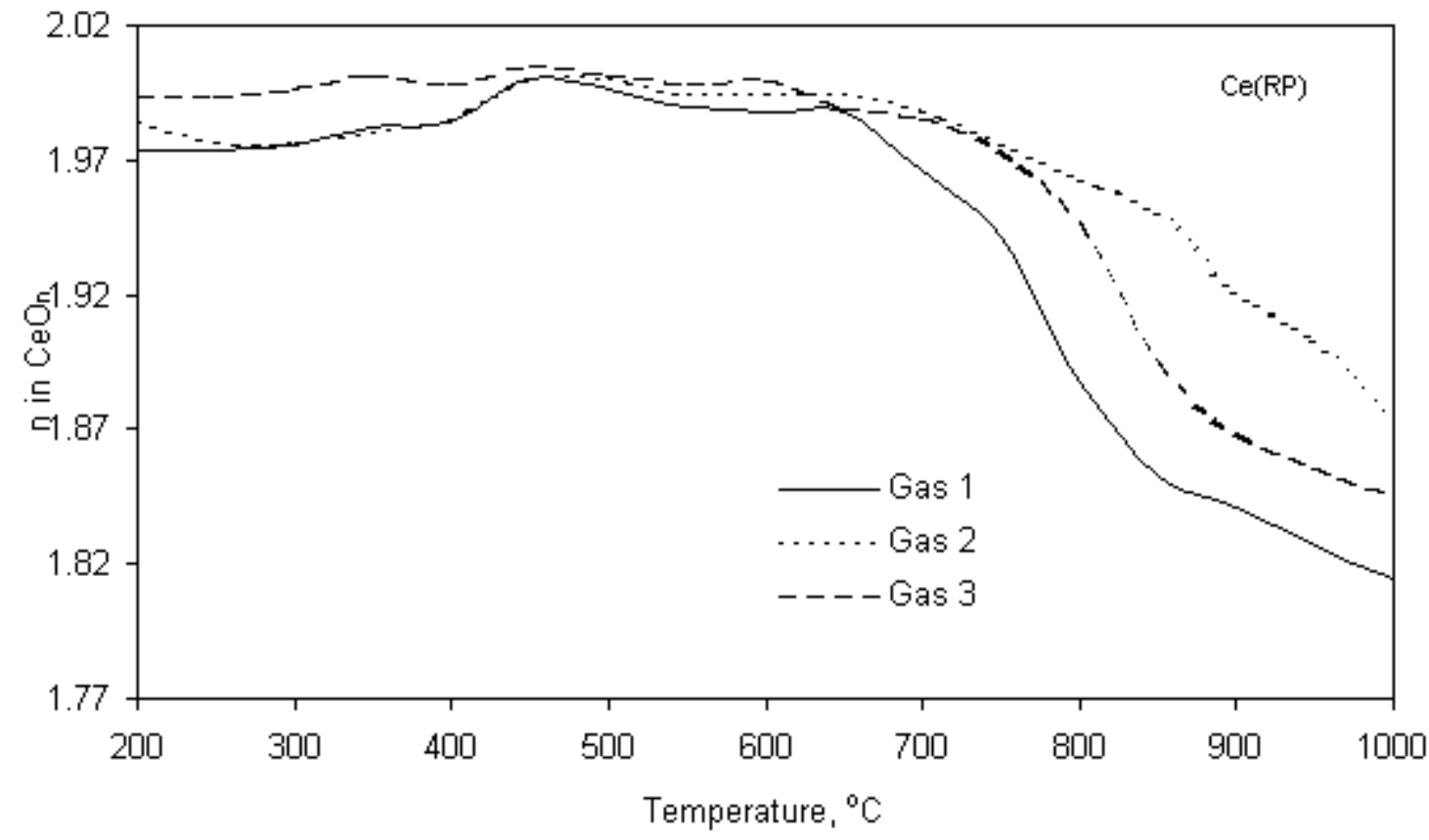

Figure 26. Reduction of $\mathrm{Ce}(\mathrm{RP})$ in Three Reducing Gas Compositions

Figure 27 compares the reducibility of $\mathrm{Ce}(\mathrm{RP})$ with that of $\mathrm{CZ}(\mathrm{Nex}) 80$ in gas 2 while Figure 28 compares the reducibility of the three LSU sorbents in gas 3 . From Figure 27 we see that reduction of $\mathrm{CZ}(\mathrm{Nex}) 80$ began at about $350^{\circ} \mathrm{C}$, almost $400^{\circ} \mathrm{C}$ lower than the initial reduction of $\mathrm{Ce}(\mathrm{RP})$. The final value of $\mathrm{n}$ for $\mathrm{CZ}(\mathrm{Nex}) 80$ was 1.82 compared to the final value of 1.88 for $\mathrm{Ce}(\mathrm{RP})$. In a similar manner, we see from Figure 28 that reduction of the two $\mathrm{CZ}(\mathrm{LSU})$ sorbents began at about $400^{\circ} \mathrm{C}$ compared to about $700^{\circ} \mathrm{C}$ for $\mathrm{Ce}(\mathrm{LSU})$, and that there was essentially no difference in the reducibility of 


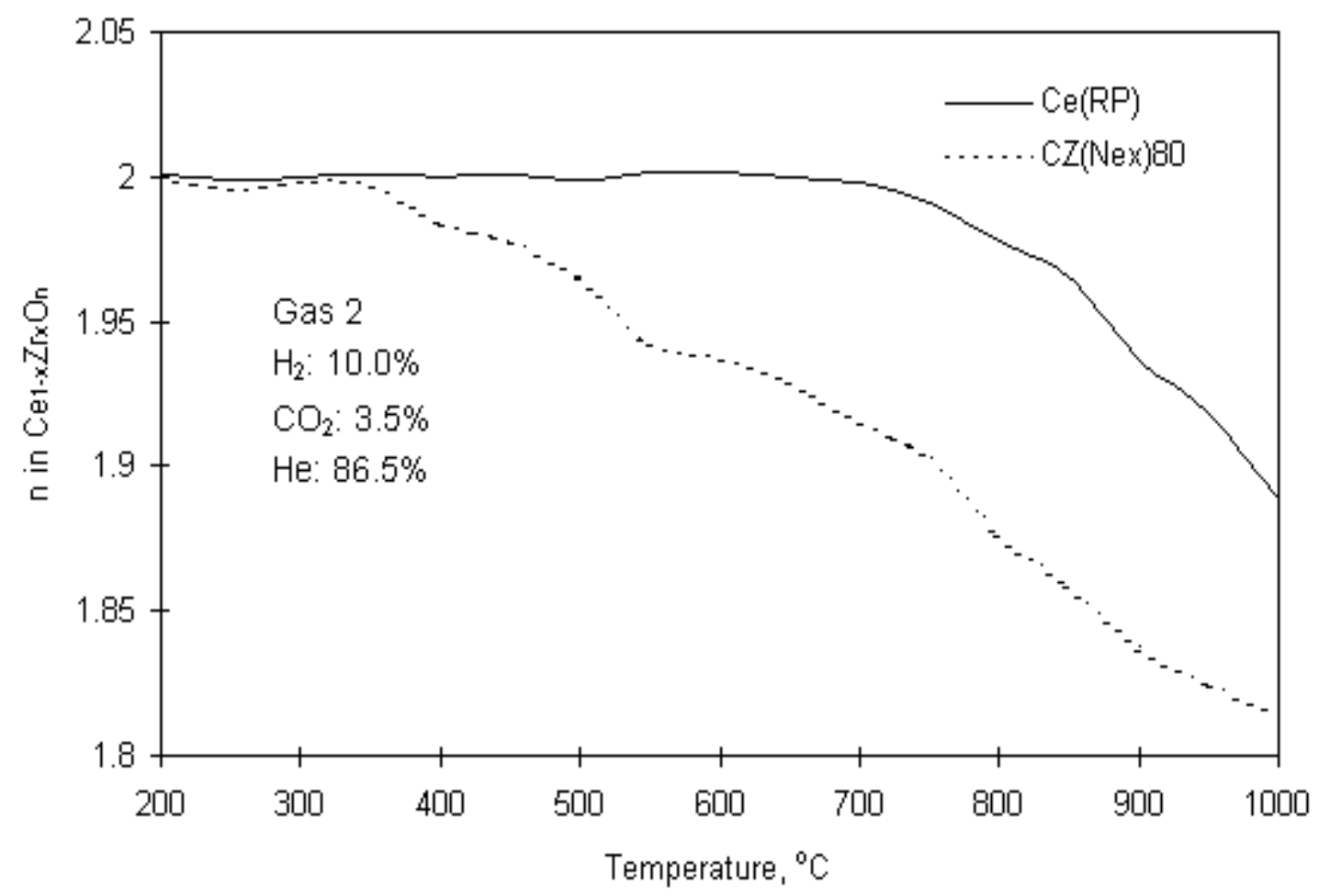

Figure 27. Comparison of Reduciility of $\mathrm{Ce}(\mathrm{RP})$ and $\mathrm{CZ}(\mathrm{Nex}) 80$ in Gas 2.

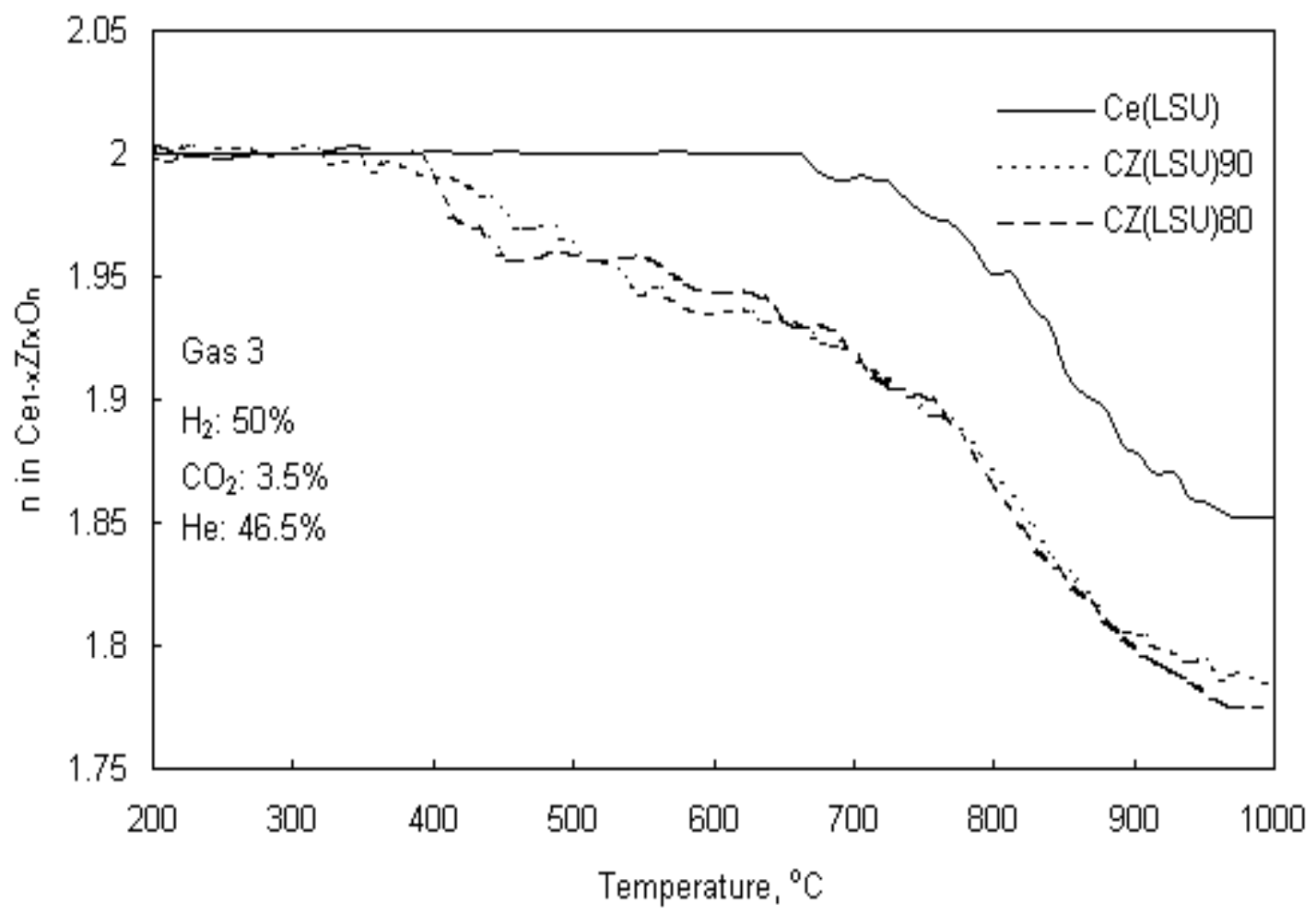

Figure 28. Reducibility of Ce(LSU), CZ(LSU)90 and CZ(LSU)80 in Gas 3. 
CZ(LSU)90 and CZ(LSU)80, where the final value of $n$ was 1.78 for both sorbents. The final value of $\mathrm{n}$ for $\mathrm{Ce}(\mathrm{LSU})$ was 1.85 .

The results shown in Figures 26, 27, and 28 were typical of all reduction results, which are summarized in Table 5. Temperatures corresponding to values of $\mathrm{n}=1.98$, 1.86 , and 1.80 as well as the values of $\mathrm{n}$ at temperatures of $700^{\circ} \mathrm{C}$ and $1000^{\circ} \mathrm{C}$ are presented for the eight test sorbents using the three reducing gas compositions. Roughly speaking, the temperature corresponding to $\mathrm{n}=1.98$ represents the beginning of reduction for each sorbent, while the temperature at $n=1.86$ is at an intermediate condition of reduction for $\mathrm{CZ}$ sorbents and near the end of reduction for Ce sorbents. Finally, the temperature at $\mathrm{n}=1.80$ is near the end of reduction for most of the $\mathrm{CZ}$ materials. The temperatures of $700^{\circ} \mathrm{C}$ and $1000^{\circ} \mathrm{C}$ represent the most commonly used experimental desulfurization temperature and the maximum reduction temperature, respectively.

Table 5 confirms that the graphical results in Figures 26, 27, and 28 applied to all sorbents. The final degree of sorbent reduction increased as the reducing power of the gas increased. For example, the final value of $\mathrm{n}$ at $1000^{\circ} \mathrm{C}$ for sorbent $\mathrm{Ce}(\mathrm{LSU})$ was 1.90 in the least powerful reducing gas $2,1.85$ in gas 2 having intermediate reducing power, and 1.82 in gas 1 having maximum reducing power. Sorbent $\mathrm{CZ}(\mathrm{Nex}) 70$ underwent the greatest levels of reduction with final values of $n=1.77,1.76$ and 1.74 in gases 2,3 , and 1 , respectively. Temperatures associated with the initial reduction $(n=1.98)$ of ceriazirconia sorbents were in the range of $280^{\circ} \mathrm{C}$ to $580^{\circ} \mathrm{C}$ while the minimum temperature for initial reduction of ceria sorbents was $660^{\circ} \mathrm{C}$. Sorbents $\mathrm{Ce}(\mathrm{RP}), \mathrm{Ce}(\mathrm{Alfa})$, and $\mathrm{Ce}(\mathrm{LSU})$ failed to reach the final value of $\mathrm{n}=1.80$ in any of the gases even at $1000^{\circ} \mathrm{C}$.

As a general rule among the ceria sorbents, $\mathrm{Ce}(\mathrm{RP})$ was more easily reduced than $\mathrm{Ce}(\mathrm{LSU})$ while $\mathrm{Ce}(\mathrm{Alfa})$ was the most difficult to reduce. Similarly, CZ(Nex) sorbents were more easily reduced than CZ(LSU), and the amount of zirconia had only a small effect on the reducibility of CZ sorbents. These results are in general agreement with the BET surface area and crystallite size results from the previous section. Small crystallite size and large surface area tended to increase the level of reducibility that could be achieved.

\section{FIXED-BED DESULFURIZATION RESULTS}

\subsection{Reaction Conditions and Dimensionless Time}

The desulfurization experiments were carried out in two stages. Initial experiments used commercially available sorbents. In these experiments the packed bed consisted of $6 \mathrm{~g}$ of sorbent intimately mixed with $3 \mathrm{~g}$ of $\mathrm{Al}_{2} \mathrm{O}_{3}$. Sulfidation gas containing $0.5 \% \mathrm{H}_{2} \mathrm{~S}$, $50 \% \mathrm{H}_{2}$, either $0 \%$ or $3.5 \% \mathrm{CO}_{2}$, and balance $\mathrm{N}_{2}$ was fed at a rate of $400 \mathrm{~cm}^{3}(\mathrm{stp}) / \mathrm{min}$. Sulfidation temperatures of $600^{\circ} \mathrm{C}, 700^{\circ} \mathrm{C}$, and $800^{\circ} \mathrm{C}$ were studied. However, the number of these tests that could be carried out was severely limited because of the small amount of $\mathrm{CZ}(\mathrm{Nex})$ sorbents available. 
Table 5. Summary of Reduction Results for Eight Test Sorbents

\begin{tabular}{|c|c|c|c|c|c|}
\hline \multirow[t]{2}{*}{ Sample } & \multicolumn{3}{|c|}{$\begin{array}{c}\text { Temperature, }{ }^{\circ} \mathrm{C}, \\
\text { Corresponding to Indicated } \\
\text { Value of } n\end{array}$} & \multicolumn{2}{|c|}{ Value of $n$ at } \\
\hline & 1.98 & 1.86 & 1.80 & $700^{\circ} \mathrm{C}$ & $1000^{\circ} \mathrm{C}$ \\
\hline \multicolumn{6}{|c|}{ Gas 1: $10 \% \mathrm{H}_{2}, 0.0 \% \mathrm{CO}_{2}$, balance $\mathrm{He}$} \\
\hline $\mathrm{Ce}(\mathrm{RP})$ & 660 & 840 & --- & 1.97 & 1.81 \\
\hline Ce(Alfa) & 670 & 850 & --- & 1.97 & 1.80 \\
\hline $\mathrm{CZ}(\mathrm{Nex}) 85$ & 280 & 720 & 840 & 1.87 & 1.74 \\
\hline $\mathrm{CZ}(\mathrm{Nex}) 80$ & 380 & 720 & 820 & 1.87 & 1.75 \\
\hline $\mathrm{CZ}(\mathrm{Nex}) 70$ & 330 & 600 & 740 & 1.81 & 1.74 \\
\hline $\mathrm{Ce}(\mathrm{LSU})$ & 630 & 880 & 1000 & 1.97 & 1.82 \\
\hline $\mathrm{CZ}(\mathrm{LSU}) 90$ & 590 & 850 & --- & 1.95 & 1.81 \\
\hline $\mathrm{CZ}(\mathrm{LSU}) 80$ & 500 & 800 & --- & 1.94 & 1.82 \\
\hline \multicolumn{6}{|c|}{ Gas 2: $10 \% \mathrm{H}_{2}, 3.5 \% \mathrm{CO}_{2}$, balance $\mathrm{He}$} \\
\hline $\mathrm{Ce}(\mathrm{RP})$ & 730 & --- & --- & 2.00 & 1.88 \\
\hline $\mathrm{Ce}$ (Alfa) & 830 & --- & --- & 2.00 & 1.91 \\
\hline $\mathrm{CZ}(\mathrm{Nex}) 85$ & 350 & 860 & --- & 1.91 & 1.82 \\
\hline $\mathrm{CZ}(\mathrm{Nex}) 80$ & 430 & 850 & --- & 1.91 & 1.81 \\
\hline $\mathrm{CZ}(\mathrm{Nex}) 70$ & 330 & 670 & 850 & 1.85 & 1.77 \\
\hline $\mathrm{Ce}(\mathrm{LSU})$ & 760 & --- & --- & 1.99 & 1.90 \\
\hline $\mathrm{CZ}(\mathrm{LSU}) 90$ & 580 & 960 & --- & 1.95 & 1.85 \\
\hline CZ(LSU)80 & 410 & 950 & --- & 1.95 & 1.85 \\
\hline \multicolumn{6}{|c|}{ Gas 3: $50 \% \mathrm{H}_{2}, 3.5 \% \mathrm{CO}_{2}$, balance $\mathrm{He}$} \\
\hline $\mathrm{Ce}(\mathrm{RP})$ & 730 & 930 & --- & 1.99 & 1.85 \\
\hline $\mathrm{Ce}($ Alfa $)$ & 770 & 950 & --- & 1.99 & 1.85 \\
\hline $\mathrm{CZ}(\mathrm{Nex}) 85$ & 320 & 760 & 890 & 1.89 & 1.77 \\
\hline $\mathrm{CZ}(\mathrm{Nex}) 80$ & 280 & 770 & 880 & 1.89 & 1.77 \\
\hline $\mathrm{CZ}(\mathrm{Nex}) 70$ & 330 & 680 & 860 & 1.85 & 1.76 \\
\hline $\mathrm{Ce}(\mathrm{LSU})$ & 740 & 940 & --- & 1.99 & 1.85 \\
\hline $\mathrm{CZ}(\mathrm{LSU}) 90$ & 440 & 810 & 890 & 1.92 & 1.78 \\
\hline $\mathrm{CZ}(\mathrm{LSU}) 80$ & 410 & 800 & 900 & 1.91 & 1.77 \\
\hline
\end{tabular}

---- : value is outside of the temperature range 
The second phase of experiments used sorbents synthesized at LSU. The sorbent charge was reduced from $6 \mathrm{~g}$ to $2 \mathrm{~g}$ to conserve sorbent. $6 \mathrm{~g}$ of $\mathrm{Al}_{2} \mathrm{O}_{3}$ was used in these experiments. The reduced sorbent charge was offset by a reduction in sulfidation gas feed rate to $80 \mathrm{~cm}^{3}(\mathrm{stp}) / \mathrm{min}$ and a change in the feed gas composition to $0.25 \% \mathrm{H}_{2} \mathrm{~S}, 10 \%$ $\mathrm{H}_{2}$, from $0.0 \%$ to $1.0 \% \mathrm{CO}_{2}$ and balance $\mathrm{N}_{2}$. The sulfidation temperature range was unchanged. The net result of these changes, in addition to conserving sorbent, was to increase the reaction time by a factor of almost 4, which increased the duration of steadystate periods, and improved our ability to detect small changes in $\mathrm{H}_{2} \mathrm{~S}$ concentration in the product gas. All tests were limited to 1 atm pressure because of the quartz reactor. No sorbent regeneration tests were carried and a new batch of sorbent was used in each test.

In most of the discussion that follows results are presented in terms of dimensionless time to permit direct comparison of sorbents having different composition. Dimensionless time is, by definition, the actual reaction time divided by a reference time associated with complete sorbent conversion with $100 \% \mathrm{H}_{2} \mathrm{~S}$ capture. The reference time is calculated from the following equation

$$
t_{\text {ref }}=\frac{(22,400) m\left(w / w_{o}\right)}{2\left(y_{s}\right) Q\left(M_{s}\right)}
$$

$\mathrm{m}$ is the mass of the initial sorbent charge, $\left(w / w_{o}\right)$ is the dimensionless sorbent weight following removal of the volatile fraction as described in section 5.3, $y_{s}$ is the mol fraction of $\mathrm{H}_{2} \mathrm{~S}$ in the feed gas, Q is the volumetric feed rate measured at standard temperature and pressure, $M_{s}$ is the molecular weight of the sorbent, 22,400 is the molar volume at standard temperature and pressure, and 2 is the stoichiometric coefficient of the sorbent in the sulfidation reaction. Table 6 summarizes the values of $t_{\text {ref }}$ for the eight test sorbents based on reaction conditions for the two phases of the experimental program. The calculations are based on the following stoichiometries

$$
\begin{aligned}
& 2 \mathrm{CeO}_{2}(\mathrm{~s})+\mathrm{H}_{2} \mathrm{~S}(\mathrm{~g})+\mathrm{H}_{2}(\mathrm{~g}) \Leftrightarrow \mathrm{Ce}_{2} \mathrm{O}_{2} \mathrm{~S}(\mathrm{~s})+2 \mathrm{H}_{2} \mathrm{O}(\mathrm{g}) \\
& 2 \mathrm{Ce}_{1-\mathrm{x}} \mathrm{Zr}_{\mathrm{x}} \mathrm{O}_{2}(\mathrm{~s})+\mathrm{H}_{2} \mathrm{~S}(\mathrm{~g})+\mathrm{H}_{2}(\mathrm{~g}) \Leftrightarrow \mathrm{Ce}_{2(1-\mathrm{x})} \mathrm{Zr}_{2 \mathrm{x}} \mathrm{O}_{2} \mathrm{~S}(\mathrm{~s})+2 \mathrm{H}_{2} \mathrm{O}(\mathrm{g})
\end{aligned}
$$

The stoichiometric equation involving $\mathrm{CeO}_{2}$ is straightforward. However, for $\mathrm{CeO}_{2}-\mathrm{ZrO}_{2}$ sorbents another option based on formation of a separate $\mathrm{ZrO}_{2}$ phase in the product is possible. This topic is addressed in more detail in a following section of this report.

Accurate measurement of sub-ppmv $\mathrm{H}_{2} \mathrm{~S}$ concentrations required that the reactor system be totally free of sulfur at the beginning of the test. Sulfur deposits on the walls of the reactor, for example, by decomposition of $\mathrm{H}_{2} \mathrm{~S}$ in a previous test could reenter the gas phase and confound the results. The reactor was chemically cleaned at the end of each sulfidation test to insure that no residual sulfur was present. At the end of a sulfidation test the reactor was cooled from sulfidation temperature under a flow of $50 \%$ $\mathrm{H}_{2}$ and $50 \% \mathrm{~N}_{2}$ in order to convert sulfur to $\mathrm{H}_{2} \mathrm{~S}$. This was followed by heating the reactor to $750^{\circ} \mathrm{C}$ in flowing air where any remaining sulfur would be converted to $\mathrm{SO}_{2}$. 
Table 6. Calculation of the Reference Times for Sulfidation Reactions

\begin{tabular}{|c|c|c|c|c|c|c|c|}
\hline Sorbent & Formula & $\begin{array}{c}\text { Initial } \\
\text { Sorbent } \\
\text { Charge, } \\
m(\mathrm{~g})\end{array}$ & $\begin{array}{c}\text { Sorbent } \\
\text { Weight } \\
\text { After } \\
\text { Volatile } \\
\text { Loss, } \\
w / w_{o}\end{array}$ & $\begin{array}{c}\text { Mol } \\
\text { Fraction } \\
\mathrm{H}_{2} \mathrm{~S}, \\
y_{s}\end{array}$ & $\begin{array}{c}\text { Volumetric } \\
\text { Feed Rate, } \\
Q \\
\left(\mathrm{~cm}^{3} / \mathrm{min}\right)\end{array}$ & $\begin{array}{c}\text { Sorbent } \\
\text { Molecular } \\
\text { Weight } \\
M_{s} \\
(\mathrm{~g} / \mathrm{mol})\end{array}$ & $\begin{array}{c}\text { Reference } \\
\text { Time, } \\
t_{\text {ref }} \\
(\mathrm{min})\end{array}$ \\
\hline $\mathrm{Ce}$ (RP) & $\mathrm{CeO}_{2}$ & 6.0 & 0.91 & 0.005 & 400 & 172.1 & 179 \\
\hline $\mathrm{Ce}(\mathrm{Alfa})$ & $\mathrm{CeO}_{2}$ & 6.0 & 0.945 & 0.005 & 400 & 172.1 & 184 \\
\hline $\mathrm{CZ}$ (Nex)85 & $\mathrm{Ce}_{0.85} \mathrm{Zr}_{0.15} \mathrm{O}_{2}$ & 6.0 & 0.94 & 0.005 & 400 & 164.8 & 191 \\
\hline $\mathrm{CZ}$ (Nex)80 & $\mathrm{Ce}_{0.80} \mathrm{Zr}_{0.20} \mathrm{O}_{2}$ & 6.0 & 0.947 & 0.005 & 400 & 162.3 & 196 \\
\hline $\mathrm{CZ}$ (Nex)70 & $\mathrm{Ce}_{0.70} \mathrm{Zr}_{0.30} \mathrm{O}_{2}$ & 6.0 & 0.943 & 0.005 & 400 & 157.4 & 203 \\
\hline Ce(LSU) & $\mathrm{CeO}_{2}$ & 2.0 & 0.948 & 0.0025 & 80 & 172.1 & 674 \\
\hline $\mathrm{CZ}$ (LSU)90 & $\mathrm{Ce}_{0.90} \mathrm{Zr}_{0.10} \mathrm{O}_{2}$ & 2.0 & 0.902 & 0.0025 & 80 & 167.2 & 577 \\
\hline $\mathrm{CZ}$ (LSU)80 & $\mathrm{Ce}_{0.80} \mathrm{Zr}_{0.20} \mathrm{O}_{2}$ & 2.0 & 0.951 & 0.0025 & 80 & 162.3 & 541 \\
\hline
\end{tabular}

Non-reacting tracer tests were made at the beginning of the experimental program to study the dynamics of the system response. The reactor was packed with $6 \mathrm{~g}$ of inert $\mathrm{Al}_{2} \mathrm{O}_{3}$ to simulate flow conditions in the presence of sorbent. A mixture of $0.5 \% \mathrm{H}_{2} \mathrm{~S}$ and balance $\mathrm{N}_{2}$ was fed and the $\mathrm{H}_{2} \mathrm{~S}$ concentration in the product gas was measured as a function of time. After certain portions of the top portion of the reactor were re-designed, the $\mathrm{H}_{2} \mathrm{~S}$ concentration in the product gas reached $90 \%$ of the feed gas concentration in the first sample taken $7.5 \mathrm{~min}$ after reactor feed was initiated. Because of this rapid response time compared to the reference time, no delay time corrections were needed when analyzing reactor data.

\subsection{Typical Reactor Response Curves}

Figures 29 and 30 show reactor response curves as a function of dimensionless time for duplicate tests using sorbent $\mathrm{Ce}(\mathrm{RP})$. Reaction conditions are shown on the figures. In addition to illustrating the type of results obtained in the sulfidation tests, these figures indicate the level of reproducibility that were achieved using different sorbent samples but identical reaction conditions. Figure 29 shows the complete test results while Figure 30 contains early results on a greatly expanded $\mathrm{H}_{2} \mathrm{~S}$ concentration scale.

The complete $\mathrm{H}_{2} \mathrm{~S}$ breakthrough curve in Figure 29 may be divided into three sections - prebreakthrough, active breakthrough, and postbreakthrouigh. The prebreakthrough section is most important as it identifies the ultimate $\mathrm{H}_{2} \mathrm{~S}$ removal capability of the sorbent at the reaction conditions. Active breakthrough began when the leading edge of the sulfidation reaction front reached the exit of the packed bed. $\mathrm{H}_{2} \mathrm{~S}$ concentration increased with time until the postbreakthrough period was reached. During postbreakthrough the sulfidation rate approached zero and the $\mathrm{H}_{2} \mathrm{~S}$ concentration of the product gas approached the concentration of the feed. 


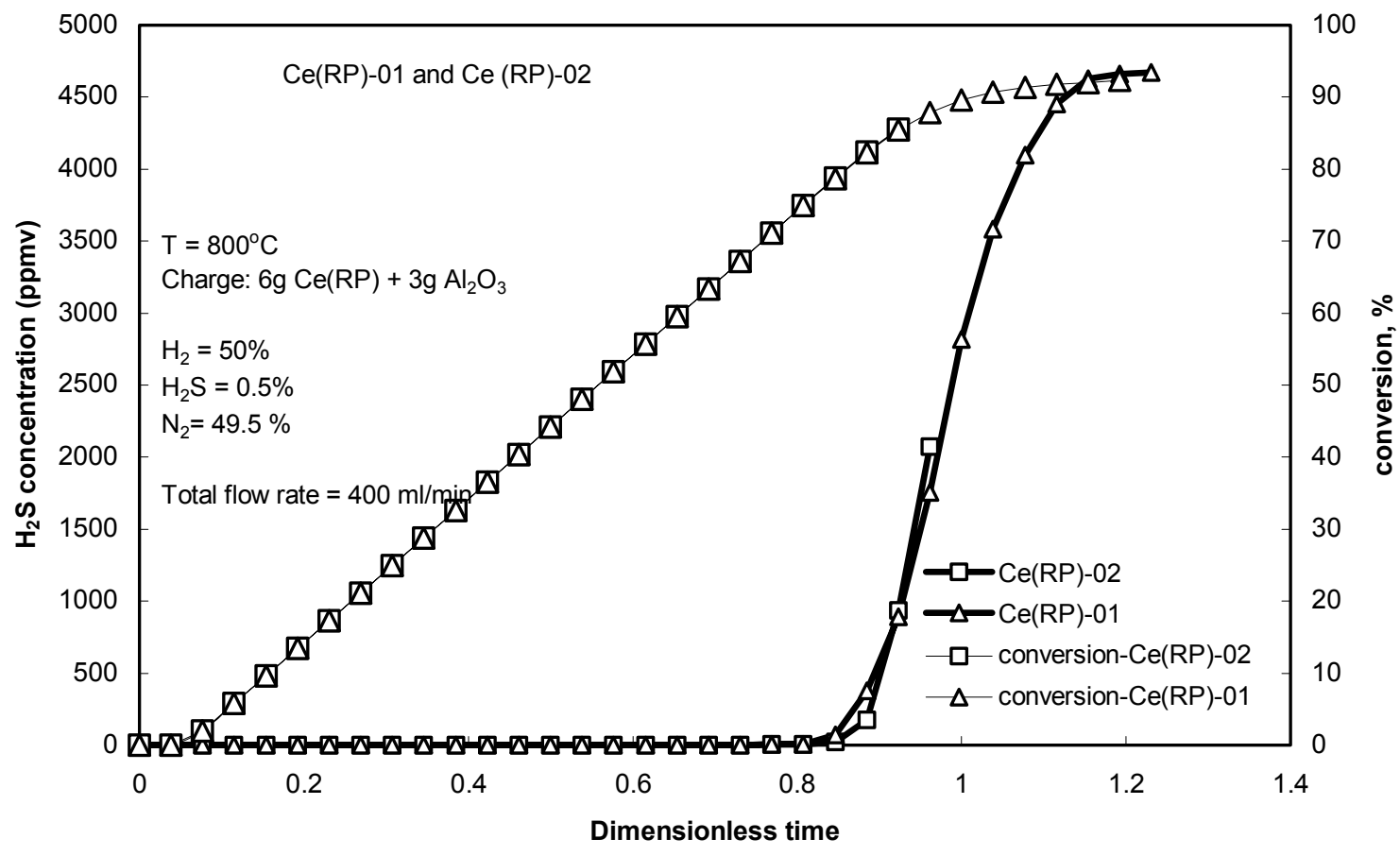

Figure 29. Typical Sulfidation Breakthrough Curves and Sorbent Conversions (Full Concentration Scale)

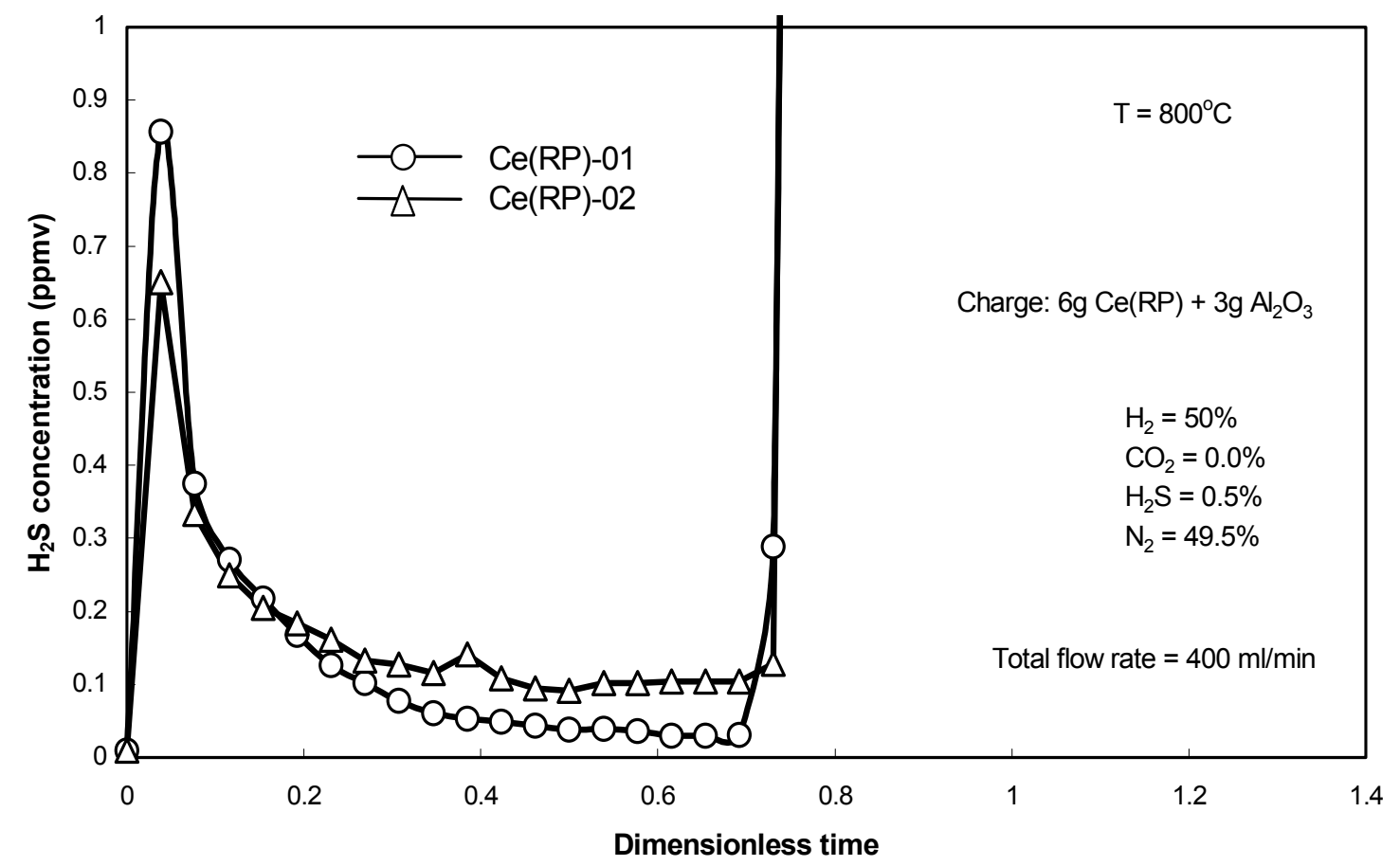

Figure 30. Typical Sulfidation Prebreakthrough Curves (Expanded Concentration Scale) 
Results of the two tests shown in Figure 29 were effectively equal in terms of the beginning and slope of the active breakthrough period. One test was carried out to completion while the second was terminated when the product $\mathrm{H}_{2} \mathrm{~S}$ concentration reached 2000 ppmv. The end of the prebreakthrough period was defined at the dimensionless time when the $\mathrm{H}_{2} \mathrm{~S}$ concentration exceeded the target value of 1 ppmv. This concentration cannot be read on the scale used in Figure 29. However, in the expanded scale of Figure 30 we see that end of prebreakthrough corresponded closely to dimensionless times of 0.75 in both tests.

Figure 29 also shows the cumulative fraction conversion of sorbent as a function of dimensionless time calculated by numerically integrating the area between the breakthrough curve and the feed concentration. During prebreakthrough when the $\mathrm{H}_{2} \mathrm{~S}$ concentration in the product was negligible compared to the feed concentration, fractional sorbent conversion and dimensionless time were effectively equal and the conversiontime line was straight with a $45^{\circ}$ angle. When breakthrough began the slope of the conversion-time curve decreased and approached zero at the beginning of the postbreakthrough period. An ideal breakthrough curve should be s-shaped and be symmetric around the point corresponding to dimensionless time $=1$ and $\mathrm{H}_{2} \mathrm{~S}$ concentration $=2,500 \mathrm{ppmv}$ (one-half of the feed concentration). It is obvious from Figure 29 that the experimental breakthrough closely approached the ideal case.

The expanded concentration scale of Figure 30 shows an initial maximum in $\mathrm{H}_{2} \mathrm{~S}$ concentration followed by a decrease to relatively constant values of about $0.1 \mathrm{ppmv}$ prior to the beginning of active breakthrough. This figure also shows that active breakthrough began at dimensionless times of about 0.75 in both tests. The early $\mathrm{H}_{2} \mathrm{~S}$ maxima are attributed to incomplete sorbent reduction at the beginning of the test. Sulfidation and reduction occurred simultaneously, and, because of the large ratio of $\mathrm{H}_{2}$ to $\mathrm{H}_{2} \mathrm{~S}$, the reduction reaction front proceeded downstream at a faster rate. At the beginning sulfidation occurred between $\mathrm{H}_{2} \mathrm{~S}$ and partially reduced $\mathrm{CeO}_{2}$; a short time later the sulfidation reaction occurred between fully reduced sorbent, $\mathrm{CeO}_{\mathrm{n}}$, and $\mathrm{H}_{2} \mathrm{~S}$.

\subsection{Commercial Ceria Sorbents}

\subsection{1. $\mathrm{Ce}(\mathrm{RP})$ vs. $\mathrm{Ce}(\mathrm{Alfa})$}

The performance of the two commercial ceria sorbents, $\mathrm{Ce}(\mathrm{RP})$ and $\mathrm{Ce}(\mathrm{Alfa})$, under identical reaction conditions is compared in Figures 31 and 32. Once again Figure 31 shows the complete performance curve while Figure 32 emphasizes the prebreakthrough region using a highly expanded $\mathrm{H}_{2} \mathrm{~S}$ concentration scale. Note however that the maximum in the concentration scale in Figure 32 is 20 ppmv compared to 1 ppmv in Figure 30.

Results in Figure 31 appear reasonably similar; prebreakthrough, active breakthrough, and postbreakthrough regions are clearly visible for both sorbents. The breakthrough curve for $\mathrm{Ce}(\mathrm{RP})$ is reasonably symmetric around dimensionless time $=1$, but $\mathrm{Ce}(\mathrm{Alfa})$ breakthrough occurred roughly $10 \%$ earlier than predicted by stoichiometry. 


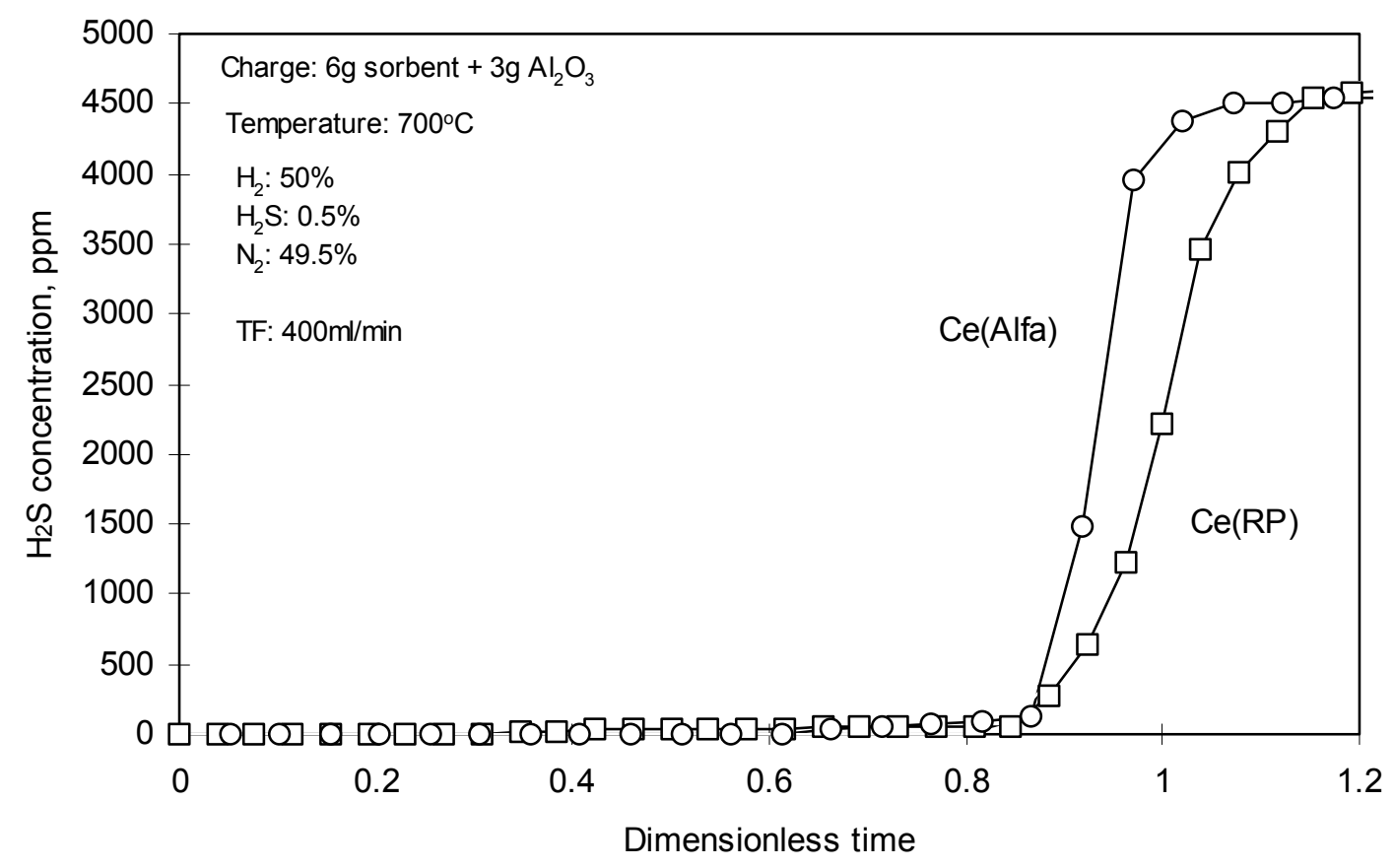

Figure 31. Sulfidation Breakthrough Curves of Pure $\mathrm{CeO}_{2}$ Sorbents (Full Concentration Scale)

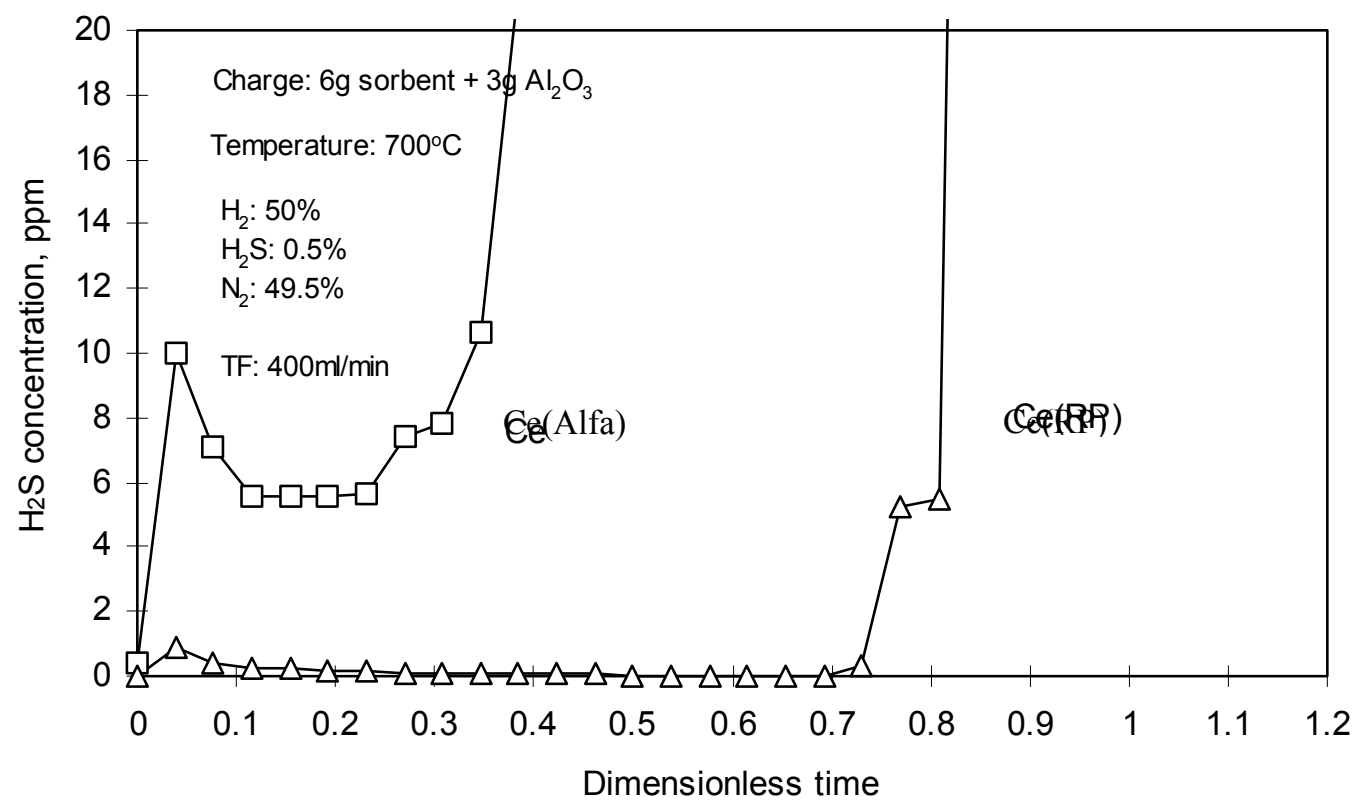

Figure 32. Sulfidation Breakthrough Curves of Pure $\mathrm{CeO}_{2}$ Sorbents (Expanded Concentration Scale) 
However, the superior performance of $\mathrm{Ce}(\mathrm{RP})$ is clear from Figure 32. The minimum $\mathrm{H}_{2} \mathrm{~S}$ concentration using $\mathrm{Ce}(\mathrm{Alfa})$ was only about 6 ppmv so there was no true prebreakthrough period during which the concentration was less than 1 ppmv. In contrast, as shown earlier, the prebreakthrough period duration for $\mathrm{Ce}(\mathrm{RP})$ extended to dimensionless time of about 0.75 . The early maxima in $\mathrm{H}_{2} \mathrm{~S}$ concentrations associated with incomplete initial reduction are present in each case.

These sulfidation results are consistent with the sorbent characterization results described earlier. The smaller crystallite size, larger surface area, and increased reducibility of $\mathrm{Ce}(\mathrm{RP})$ compared to $\mathrm{Ce}(\mathrm{Alfa})$ would be expected to lead to superior sulfidation performance. Because of poor performance, further testing of commercial ceria sorbents was limited to $\mathrm{Ce}(\mathrm{RP})$.

\subsubsection{The Effect of Temperature on Ce(RP)}

The sulfidation of $\mathrm{Ce}(\mathrm{RP})$ sorbent was tested at temperatures of $600^{\circ} \mathrm{C}, 700^{\circ} \mathrm{C}$, and $800^{\circ} \mathrm{C}$ with results during the prebreakthrough period on an expanded concentration scale shown in Figure 33. Each test produced a small early maximum followed by a decrease in concentration with time. The local maxima decreased as the sulfidation temperature decreased, from $2.7 \mathrm{ppmv}$ at $800^{\circ} \mathrm{C}$ to $0.9 \mathrm{ppmv}$ at $700^{\circ} \mathrm{C}$ and to $0.3 \mathrm{ppmv}$ at $600^{\circ} \mathrm{C}$. In the prebreakthrough region following the local maxima (dimensionless time $>0.2$ ) the $\mathrm{H}_{2} \mathrm{~S}$ concentration at $800^{\circ} \mathrm{C}$ was about 0.25 ppmv and was about $0.1 \mathrm{ppmv}$ at both $700^{\circ} \mathrm{C}$ and $600^{\circ} \mathrm{C}$. The duration of the prebreakthrough period increased with increasing temperature, from about 0.58 at $600^{\circ} \mathrm{C}$ to 0.75 at $700^{\circ} \mathrm{C}$ and to 0.78 at $800^{\circ} \mathrm{C}$.

The earlier breakthrough at lower temperature is attributed to the decreased kinetics while the decrease in prebreakthrough concentration at lower temperature is attributed to more favorable thermodynamics. Since the sulfidation reaction is exothermic the equilibrium $\mathrm{H}_{2} \mathrm{~S}$ concentration increases at higher temperature.

\subsubsection{Pre-reduction of $\mathrm{Ce}(\mathrm{RP})$}

In one test at $800^{\circ} \mathrm{C}$ the sorbent was pre-reduced for $4 \mathrm{hr}$ in a sulfur-free gas having otherwise the same composition as the sulfidation gas. This arrangement separated the reduction and sulfidation reactions so that sulfidation began over a fully reduced sorbent. Sulfidation results with and without pre-reduction are compared in Figure 34. With pre-reduction the $\mathrm{H}_{2} \mathrm{~S}$ concentration remained near zero for dimensionless times less than 0.3 . Without pre-reduction, the early $\mathrm{H}_{2} \mathrm{~S}$ maximum of about 2.7 ppmv was followed by an extended prebreakthrough period where the concentration was about $0.25 \mathrm{ppmv}$ and the end of the prebreakthrough period occurred at dimensionless time of about 0.78 . The lower prebreakthrough concentration following pre-reduction was expected but the shorter duration of the prebreakthrough period was disappointing, and also opposite to results obtained when LSU sorbents were prereduced. These results are discussed in a later section of this report. 


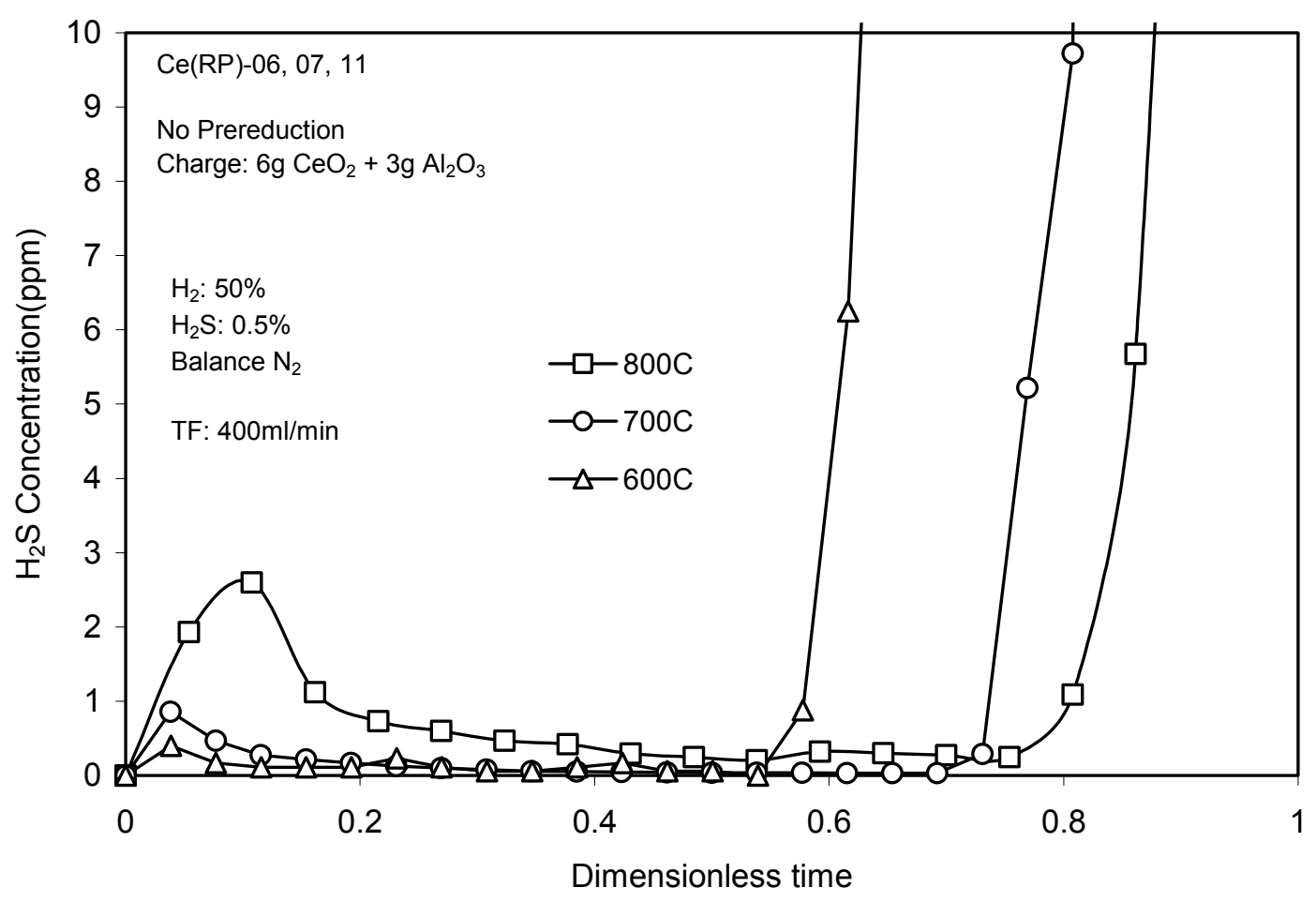

Figure 33. Temperature Effect on Sulfidation of Ce(RP)

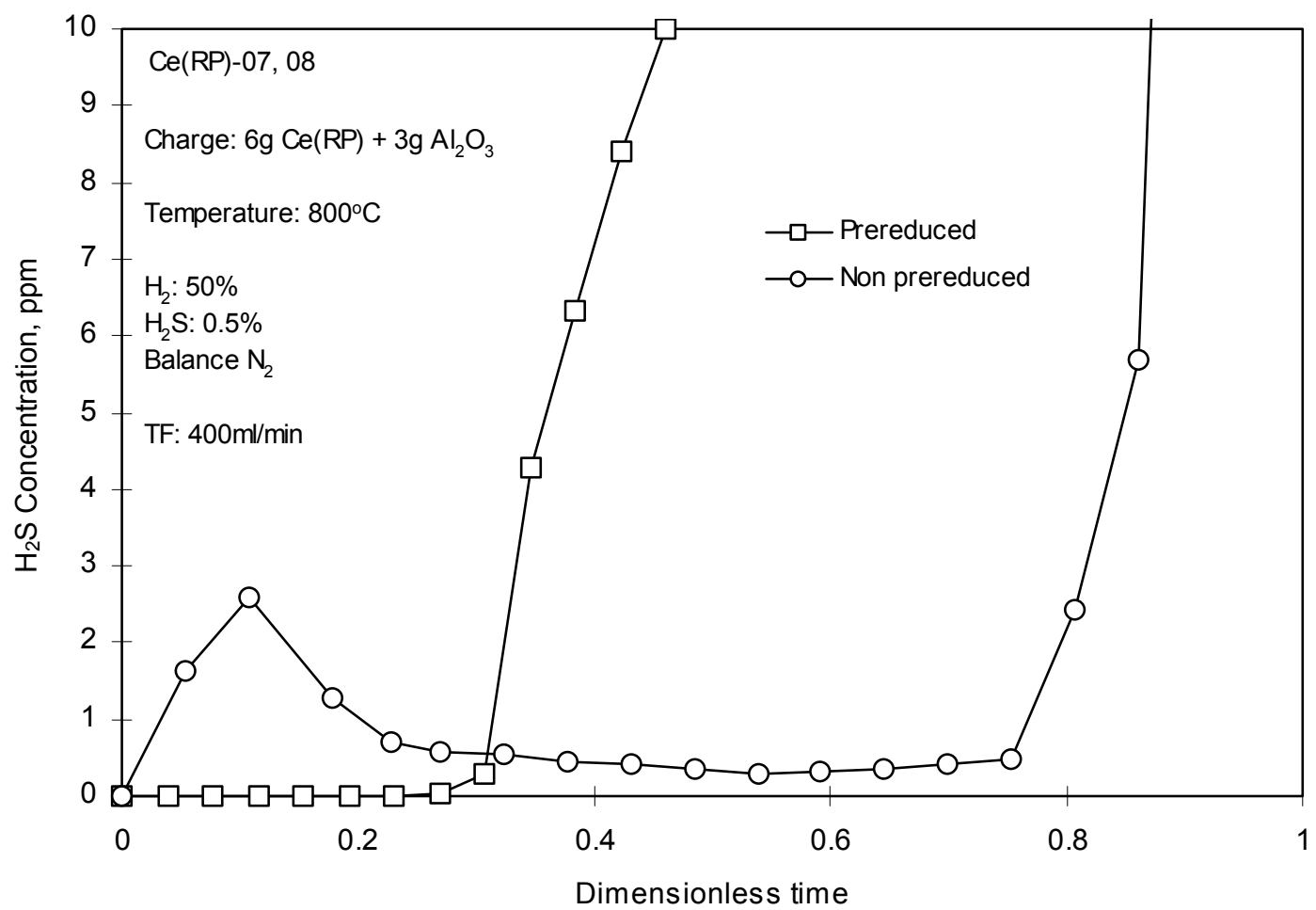

Figure 34. The Effect of Pre-reduction on Sulfidation of Ce(RP) 


\subsubsection{The Effect of $\mathrm{CO}_{2}$ on Sulfidation of $\mathrm{Ce}(\mathrm{RP})$}

The addition of $\mathrm{CO}_{2}$ was used to control the reducing power of the sulfidation feed gas. Sulfidation results with the feed gas containing $0 \%$ and $3.5 \% \mathrm{CO}_{2}$ are compared in Figure 35. The logarithmic concentration scale between 0.1 and $1000 \mathrm{ppmv}$ $\mathrm{H}_{2} \mathrm{~S}$ was necessary to show clearly both test results. The test without $\mathrm{CO}_{2}$ addition is the same as shown previously in Figure 34. An extended prebreakthrough region followed the early $\mathrm{H}_{2} \mathrm{~S}$ maximum and the beginning of active breakthrough occurred at dimensionless time of about 0.78 . With $3.5 \% \mathrm{CO}_{2}$ in the feed gas there was no true prebreakthrough period. $\mathrm{H}_{2} \mathrm{~S}$ concentration in the first three samples of about $5 \mathrm{ppmv}$ was followed by a rapid increase to $250 \mathrm{ppmv}$ and a gradual increase to $400 \mathrm{ppmv}$. A second breakthrough began at dimensionless time of 0.80 and the $\mathrm{H}_{2} \mathrm{~S}$ concentration increased to near the feed concentration thereafter.

The $\mathrm{CO}_{2}$-containing feed gas composition on a sulfur-free basis was the same as gas 3 in the sorbent reduction tests. Table 5 shows that $\mathrm{Ce}(\mathrm{RP})$ was only slightly reduced in this gas composition. On this basis, we may conclude that the reaction was, for practical purposes, between $\mathrm{CeO}_{2}$ and $\mathrm{H}_{2} \mathrm{~S}$. HSC Chemistry (Roine, 1999) equilibrium calculations gave an equilibrium $\mathrm{H}_{2} \mathrm{~S}$ concentration of $166 \mathrm{ppmv}$ at $700^{\circ} \mathrm{C}$ in this gas composition. Thus, the experimental concentrations in the range of 250 to $400 \mathrm{ppmv}$ are not unreasonable.

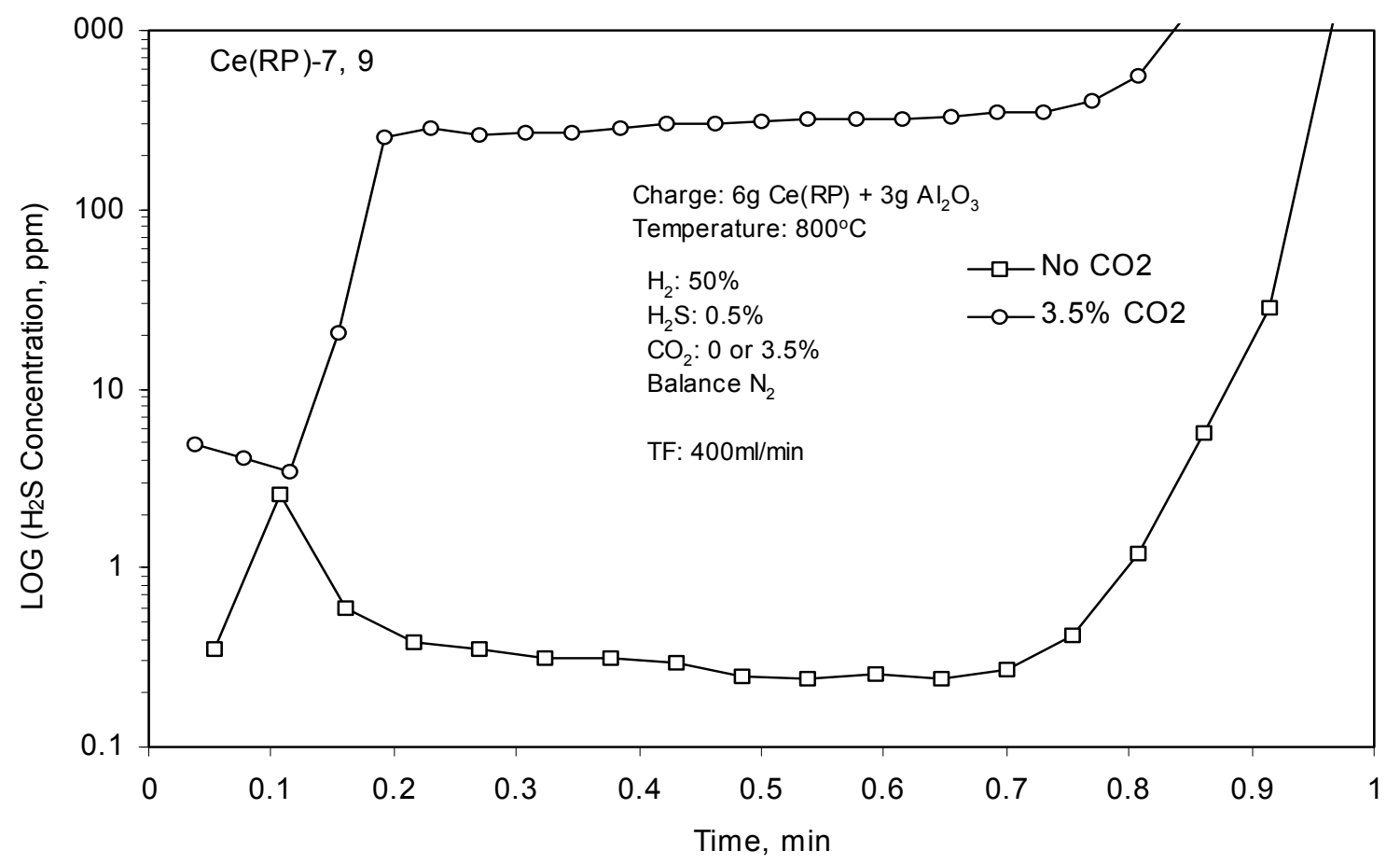

Figure 35. The Effect of $\mathrm{CO}_{2}$ on Sulfidation of $\mathrm{Ce}(\mathrm{RP})$ 


\subsection{Commercial Ceria-Zirconia Sorbents}

After using some of the materials in characterization tests, sufficient quantities of the ceria-zirconia sorbents donated by NexTech Materials - CZ(Nex)85, CZ(Nex)80, and $\mathrm{CZ}(\mathrm{Nex}) 70$ - were available to permit only three or a maximum of four sulfidation tests.

One of the first questions to be addressed with the ceria-zirconia sorbents was the proper sulfidation stoichiometry. Two reasonable stoichiometries could be postulated. The stoichiometry selected was presented as equation (10) and is repeated here

$$
2 \mathrm{Ce}_{1-\mathrm{x}} \mathrm{Zr}_{\mathrm{x}} \mathrm{O}_{2}(\mathrm{~s})+\mathrm{H}_{2} \mathrm{~S}(\mathrm{~g})+\mathrm{H}_{2}(\mathrm{~g}) \Leftrightarrow \mathrm{Ce}_{2(1-\mathrm{x})} \mathrm{Zr}_{2 \mathrm{x}} \mathrm{O}_{2} \mathrm{~S}(\mathrm{~s})+2 \mathrm{H}_{2} \mathrm{O}(\mathrm{g})
$$

The second possible stoichiometry is

$$
\begin{aligned}
& 2 \mathrm{Ce}_{1-\mathrm{x}} \mathrm{Zr}_{\mathrm{x}} \mathrm{O}_{2}(\mathrm{~s})+(1-\mathrm{x}) \mathrm{H}_{2}(\mathrm{~g})+(1-\mathrm{x}) \mathrm{H}_{2} \mathrm{~S}(\mathrm{~g}) \Leftrightarrow \\
& (1-\mathrm{x}) \mathrm{Ce}_{2} \mathrm{O}_{2} \mathrm{~S}(\mathrm{~s})+2 \mathrm{xZrO}_{2}(\mathrm{~s})+2(1-\mathrm{x}) \mathrm{H}_{2} \mathrm{O}(\mathrm{g})
\end{aligned}
$$

These differ in two important ways. The second requires formation of a separate $\mathrm{ZrO}_{2}$ phase during sulfidation while the first does not. Phase separation, which in most cases can be checked using x-ray diffraction, could not be detected in this case since the $\mathrm{Ce}_{2} \mathrm{O}_{2} \mathrm{~S}$ or $\mathrm{Ce}_{2(1-x)} \mathrm{Zr}_{2 \mathrm{x}} \mathrm{O}_{2} \mathrm{~S}$ products were pyrophoric. They oxidizes spontaneously in air liberating $\mathrm{SO}_{2}$ and reforming $\mathrm{CeO}_{2}$ or $\mathrm{Ce}_{1-\mathrm{x}} \mathrm{Zr}_{\mathrm{x}} \mathrm{O}_{2}$. The second option also requires that the sorbent sulfur capacity be reduced as more $\mathrm{ZrO}_{2}$ is added, while the first actually implies a small increase in sulfur capacity because the atomic weight of zirconium is less than that of cerium. Our conclusion that the first stoichiometry was applicable was based primarily on the analysis of $\mathrm{H}_{2} \mathrm{~S}$ breakthrough curves as a function of dimensionless time. The symmetries of the breakthrough curves around dimensionless time values of 1.0 were much better when the reference time was based on equation (10). Dimensionless times for all ceria-zirconia sorbents presented in Table 6 are based on the stoichiometry of equation (10).

\subsubsection{Comparison of $\mathrm{CZ}(\mathrm{Nex})$ and $\mathrm{Ce}(\mathrm{RP})$}

The results of three sulfidation tests using $\mathrm{Ce}(\mathrm{RP}), \mathrm{CZ}(\mathrm{Nex}) 85$, and $\mathrm{CZ}(\mathrm{Nex}) 80$ are shown in Figure 36. The use of dimensionless time is important in this case because of differences in volatile contents and compositions of each sorbent. The reference times corresponding to dimensionless time $=1$ for these sorbents were presented in Table 6 .

The early $\mathrm{H}_{2} \mathrm{~S}$ maxima were present for the $\mathrm{CZ}(\mathrm{Nex})$ sorbents as well as for $\mathrm{Ce}(\mathrm{RP})$. All three sorbents showed a prebreakthrough steady state during which time the $\mathrm{H}_{2} \mathrm{~S}$ concentration was below the 1 ppmv target. However, the prebreakthrough $\mathrm{H}_{2} \mathrm{~S}$ concentration of about $0.25 \mathrm{ppmv}$ with $\mathrm{Ce}(\mathrm{RP})$ was significantly below the 0.3 to 0.4 ppmv levels associated with the two $\mathrm{CZ}(\mathrm{Nex})$ sorbents. However, the most striking feature of Figure 36 is the relatively short duration of the prebreakthrough time for the $\mathrm{CZ}(\mathrm{Nex})$ sorbents compared to $\mathrm{Ce}(\mathrm{RP})$, approximately 0.4 versus 0.8 . 
While the results of these tests were counter to the presumption that $\mathrm{ZrO}_{2}$ addition would enhance the desulfurization capability of a $\mathrm{CeO}_{2}$ sorbent, it is important to recall that the structural characteristics, crystallite size and BET surface area, coupled with the greater reducibility of $\mathrm{Ce}(\mathrm{RP})$ could overwhelm any advantages that might be associated with $\mathrm{ZrO}_{2}$ addition. If, for example, the $\mathrm{CZ}(\mathrm{Nex})$ results had been compared to sulfidation results from $\mathrm{Ce}$ (Alfa) such as shown in Figure 32, one might conclude that $\mathrm{ZrO}_{2}$ addition had a positive effect on $\mathrm{H}_{2} \mathrm{~S}$ removal. This might be equally false since the properties of the $\mathrm{CZ}(\mathrm{Nex})$ sorbents were superior to those of $\mathrm{Ce}(\mathrm{Alfa})$. It was at this point that we began to investigate the in-house preparation of ceria and ceria-zirconia sorbents, both to provide sufficient quantities for a full investigation and to at least minimize the effect of variable structural properties.

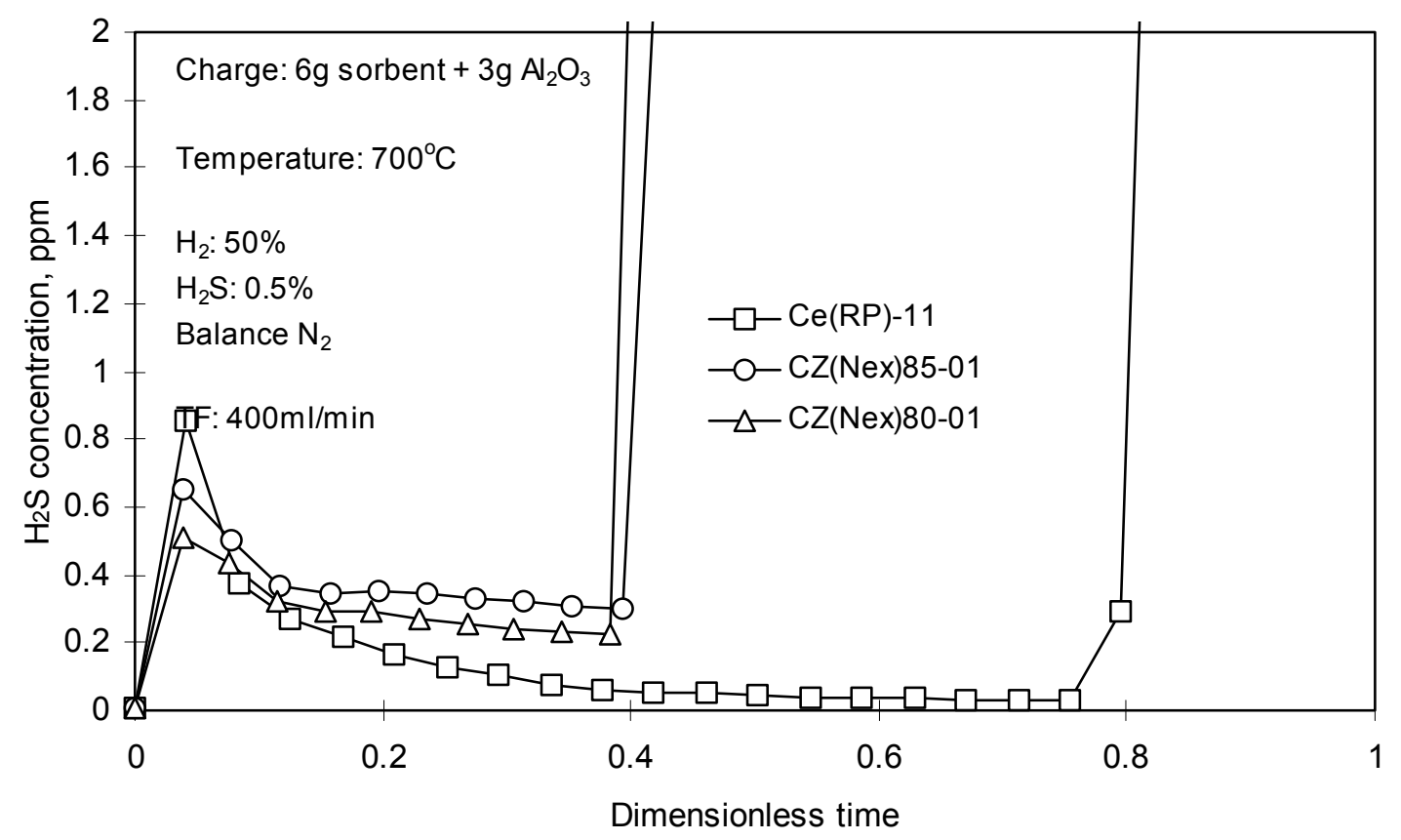

Figure 36. Comparison of the Sulfidation of $\mathrm{Ce}(\mathrm{RP})$ and $\mathrm{CZ}(\mathrm{Nex})$

\subsubsection{Pre-reduction of $\mathrm{CZ}(\mathrm{Nex}) 85$}

The results of sulfidation tests using $\mathrm{CZ}(\mathrm{Nex}) 85$ with and without pre-reduction are shown in Figure 37. The only difference in this pair of tests and the similar pair using $\mathrm{Ce}(\mathrm{RP})$ shown in Figure 34 was the pre-reduction and sulfidation temperature. $800^{\circ} \mathrm{C}$ was used with $\mathrm{Ce}(\mathrm{RP})$ while $700^{\circ} \mathrm{C}$ was used in these tests with $\mathrm{CZ}(\mathrm{Nex}) 85$. Prereduction eliminated the early $\mathrm{H}_{2} \mathrm{~S}$ concentration maximum and reduced the prebreakthrough $\mathrm{H}_{2} \mathrm{~S}$ concentration from about $0.2 \mathrm{ppmv}$ to near zero. The duration of the prebreakthrough period using pre-reduced $\mathrm{CZ}(\mathrm{Nex}) 85$ decreased by a relatively small amount, from dimensionless time of 0.35 without pre-reduction to 0.3 with pre-reduction. The decrease in the prebreakthrough duration was much smaller than with $\mathrm{Ce}(\mathrm{RP})$, which may be attributed to the lower temperature. 


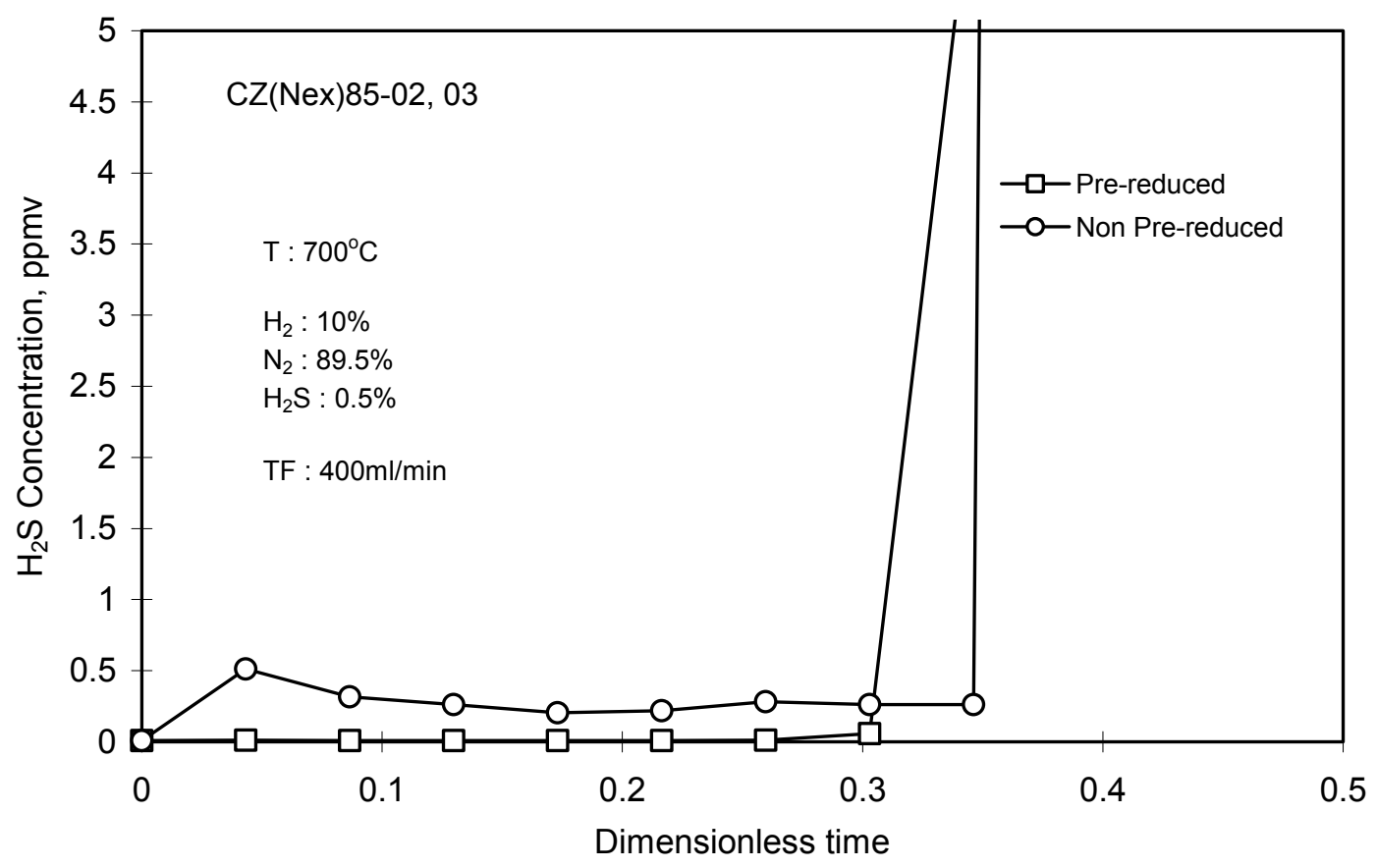

Figure 37. The Effect of Pre-reduction on Sulfidation of CZ(Nex)85

\subsubsection{The Effect of $\mathrm{CO}_{2}$ on Sulfidation of $\mathrm{CZ}(\mathrm{Nex}) 70$}

Addition of $3.5 \% \mathrm{CO}_{2}$ to the feed gas almost totally destroyed the ability of $\mathrm{CZ}(\mathrm{Nex}) 70$ to remove $\mathrm{H}_{2} \mathrm{~S}$. This is shown in Figure 38 where the entire $\mathrm{H}_{2} \mathrm{~S}$ breakthrough curve is plotted versus dimensional time. Dimensional time is used so that results from a nonreacting tracer test as well as a sulfidation test using $\mathrm{Ce}(\mathrm{RP})$ at the same reaction conditions may be included for comparison. The $\mathrm{Ce}(\mathrm{RP})$ test is the same as shown earlier in Figure 35 using a logarithmic concentration scale.

While, as shown in Table 5, $\mathrm{CZ}(\mathrm{Nex}) 70$ underwent the greatest level of reduction in the sulfur-free reducing gas having the same composition as used in the sulfidation test, the $\mathrm{H}_{2} \mathrm{~S}$ concentration in the $\mathrm{CZ}(\mathrm{Nex}) 70$ sulfidation test reached 500 ppmv by the third sample, $4500 \mathrm{ppmv}$ in the fourth sample, and then gradually approached 5000 ppmv. In contrast, the $\mathrm{H}_{2} \mathrm{~S}$ concentration remained at a low level for five samples using $\mathrm{Ce}(\mathrm{RP})$, then rose to a plateau in the $300-400 \mathrm{ppmv}$ level where it remained for 150 minutes before increasing rapidly. The nonreacting tracer test shown in Figure 38 occurred at $700^{\circ} \mathrm{C}$ instead of $800^{\circ} \mathrm{C}$, but it is obvious, in comparing the tracer and $\mathrm{Ce}(\mathrm{Nex}) 70$ results, that very little $\mathrm{H}_{2} \mathrm{~S}$ was removed by $\mathrm{CZ}(\mathrm{Nex}) 70$ at these conditions. No additional tests using $\mathrm{CZ}(\mathrm{Nex}) 70$ were possible because of the small quantity available.

\subsection{LSU Ceria and Ceria-Zirconia Sorbents}

Three ceria and ceria-zirconia sorbents were prepared at LSU to avoid the limited availability and widely varying structural properties associated with the commercially 


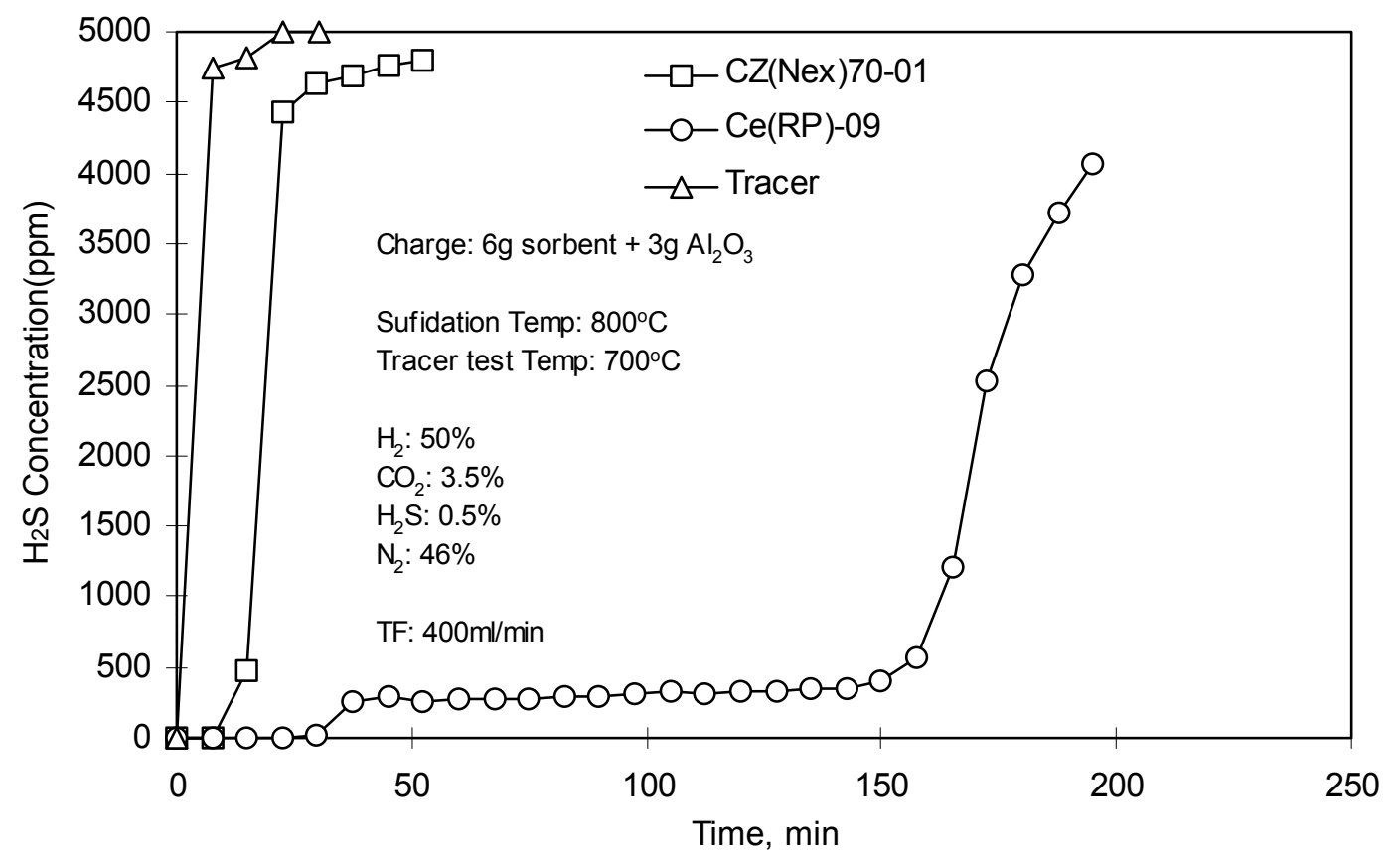

Figure 38. The Effect of $\mathrm{CO}_{2}$ on Sulfidation of $\mathrm{CZ}(\mathrm{Nex}) 70$

available sorbents. The preparation method was described in earlier sections of this report. Reaction conditions were also changed to conserve sorbent, to extend the duration of the steady-state periods, and to increase the sensitivity of the product gas analysis system to small changes in $\mathrm{H}_{2} \mathrm{~S}$ concentration. The resultant increases in reaction reference times corresponding to dimensionless time $=1$, have been summarized in Table 6.

\subsubsection{Defining Reference Time for Ceria-Zirconia Sorbents}

The discussion surrounding Table 6 indicated that the calculation of dimensionless time was based on the following stoichiometry

$$
2 \mathrm{Ce}_{1-\mathrm{x}} \mathrm{Zr}_{\mathrm{x}} \mathrm{O}_{2}(\mathrm{~s})+\mathrm{H}_{2} \mathrm{~S}(\mathrm{~g})+\mathrm{H}_{2}(\mathrm{~g}) \Leftrightarrow \mathrm{Ce}_{2(1-\mathrm{x})} \mathrm{Zr}_{2 \mathrm{x}} \mathrm{O}_{2} \mathrm{~S}(\mathrm{~s})+2 \mathrm{H}_{2} \mathrm{O}(\mathrm{g})
$$

An alternate sulfidation stoichiometry based on ceria-zirconia phase separation is

$$
\begin{aligned}
& 2 \mathrm{Ce}_{1-\mathrm{x}} \mathrm{Zr}_{\mathrm{x}} \mathrm{O}_{2}(\mathrm{~s})+(1-\mathrm{x}) \mathrm{H}_{2} \mathrm{~S}(\mathrm{~g})+(1-\mathrm{x}) \mathrm{H}_{2}(\mathrm{~g}) \Leftrightarrow \\
& (1-\mathrm{x}) \mathrm{Ce}_{2} \mathrm{O}_{2} \mathrm{~S}(\mathrm{~s})+2 \mathrm{xZrO}_{2}(\mathrm{~s})+2(1-\mathrm{x}) \mathrm{H}_{2} \mathrm{O}(\mathrm{g})
\end{aligned}
$$

It was not possible to analyze directly for phase separation, for example by XRD, because the two products, $\mathrm{Ce}_{2(1-x)} \mathrm{Zr}_{2 \mathrm{x}} \mathrm{O}_{2} \mathrm{~S}$ or $\mathrm{Ce}_{2} \mathrm{O}_{2} \mathrm{~S}$, are pyrophoric.

Reference times in minutes corresponding to dimensionless time $=1$ for the three LSU sorbents and the two possible stoichiometries are compared in Table 7. Recall that 
the reference time calculation includes corrections both for $\mathrm{CeO}_{2}-\mathrm{ZrO}_{2}$ composition and for volatile content of the sorbent. The stoichiometry in which a separate $\mathrm{ZrO}_{2}$ phase is formed during sulfidation requires that the reference time be reduced as more zirconia is added. In contrast, when there is no $\mathrm{ZrO}_{2}$ phase separation, the reference time for sorbents having equal volatile content will actually increase because the molecular weight of zirconia is less than that of ceria. As shown in the table, the reference time increases by $6.2 \%$, from $674 \mathrm{~min}$ to $716 \mathrm{~min}$ between $\mathrm{Ce}(\mathrm{LSU})$ and $\mathrm{CZ}$ (LSU) 80 with no $\mathrm{ZrO}_{2}$ phase separation, compared to a $20 \%$ reduction in reference time, from 674 min to $541 \mathrm{~min}$ for the same sorbents with $\mathrm{ZrO}_{2}$ phase separation. The decrease in reference time between $\mathrm{Ce}(\mathrm{LSU})$ and $\mathrm{CZ}(\mathrm{LSU}) 90$ is due to the higher volatile content of CZ(LSU) 90 as shown in Table 6.

Table 7. Reference Times for Two Sulfidation Stoichiometries

\begin{tabular}{|c|c|c|c|}
\hline Sorbent & $\mathrm{Ce}(\mathrm{LSU})$ & $\mathrm{CZ}(\mathrm{LSU}) 90$ & $\mathrm{CZ}(\mathrm{LSU}) 80$ \\
\hline \multicolumn{2}{|c|}{ Reference Time (min) Corresponding to Dimensionless Time $=1$} & \\
\hline Stoichiometry & & & \\
\hline $\begin{array}{c}2 \mathrm{Ce}_{1-\mathrm{x}} \mathrm{Zr}_{\mathrm{x}} \mathrm{O}_{2}(\mathrm{~s})+\mathrm{H}_{2} \mathrm{~S}(\mathrm{~g})+\mathrm{H}_{2}(\mathrm{~g}) \Leftrightarrow \\
\mathrm{Ce}_{2(1-\mathrm{x})} \mathrm{Zr}_{2 \mathrm{x}} \mathrm{O}_{2} \mathrm{~S}(\mathrm{~s})+2 \mathrm{H}_{2} \mathrm{O}(\mathrm{g})\end{array}$ & 674 & 658 & 716 \\
\hline $\begin{array}{c}2 \mathrm{Ce}_{1-\mathrm{x}} \mathrm{Zr}_{\mathrm{x}} \mathrm{O}_{2}(\mathrm{~s})+(1-\mathrm{x}) \mathrm{H}_{2} \mathrm{~S}(\mathrm{~g})+(1-\mathrm{x}) \mathrm{H}_{2}(\mathrm{~g}) \Leftrightarrow \\
(1-\mathrm{x}) \mathrm{Ce}_{2} \mathrm{O}_{2} \mathrm{~S}(\mathrm{~s})+2 \mathrm{xZrO}_{2}(\mathrm{~s})+2(1-\mathrm{x}) \mathrm{H}_{2} \mathrm{O}(\mathrm{g})\end{array}$ & 674 & 577 & 541 \\
\hline
\end{tabular}

In an ideal sulfidation reaction in which the overall breakthrough curve is symmetric with respect to time, the $\mathrm{H}_{2} \mathrm{~S}$ concentration in the product gas should reach one-half the feed concentration at the reference time. Complete breakthrough curves on a dimensional time basis for the three LSU sorbents at a sulfidation temperature of $750^{\circ} \mathrm{C}$ are shown in Figure 39. The experimental reference times for the three tests are in the range of 710 to $740 \mathrm{~min}$, much closer to calculated reference times associated with no $\mathrm{ZrO}_{2}$ phase separation. In particular, the experimental reference time of $710 \mathrm{~min}$ for $\mathrm{CZ}$ (LSU) 80 is almost identical to the calculated reference time of $716 \mathrm{~min}$, and is $20 \%$ larger than the calculated reference time of 541 min based on $\mathrm{ZrO}_{2}$ phase separation. The experimental reference times for $\mathrm{Ce}(\mathrm{LSU})$ and $\mathrm{CZ}(\mathrm{LSU}) 90$ are about $10 \%$ larger than calculated based on no $\mathrm{ZrO}_{2}$ phase separation, but this is due to the unsymmetrical breakthrough curves caused by the $\mathrm{H}_{2} \mathrm{~S}$ concentration plateaus in the general time range of 350 to 650 min easily visible in Figure 39 .

\subsubsection{The Effect of Sulfidation Temperature}

Figures 40 and 41 indicate the effect of sulfidation temperature on sorbents $\mathrm{Ce}(\mathrm{LSU})$ and $\mathrm{CZ}(\mathrm{LSU}) 80$, respectively. The $\mathrm{H}_{2} \mathrm{~S}$ concentration scale is greatly magnified to emphasize the prebreakthrough region. With $\mathrm{Ce}(\mathrm{LSU})$ in Figure 40 there is a clear early maximum in $\mathrm{H}_{2} \mathrm{~S}$ concentration of $2.3 \mathrm{ppmv}$ at $600^{\circ} \mathrm{C}$ followed by a decrease to $0.2 \mathrm{ppmv}$ just prior to breakthrough at dimensionless time of about 0.25 . At higher temperatures the early maxima are much smaller, the minimum prebreakthrough concentrations are slightly lower, and the duration of the prebreakthrough time increases with increasing temperature. Prebreakthrough $\mathrm{H}_{2} \mathrm{~S}$ concentrations of about $0.1 \mathrm{ppmv}$ 


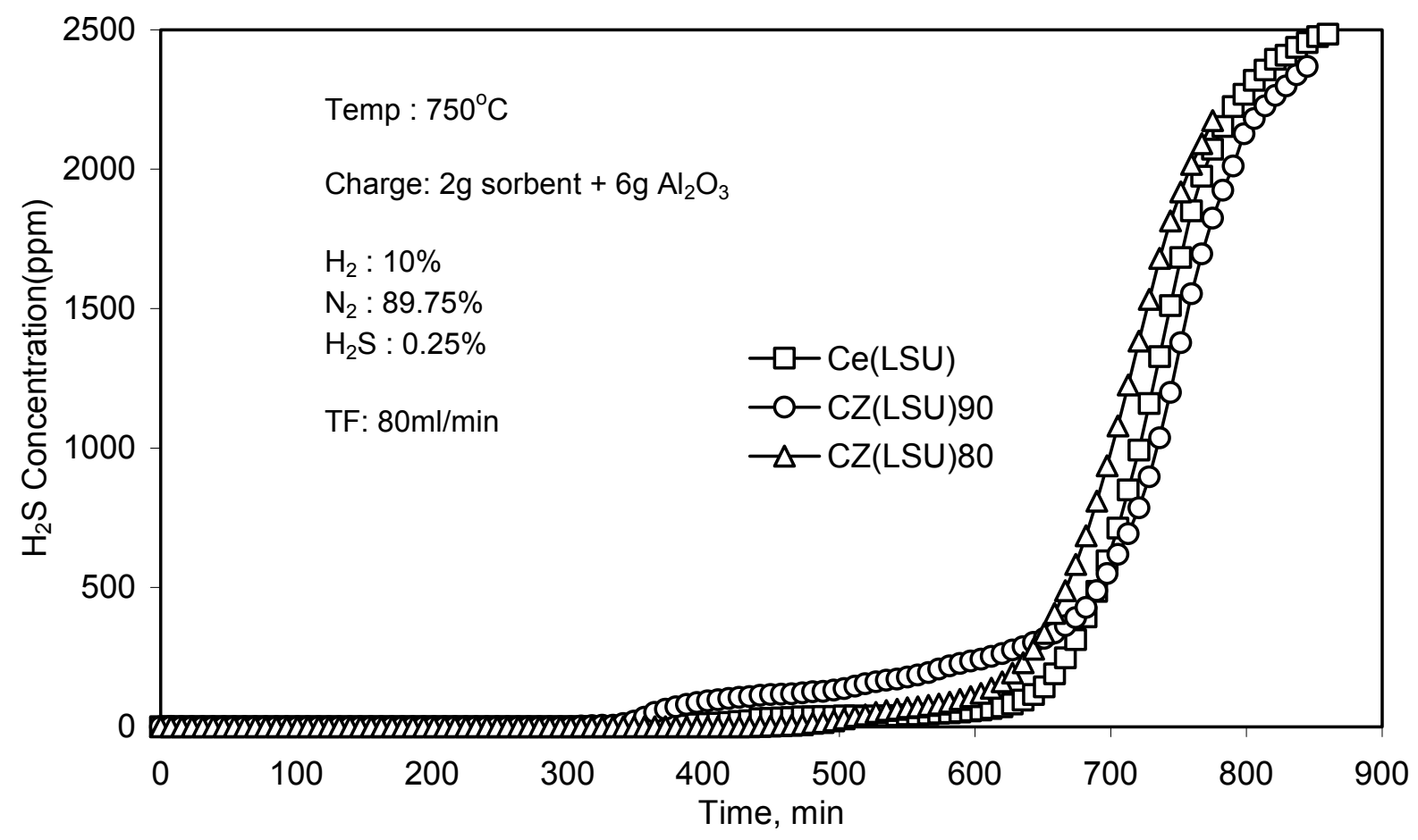

Figure 39. Complete Sulfidation Breakthrough Curves Using LSU Sorbents

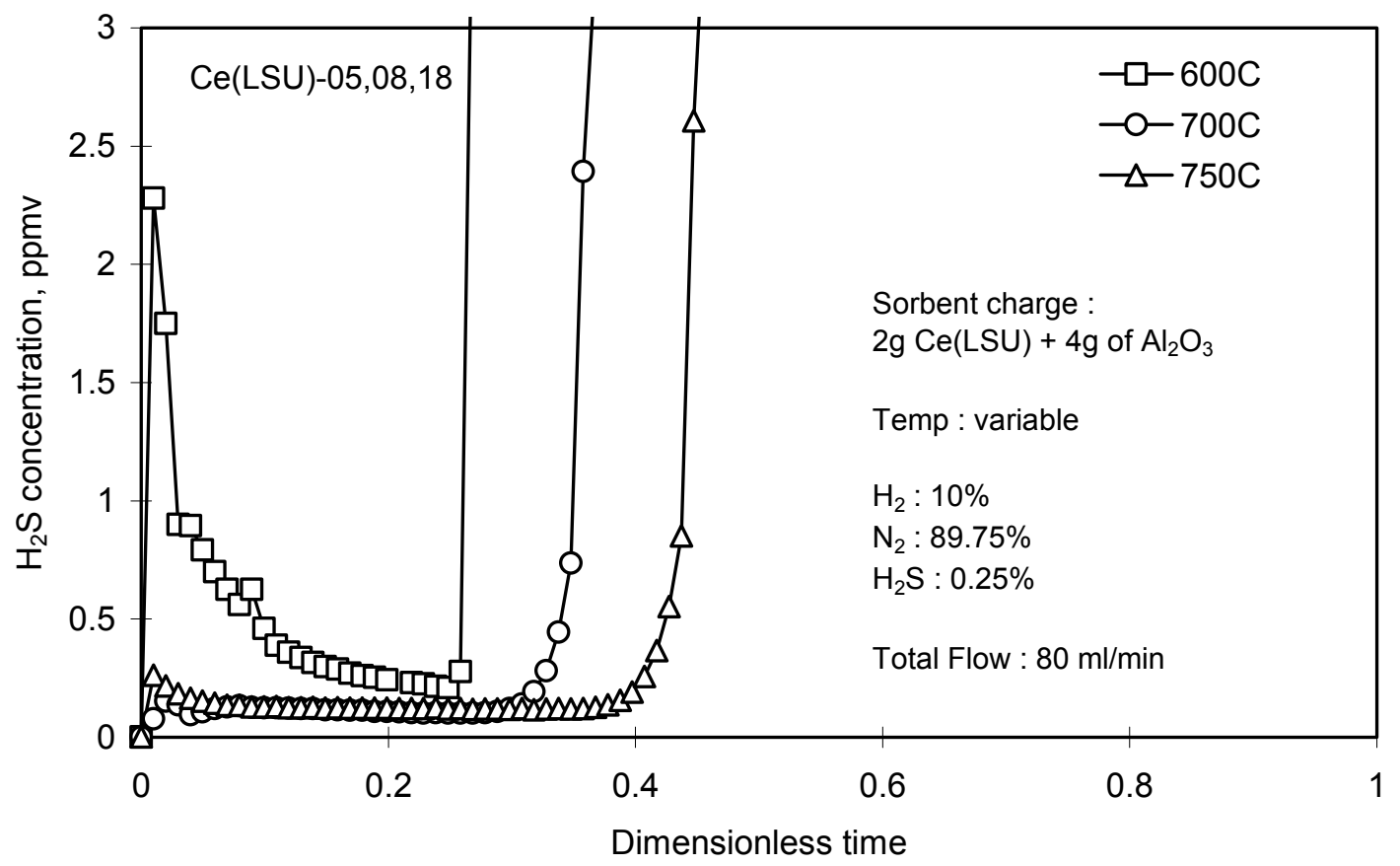

Figure 40. The Effect of Temperature on Sulfidation of Ce(LSU) 


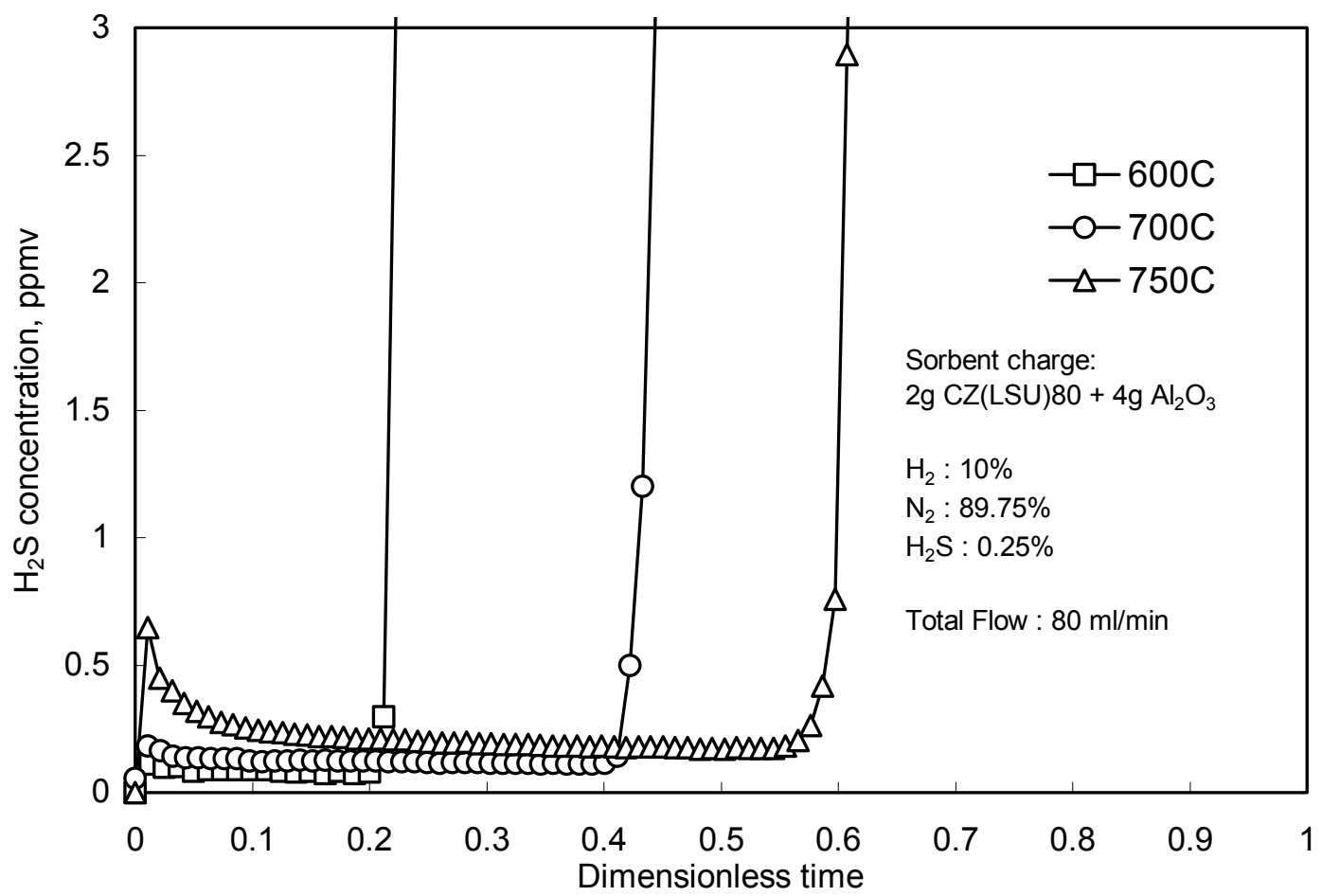

Figure 41. The Effect of Temperature on Sulfidation of CZ(LSU)80

were achieved at both $700^{\circ} \mathrm{C}$ and $750^{\circ} \mathrm{C}$, while the prebreakthrough durations at these temperatures were about 0.35 and 0.43 , respectively.

In Figure 41 using CZ(LSU)80, there was only a small prebreakthrough maximum at $750^{\circ} \mathrm{C}$. Prebreakthrough $\mathrm{H}_{2} \mathrm{~S}$ concentrations were all in the range of 0.1 to $0.25 \mathrm{ppmv}$, and the duration of the prebreakthrough period ranged from dimensionless times of just over 0.2 at $600^{\circ} \mathrm{C}$ to about 0.6 at $750^{\circ} \mathrm{C}$. The prebreakthrough minimum concentrations were approximately the same for both sorbents and the most significant difference in the results from Figures 40 and 41 were the increases in the duration of the prebreakthrough time associated with $\mathrm{CZ}(\mathrm{LSU}) 80$ at $700^{\circ} \mathrm{C}$ and $750^{\circ} \mathrm{C}$. The effect of temperature on the third LSU sorbent, CZ(LSU)80 (not shown), was similar.

A more detailed comparison of the performance of the three LSU sorbents at a sulfidation temperature of $700^{\circ} \mathrm{C}$ is shown in Figure 42. All prebreakthrough $\mathrm{H}_{2} \mathrm{~S}$ concentrations were near the $0.1 \mathrm{ppmv}$ level, and the only significant difference was the longer prebreakthrough time associated with $\mathrm{CZ}(\mathrm{LSU}) 80$.

\subsubsection{The Effect of Pre-reduction}

The effect of pre-reduction of the LSU sorbents for 4 hours in a sulfur-free gas at the planned sulfidation temperature was similar to the effect reported earlier for the commercial sorbents. This is shown in Figure 43 for CZ(LSU) 90 where sulfidation results with and without pre-reduction at $700^{\circ} \mathrm{C}$ are presented. Pre-reduction reduced the $\mathrm{H}_{2} \mathrm{~S}$ concentration during the prebreakthrough period from about $0.1 \mathrm{ppmv}$ to effectively 


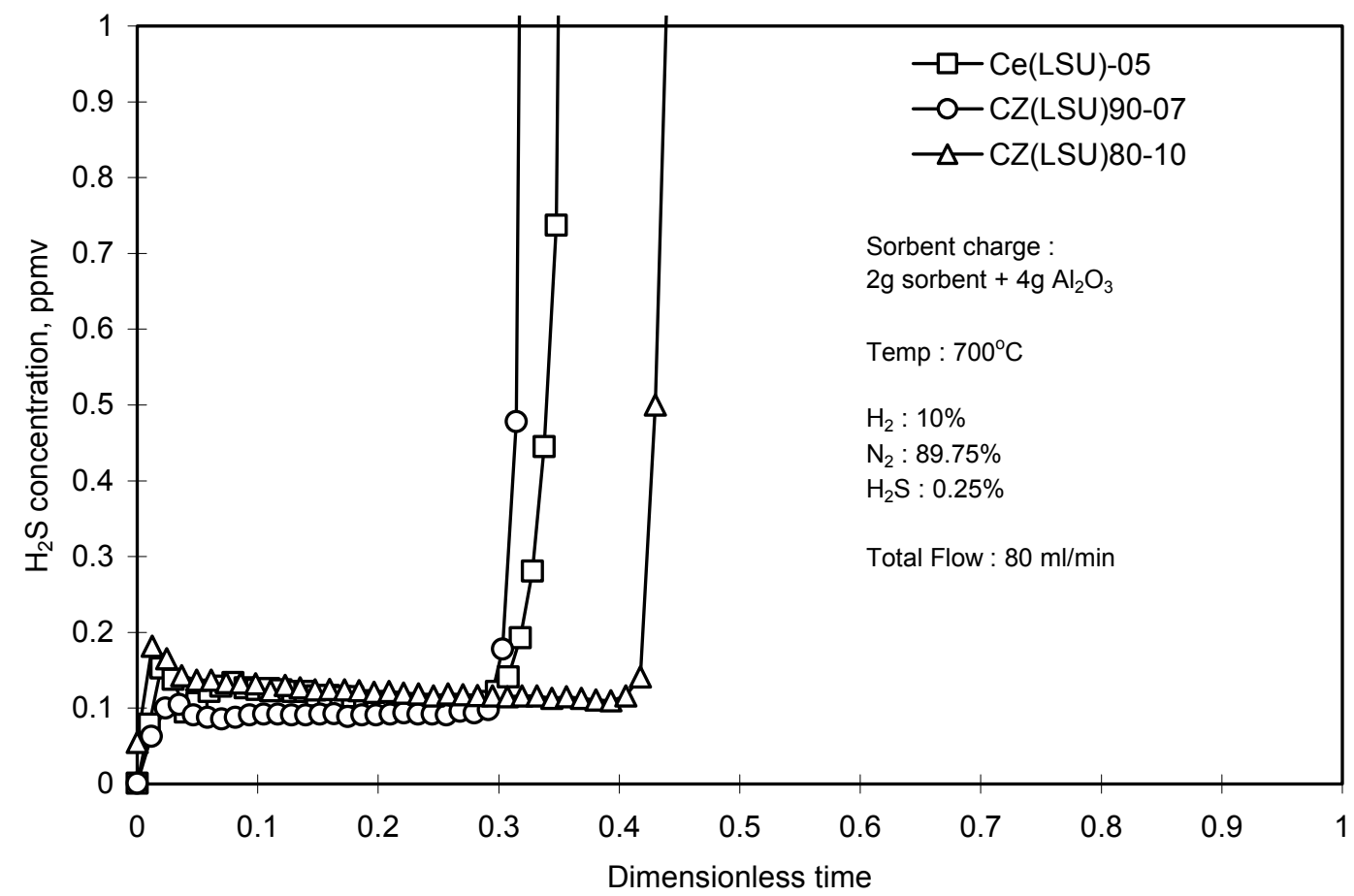

Figure 42. Comparison of the Sulfidation Performance of Ce(LSU), CZ(LSU)90, and CZ(LSU) 80

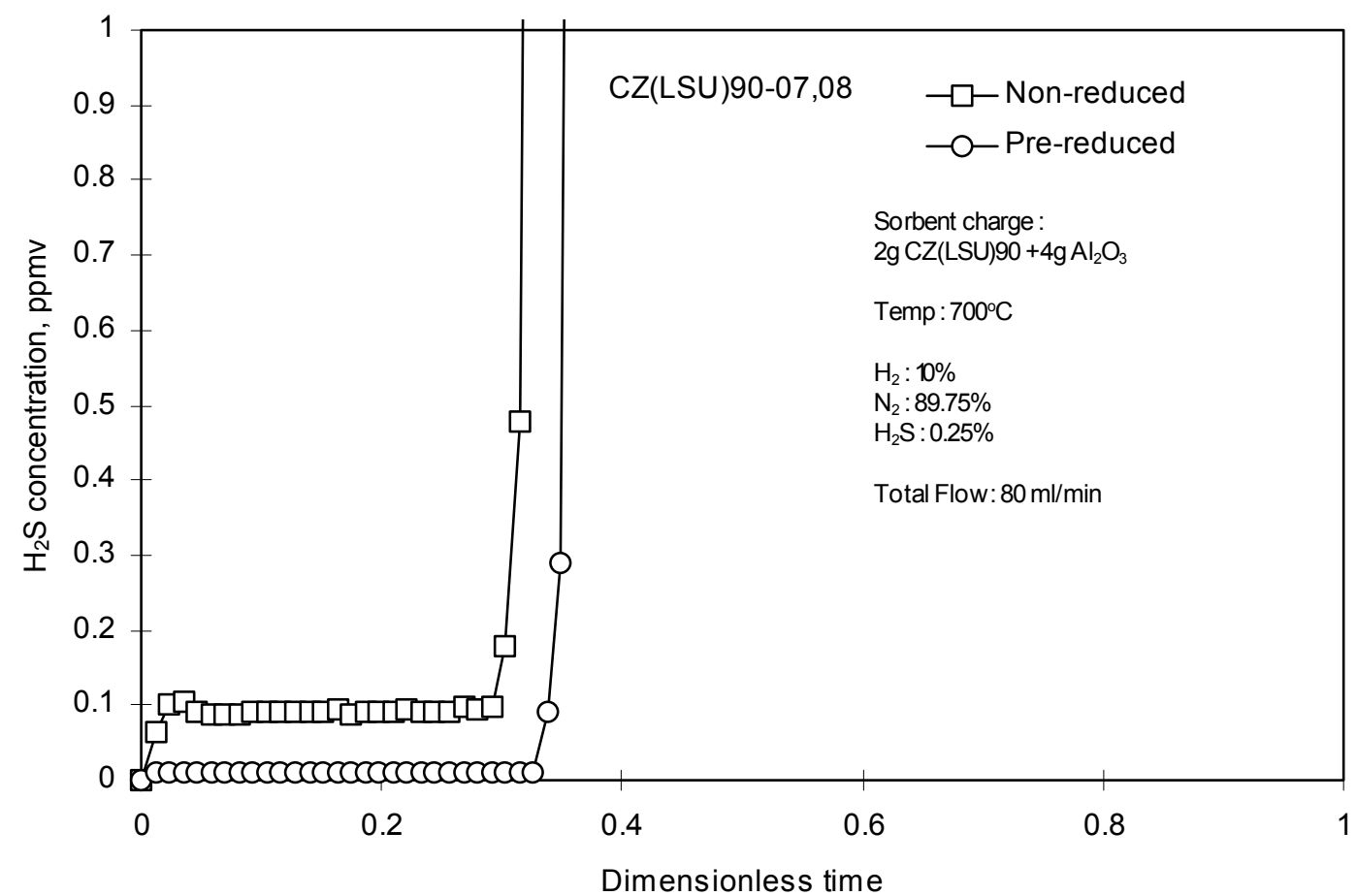

Figure 43. The Effect of Prereduction on Sulfidation of CZ(LSU)90 
zero, and prolonged the duration of the prebreakthrough period by a small amount. A similar result was obtained using $\mathrm{Ce}(\mathrm{LSU})$ and $\mathrm{CZ}(\mathrm{LSU}) 80$ except that there was a small reduction in the duration of the prebreakthrough period using $\mathrm{Ce}(\mathrm{LSU})$ and a somewhat larger increase in the prebreakthrough period duration using CZ(LSU)80.

\subsubsection{The Effect of $\mathrm{CO}_{2}$ Addition}

The real test of the ceria-zirconia sorbents is their performance in less reducing feed gas compositions, i.e., feed gases containing increasing quantities of $\mathrm{CO}_{2}$. Complete breakthrough curves for $\mathrm{Ce}(\mathrm{LSU})$ with the feed gas containing from $0.0 \%$ to $1.0 \% \mathrm{CO}_{2}$ are shown in Figure 44, while Figure 45 shows the prebreakthrough region using an expanded $\mathrm{H}_{2} \mathrm{~S}$ concentration scale. On the concentration scale of Figure 44, there are four distinct regions with an intermediate plateau region separating initial and final breakthrough periods.

As shown in Figure 45, there is a true prebreakthrough period in which the $\mathrm{H}_{2} \mathrm{~S}$ concentration was less than 1 ppmv corresponding to each feed gas composition. Following initial maxima, the prebreakthrough concentrations were about $0.1 \mathrm{ppmv} \mathrm{H}_{2} \mathrm{~S}$ when the feed gas contained $0.0 \%, 0.2 \%$, and $1.0 \% \mathrm{CO}_{2}$. Results of the test using a feed gas containing $0.5 \% \mathrm{CO}_{2}$ appear to be somewhat anomalous as there was no prebreakthrough steady state. The initial maximum of about $0.65 \mathrm{ppmv} \mathrm{H}_{2} \mathrm{~S}$ was followed by a period in which the concentration declined steadily to about 0.4 ppmv just before initial breakthrough to the plateau region. The duration of the prebreakthrough period decreased from dimensionless time of about 0.35 with $0.0 \% \mathrm{CO}_{2}$ in the feed gas to about 0.12 when the feed gas contained both $0.5 \%$ and $1.0 \% \mathrm{CO}_{2}$.

The $\mathrm{H}_{2} \mathrm{~S}$ concentration during the plateau region also increased with increasing $\mathrm{CO}_{2}$ concentration. The concentration plateaus increased from roughly $100 \mathrm{ppmv}$ with no $\mathrm{CO}_{2}$ to $250 \mathrm{ppmv}$ with $0.2 \% \mathrm{CO}_{2}$ to $320 \mathrm{ppmv}$ with $0.5 \% \mathrm{CO}_{2}$ and to $450 \mathrm{ppmv}$ with $1.0 \% \mathrm{CO}_{2}$. We suggest that these plateaus represent direct reaction of $\mathrm{H}_{2} \mathrm{~S}$ with unreduced $\mathrm{CeO}_{2}$.

Figures 46 and 47 show the comparable breakthrough curves using CZ(LSU)80 as a function of $\mathrm{CO}_{2}$ concentration. As before, Figure 46 shows the entire breakthrough on a full $\mathrm{H}_{2} \mathrm{~S}$ concentration scale while Figure 47 emphasizes the prebreakthrough region on an expanded concentration scale. Once again there is a true prebreakthrough period during which the $\mathrm{H}_{2} \mathrm{~S}$ concentration is reduced below $1 \mathrm{ppmv}$ at each of the $\mathrm{CO}_{2}$ concentrations. The prebreakthrough concentrations were roughly $0.1 \mathrm{ppmv}$ when the feed gas contained $0.5 \%$ or less $\mathrm{CO}_{2}$ and was about $0.4 \mathrm{ppmv}$ when the feed gas contained $1.0 \% \mathrm{CO}_{2}$. The duration of the prebreakthrough period decreased as the $\mathrm{CO}_{2}$ concentration increased.

There was, however, no true plateau region associated with $\mathrm{CZ}(\mathrm{LSU}) 80$. Instead, when the feed gas contained $\mathrm{CO}_{2}$ there was an initial sharp increase in $\mathrm{H}_{2} \mathrm{~S}$ concentration followed by a gradual but continual increase until the feed and product gas concentrations 


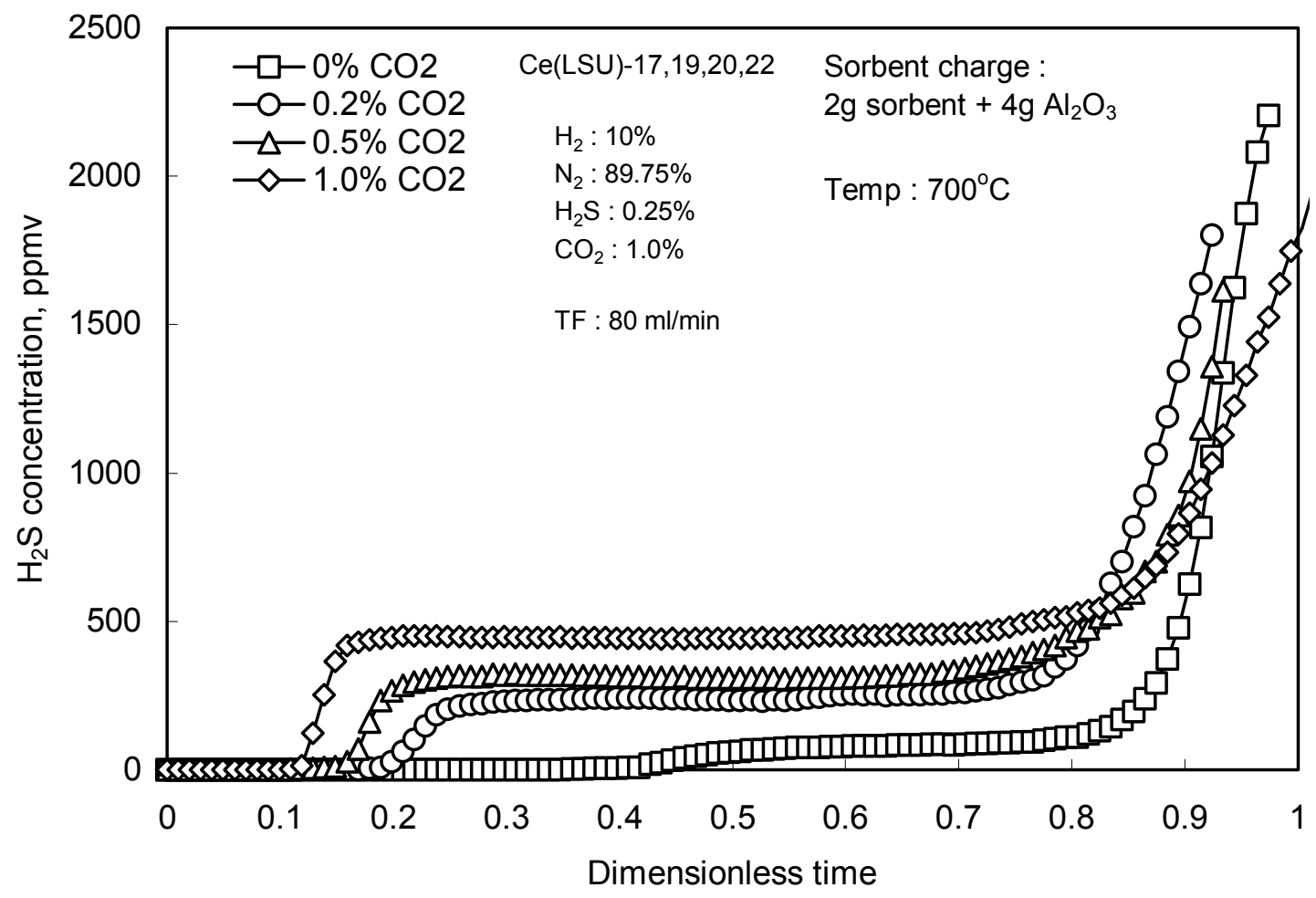

Figure 44. The Effect of $\mathrm{CO}_{2}$ Addition Using $\mathrm{Ce}(\mathrm{LSU})$ (Full Concentration Scale)

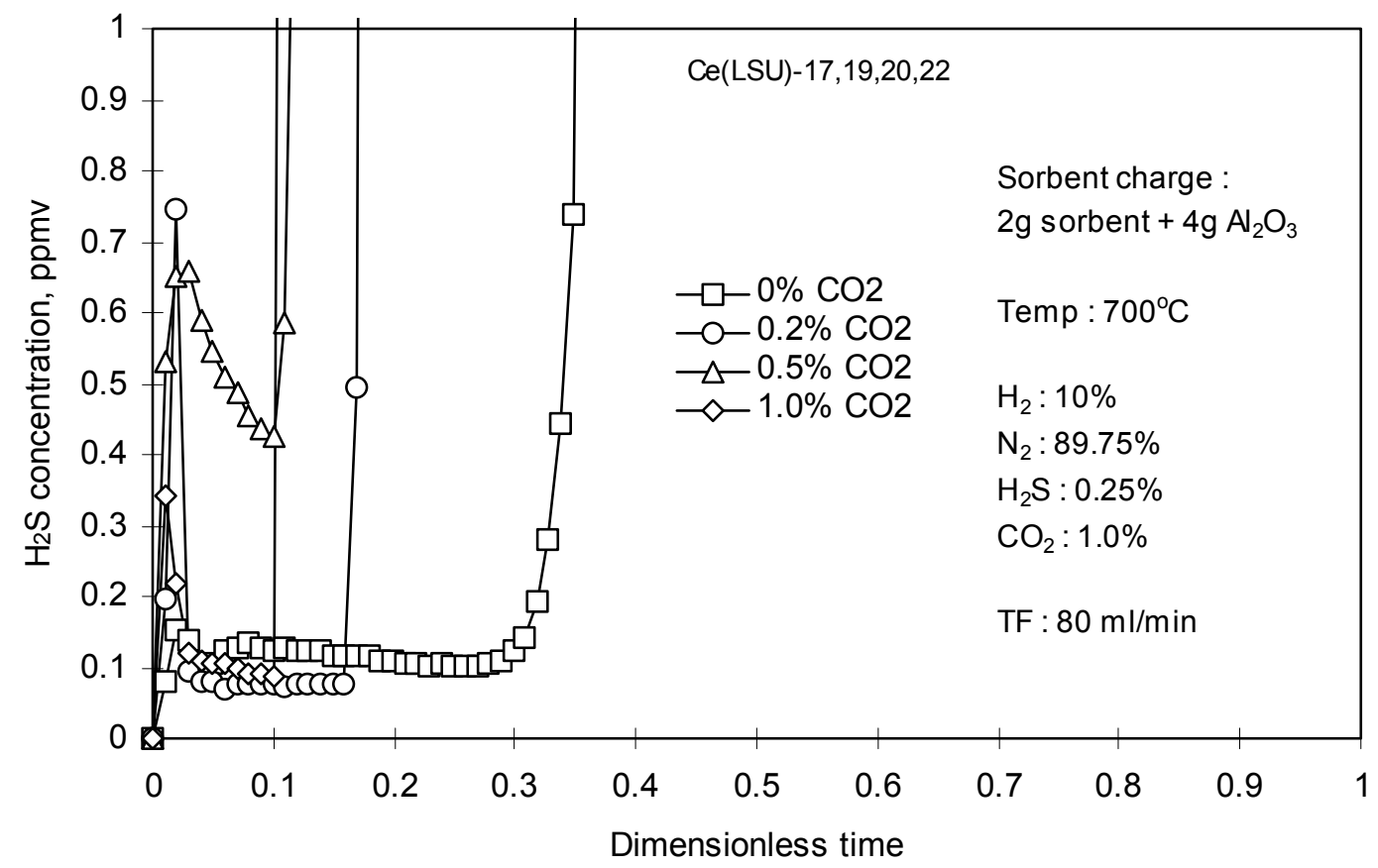

Figure 45. The Effect of $\mathrm{CO}_{2}$ Addition Using $\mathrm{Ce}(\mathrm{LSU})$ (Expanded Concentration Scale) 


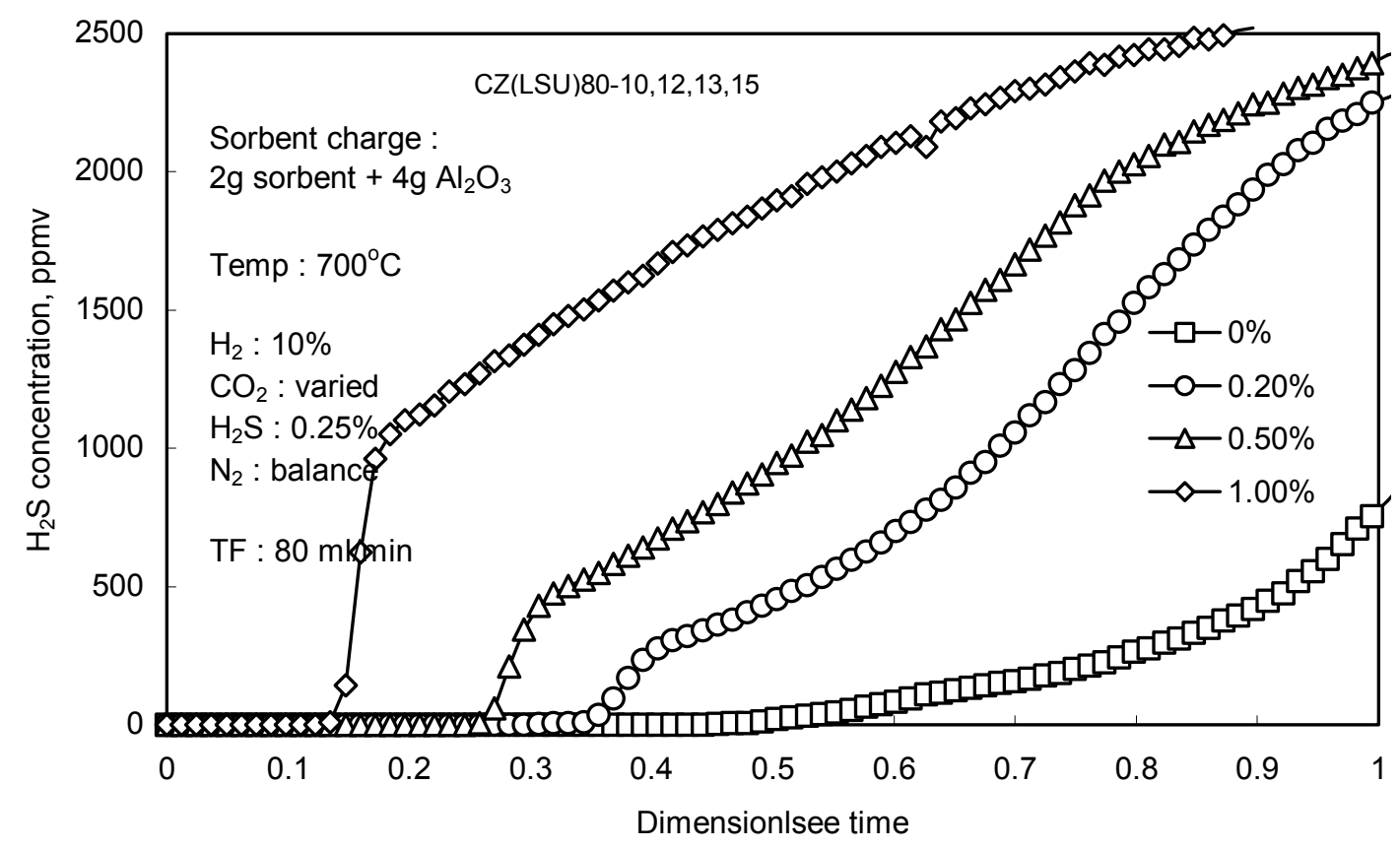

Figure 46. The Effect of $\mathrm{CO}_{2}$ Addition Using $\mathrm{CZ}(\mathrm{LSU}) 80$ (Full Concentration Scale)

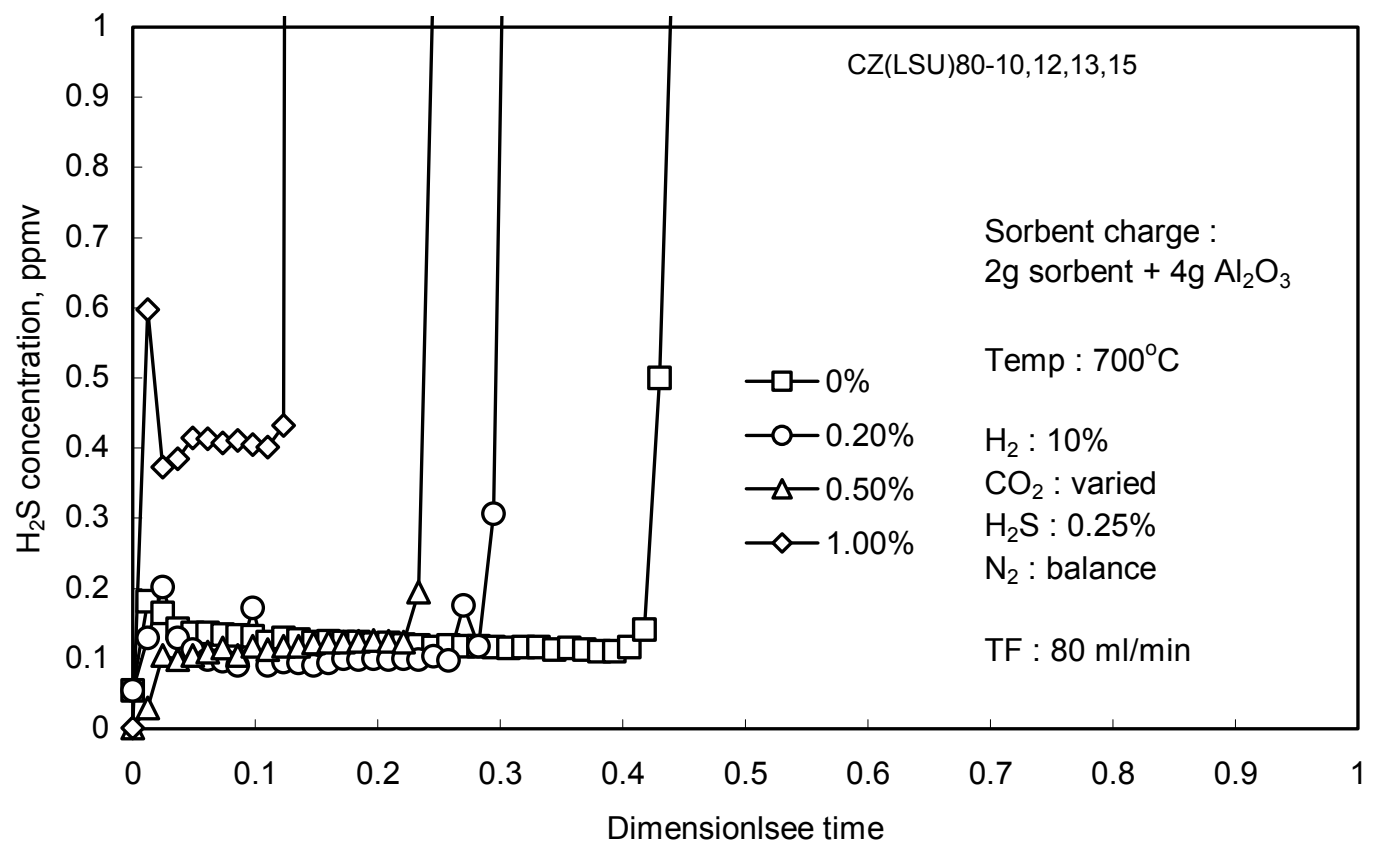

Figure 47. The Effect of $\mathrm{CO}_{2}$ Addition Using $\mathrm{CZ}$ (LSU) 80 (Expanded Concentration Scale) 
were approximately equal. The fact that the $\mathrm{H}_{2} \mathrm{~S}$ concentrations at dimensionless times = 1 were considerably greater than one-half the feed concentration in all of the tests shown in Figure 45 in which the feed gas contained $\mathrm{CO}_{2}$ indicates that the total sorbent capacity for $\mathrm{H}_{2} \mathrm{~S}$ sorption was reduced in the presence of $\mathrm{CO}_{2}$.

A summary of all results from tests in which $\mathrm{CO}_{2}$ was present in the feed gas was varied is presented in Table 8 . The $\mathrm{CO}_{2}$ concentration was varied from $0.0 \%$ to $1.0 \%$ using a sulfidation temperature of $700^{\circ} \mathrm{C}$. All three of the LSU sorbents were tested. The table lists the steady-state prebreakthrough $\mathrm{H}_{2} \mathrm{~S}$ concentrations, excluding local early maxima, and the dimensionless times corresponding to the beginning of active breakthrough, defined, as previously, as the time at which the $\mathrm{H}_{2} \mathrm{~S}$ concentration exceeds 1 ppmv.

Table 8. Summary of Sulfidation Test Results at $700^{\circ} \mathrm{C}$ Using LSU Sorbents and Varying $\mathrm{CO}_{2}$ Feed Gas Concentrations

\begin{tabular}{|c|c|c|c|c|}
\hline \multicolumn{2}{|c|}{ Sorbent } & $\mathrm{Ce}(\mathrm{LSU})$ & $\mathrm{CZ}(\mathrm{LSU}) 90$ & $\mathrm{CZ}(\mathrm{LSU}) 80$ \\
\hline \multirow{4}{*}{$\begin{array}{c}\mathrm{H}_{2} \mathrm{~S} \text { Prebreakthrough } \\
\text { Concentration }\end{array}$} & $0 \% \mathrm{CO}_{2}$ & 0.1 & 0.1 & 0.1 \\
\cline { 2 - 5 } Level, ppmv & $0.2 \% \mathrm{CO}_{2}$ & 0.1 & 0.1 & 0.1 \\
\cline { 2 - 5 } & $0.5 \% \mathrm{CO}_{2}$ & --- & 0.1 & 0.1 \\
\cline { 2 - 5 } & $1.0 \% \mathrm{CO}_{2}$ & 0.1 & 0.1 & 0.4 \\
\hline Dimensionless Time at the & $0 \% \mathrm{CO}_{2}$ & 0.35 & 0.32 & 0.44 \\
\cline { 2 - 5 } $\begin{array}{c}\text { Beginning of Active } \\
\text { Breakthrough }\end{array}$ & $0.2 \% \mathrm{CO}_{2}$ & 0.17 & 0.17 & 0.30 \\
\cline { 2 - 5 } & $0.5 \% \mathrm{CO}_{2}$ & 0.12 & 0.13 & 0.24 \\
\cline { 2 - 5 } & $1.0 \% \mathrm{CO}_{2}$ & 0.12 & 0.13 & 0.15 \\
\hline
\end{tabular}

The table shows that, with the exception of two of the twelve tests, the $\mathrm{H}_{2} \mathrm{~S}$ concentration was reduced to near the $0.1 \mathrm{ppmv}$ level during the prebreakthrough period. The two exceptions involved $\mathrm{Ce}(\mathrm{LSU})$ using $0.5 \% \mathrm{CO}_{2}$ and $\mathrm{CZ}$ (LSU) 80 using $1.0 \% \mathrm{CO}_{2}$. The first of these exceptions was illustrated in Figure 45 where a steady-state prebreakthrough period was not reached although the average $\mathrm{H}_{2} \mathrm{~S}$ concentration was about $0.5 \mathrm{ppmv}$ for a reasonable time. The second exception involved CZ(LSU) 80 using $1.0 \% \mathrm{CO}_{2}$ where a good steady state was achieved, but at the somewhat elevated $\mathrm{H}_{2} \mathrm{~S}$ concentration of 0.4 ppmv. Although the addition of $\mathrm{ZrO}_{2}$ did not have a significant effect on lowering $\mathrm{H}_{2} \mathrm{~S}$ concentration, we must realize that little improvement was possible from the $0.1 \mathrm{ppmv}$ level.

The clear results from this test series involves the duration of the prebreakthrough time. The prebreakthrough time clearly decreased as the reducing power of the feed gas decreased (increased $\mathrm{CO}_{2}$ concentration). Also, while there was little difference in the duration of the prebreakthrough time between $\mathrm{Ce}(\mathrm{LSU})$ and $\mathrm{Ce}(\mathrm{LSU}) 90$, there was a clear increase when the $\mathrm{ZrO}_{2}$ content was increased in $\mathrm{Ce}(\mathrm{LSU}) 80$, from $25 \%$ in $1.0 \%$ $\mathrm{CO}_{2}$ to $100 \%$ in $0.5 \% \mathrm{CO}_{2}$. These results suggest the possibility that further improvements might be possible if the $\mathrm{ZrO}_{2}$ concentration had been increased to still higher levels. 


\section{Summary and Conclusions}

1. Electrochemical synthesis can be used to produce mixed $\mathrm{CeO}_{2}-\mathrm{ZrO}_{2}$ powders. XRD and TEM analysis show that the powders were nanoncrystalline and had diameters of about $5 \mathrm{~nm}$. The product was a solid solution of $\mathrm{ZrO}_{2}$ in $\mathrm{CeO}_{2}$ at low $\mathrm{ZrO}_{2}$ content with a separate $\mathrm{ZrO}_{2}$ phase formed at higher $\mathrm{ZrO}_{2}$ levels. Unfortunately, the quantity of material that could be prepared electrochemically was too small to permit testing as a desulfurization sorbent.

2. The pulsed flame photometric detector, which is roughly ten times more sensitive for $\mathrm{H}_{2} \mathrm{~S}$ than the standard flame photometric detector, was able to detect reliably $\mathrm{H}_{2} \mathrm{~S}$ concentrations as low as $0.1 \mathrm{ppmv}$.

3. Commercial sorbents composed of pure $\mathrm{CeO}_{2}$ from Rhone Poulenc and $\mathrm{CeO}_{2-}$ $\mathrm{ZrO}_{2}$ solid solutions from NexTech Materials were capable of reducing the $\mathrm{H}_{2} \mathrm{~S}$ concentration from highly reducing synthesis gas to less than 1 ppmv over the temperature range of $600^{\circ} \mathrm{C}$ to $800^{\circ} \mathrm{C}$. Addition of $\mathrm{CO}_{2}$ to the feed gas had an adverse effect on $\mathrm{H}_{2} \mathrm{~S}$ removal.

4. Because of the wide variation in surface area and grain size of these commercially available sorbents, it was impossible to separate and evaluate the effect of $\mathrm{ZrO}_{2}$ addition.

5. Solid solutions of $\mathrm{CeO}_{2}-\mathrm{ZrO}_{2}$ were successfully prepared at LSU using a coprecipitation technique. The surface areas and grain sizes of these materials were larger than those of the $\mathrm{CeO}_{2}$ from Rhone Poulenc and the $\mathrm{CeO}_{2}-\mathrm{ZrO}_{2}$ from NexTech, but were reasonably constant so that the effect of $\mathrm{ZrO}_{2}$ addition could be studied.

6. The three LSU sorbents $-\mathrm{CeO}_{2}, \mathrm{Ce}_{0.9} \mathrm{Zr}_{0.1} \mathrm{O}_{2}$, and $\mathrm{Ce}_{0.8} \mathrm{Zr}_{0.2} \mathrm{O}_{2}$ - were also successful in reducing $\mathrm{H}_{2} \mathrm{~S}$ concentrations from highly reducing synthesis gas to sub-ppmv levels over the temperature range of $600^{\circ} \mathrm{C}$ to $750^{\circ} \mathrm{C}$.

7. Sub-ppmv $\mathrm{H}_{2} \mathrm{~S}$ concentrations were also achieved with each LSU sorbent when as much as $1.0 \% \mathrm{CO}_{2}$ was added to the feed gas. However, the prebreakthrough duration during which time the sub-ppmv concentrations were achieved was reduced considerably.

8. Although minimum $\mathrm{H}_{2} \mathrm{~S}$ concentrations were not decreased by the addition of $\mathrm{ZrO}_{2}$, the duration of the prebreakthrough period during which product gas $\mathrm{H}_{2} \mathrm{~S}$ concentration remained at the sub-ppmv level was longer with $\mathrm{Ce}_{0.8} \mathrm{Zr}_{0.2} \mathrm{O}_{2}$ than with $\mathrm{CeO}_{2}$. 


\section{References}

Bevan, D. and Kordis, J., 1964, Mixed Oxides of the Type $\mathrm{MoO}_{3}-1$. Oxygen Dissociation Pressure and Phase Relationship in the System $\mathrm{CeO}_{2}-\mathrm{Ce}_{2} \mathrm{O}_{3}$ at High Temperatures, Journal of Inorganic and Nuclear Chemistry, 26, 1509.

Bauer, H.H., et al., 1978, "Instrumental Analysis," Allyn and Bacon Chemistry Series, 383-440.

Bunluesin, T., Gorte, R., and Graham, G., 1997, CO Oxidation for the Characterization of Reproducibility in Oxygen Storage Components of Three-Way Automotive Catalysts, Applied Catalysis B., Environmental, 14, 105.

Colon, G., Pijolat, M., Valdivieso, F., Vidal, H., Kaspar, J., Daturi, M., Binet, C., Lavalley, J., Baker, R., and Bernal, S., 1998, Surface and Structural Characterization of $\mathrm{Ce}_{\mathrm{x}} \mathrm{Zr}_{1-\mathrm{x}} \mathrm{O}_{2}$ Mixed Oxides as Potential Three-Way Catalyst Promoters, Journal of the Chemical Society, Faraday Transactions, 94, 3717.

Cuif, J.-P., Blanchard, G., Touret, O., Marczi, M., and Quemere, E., 1996, Proceedings of the 1996 International Fall Fuels and Lubricants Meeting of the Society of Automotive Engineers, San Antonio, TX, 73.

Focht, G. D., Ranade, P. V., and Harrison, D. P., 1988, High Temperature Desulfurization Using Zinc Ferrite: Reduction and Sulfidation Kinetics, Chemical Engineering Science, $\underline{43}, 3005$.

Gibson, J. B., and Harrison, D. P., 1980, The Reaction Between Hydrogen Sulfide and Single Spherical Pellets of Zinc Oxide, Industrial and Engineering Chemistry, Process Design and Development, 19, 231.

Harrison, D. P., 1998, Performance Analysis of $\mathrm{ZnO}$-Based Sorbents in Removal of $\mathrm{H}_{2} \mathrm{~S}$ from Fuel Gas, in Desulfurization of Hot Coal Gas, A. Atimtay and D. P. Harrison, eds., Springer, Berlin, 213.

Hori, C., Permana, H., Ng, K., Brenner, A., Moore, K., Rahmoeller, K., and Belton, D., 1998, Thermal Stability of Oxygen Storage Properties in a Mixed $\mathrm{CeO}_{2}-\mathrm{ZrO}_{2}$ System, Applied Catalysis B, Environmental, 16, 105.

Mukherjee, A., Yi, K., Podlaha, E., and Harrison, D., 2001, High Efficiency Desulfurization of Synthesis Gas, Annual Report, U.S. Department of Energy Project DE-PS26-00FT40676.

Ozawa, M., 1997, Role of Cerium-Zirconium Mixed Oxides as Catalysts for Car Pollution: A Short Review, Journal of Alloys and Compounds, 275, 886. 
Podlaha, E.P., Bogli, A., Bonhote, Ch. and Landolt, 1997, Development of a New, Pseudo-Inverted Disk Electrode, D. Journal of Applied Electrochemistry, 27, 805.

Roine, A., 1999, HSC Chemistry for Windows, User's Manual, Outokumpu Research Oy, Pori, Finland

Sorensen, O., 1976, Thermodynamic Studies of the Phase Relationships of Nonstoichiometric Cerium Oxides at Higher Temperatures, Journal of Solid State Chemistry, $\underline{18}, 217$.

Switzer, A., 1987, Electrochemical Synthesis of Ceramic Films and Powders, Journal of the American Ceramic Society Bulletin , 66[10], 1521.

Trovarelli, A., 1996, Catalytic Properties of Ceria and $\mathrm{CeO}_{2}-$ Containing Materials, Catalysis Reviews: Science and Engineering, 38, 439.

Trovarelli, A., de Leitenburg, C., and Colcetti, G., 1997, Design Better Cerium-Based Oxidation Catalysts, CHEMTECH, 27, 32.

Woods, M. C., Gangwal, S. K., Jothimurugesan, K., and Harrison, D. P., 1990, The Reaction Between $\mathrm{H}_{2} \mathrm{~S}$ and Zinc Oxide-Titanium Oxide Sorbent: 1. Single Pellet Kinetic Studies, Industrial and Engineering Chemistry Research, 29, 1160.

Yi, K., Podlaha, E., and Harrison, D., 2002, High Efficiency Desulfurization of Synthesis Gas, Annual Report, U.S. Department of Energy Project DE-PS26-00FT40676.

Yi, K., Podlaha, E., and Harrison, D., 2003, High Efficiency Desulfurization of Synthesis Gas, Annual Report, U.S. Department of Energy Project DE-PS26-00FT40676.

Zamar, F., Trovarelli, A., de Leitenburg, C., and Dolcetti, G., 1995, $\mathrm{CeO}_{2}-\mathrm{Based} \mathrm{Solid}$ Solutions with the Fluorite Structure as Novel and Effective Catalysts for Methane Combustion, Journal of the Chemical Society, Chemical Communications, 965.

Zeng, Y, Zhang, S., Groves, F. R., and Harrison, D. P., 1999, High Temperature Gas Desulfurization with Elemental Sulfur Production, Chemical Engineering Science, 54, 3007.

Zeng, Y., Kaytakoglu, S., and Harrison, D. P., 2000, Reduced Cerium Oxide as an Efficient and Durable High Temperature Desulfurization Sorbent, Chemical Engineering Science, $\underline{55}, 4893$. 